\title{
Circulatory response to pregnancy in formerly preeclamptic women and healthy parous controls
}

Citation for published version (APA):

Spaanderman, M. E. A. (2001). Circulatory response to pregnancy in formerly preeclamptic women and healthy parous controls. [Doctoral Thesis, Maastricht University]. Universiteit Maastricht. https://doi.org/10.26481/dis.20010216ms

Document status and date:

Published: 01/01/2001

DOI:

10.26481/dis.20010216ms

Document Version:

Publisher's PDF, also known as Version of record

\section{Please check the document version of this publication:}

- A submitted manuscript is the version of the article upon submission and before peer-review. There can be important differences between the submitted version and the official published version of record.

People interested in the research are advised to contact the author for the final version of the publication, or visit the DOI to the publisher's website.

- The final author version and the galley proof are versions of the publication after peer review.

- The final published version features the final layout of the paper including the volume, issue and page numbers.

Link to publication

\footnotetext{
General rights rights.

- You may freely distribute the URL identifying the publication in the public portal. please follow below link for the End User Agreement:

www.umlib.nl/taverne-license

Take down policy

If you believe that this document breaches copyright please contact us at:

repository@maastrichtuniversity.nl

providing details and we will investigate your claim.
}

Copyright and moral rights for the publications made accessible in the public portal are retained by the authors and/or other copyright owners and it is a condition of accessing publications that users recognise and abide by the legal requirements associated with these

- Users may download and print one copy of any publication from the public portal for the purpose of private study or research.

- You may not further distribute the material or use it for any profit-making activity or commercial gain

If the publication is distributed under the terms of Article $25 \mathrm{fa}$ of the Dutch Copyright Act, indicated by the "Taverne" license above, 


\section{C}

IRCULATORY RESPONSE TO PREGNANCY IN FORMERLY PREECLAMPTIC WOMEN AND HEALTHY PAROUS CONTROLS 
ISBN 90-9014531-1

(1) M.E.A. SpaAniderman, MaAsiricht, 2001

GFIJREKT DOOR UNIGRAPHIC, UNIVERSTTEIT MAASTRICHT 


\title{
Circulatory Response to PREGNANCY IN FORMERLY \\ PREECLAMPTIC WOMEN AND HEALTHY PAROUS CONTROLS
}

\section{Proefschrift}

\author{
ter verkrijging van de graad van doctor \\ aan de Universiteit Maastricht, \\ op gezag van de Rector Magnificus, \\ Prof. dr. A.C. Nieuwenhuijzen Kruseman, \\ volgens het besluit van het College van Decanen, \\ in het openbaar te verdedigen \\ op vrijdag 16 februari 2001 om 14:00 uur
} door

Marc Erich August Spaanderman 


\section{Promotores:}

Prof. dr. J. de Haan

Prof. dr. P.W. de Leeuw

\section{CO-PROMOTOR:}

Dr. L.L.H. Pecters

\section{BEOORDELINGSCOMMISSIE:}

Prof. dr. H.A.J. Stuijker Boudier (voorzitter)

Prof. dr. F.A. van Assche (Katholicke Universitejt Leuven)

Prof. dr. W.H. Birkenhäger (Erasmus Universiteit Rotterdam)

Prot. dr. J.G. Nijhuis

Prof. dr. J. Rosing

The studies described in this thesis were financially supponed by the Profileringstonds (project P2F)

Financial support by the Netherlands Heart Foundation for the publication of this thesis is gralefully acknowledged. 
CONTENTS

PAGE

Chapter 1

General introduction

$7-12$

ChaPTer 2

Asymptomatic formerly preeclamptic women have

latent hemodynamic abnormalities

Chapter 3

Changes in hemodynamics and volume homeostasis

with the menstrual cycle in women with a history of preeclampsia

Chapter 4

The effect of pregnancy on the compliance of

$47-64$

large arteries and veins in normal parous controls

and formerly preeclamptics

Chapter 5

The cardiac output increases independent of

basal metabolic rate in early human pregnancy

ChAPTER 6

Maladaptation to pregnancy: a role for atrial

natriuretic peptide?

Chapter 7

Pre-pregnant prediction of recurrent preeclampsia and/or

fetal growth restriction in formerly preeclamptic women

Chapter 8 General discussion

123-142

ChAPTER 9 Future research

$143-146$

Chapter 10

Summary / Samenvatting

$147-153$

Dankwoord

Curriculum vitae 
Chapter 1

GENERAL INTRODUCTION 


\section{Chapter 1}

\section{General introduction}

High blood pressure complicates almost $10 \%$ of all pregnancies ${ }^{1}$. It is, together with obstetric hemorrhage, embolism and obstetric infection, the most common cause of maternal mortality. In the western world, an incidence of 1.7-1.8 maternal deaths per 100,000 live births has been reported ${ }^{2}, 3$. Since maternal hypertension predisposes for fetal growth restriction and iatrogenic preterm delivery, it is also an important cause of perinatal morbidity and mortality.

Elevated blood pressure during pregnancy can be subdivided into a form that antedates pregnancy (chronic hypertension) and a form that is confined to the period of pregnancy (pregnancy-induced hypertension). Pregnancy-induced hypertension complicated by proteinuria is called preeclampsia while preeclampsia developing in women with preexistent hypertension is called 'superimposed preeclampsia' '. In precclampsia, generalized vasospasm, increased capillary permeability and enhanced platelet aggregation hamper the cardiovascular function. These functional defects appear to be triggered by endothelial dysfunction ${ }^{4}$. They may initiate a vicious circle, which leads to further jeopardy of the endothelial function and with it, detoriation of the hypertension, enhanced activation of the clotting system, hemolysis, and finally, besides progressive placental insufficiency, compromised function of several maternal organs such as the kidneys, liver and in case of eclampsia, the brain.

Since the cause of preeclampsia is still obscure, current management is limited to symptomatic relief and delivery. Unfortunately, only the latter can be considered causal as it involves the removal of the placenta, the presumed initiator of the pathogenic cascade. For a more appropriate causal treatment of preeclampsia, a better insight in its pathogenesis is mandatory.

Morphologic evidence for endothelial-cell injury may be obtained by fundoscopic inspection of the retina. However, the typical renal lesion known as glomerular endotheliosis is pathognomonic ${ }^{5}$. It is characterized by diffusely enlarged, bloodless glomeruli with, in the endothelial cells, hypertrophy of the cytoplasmatic organelles, particularly the lysosomes. Occasionally, sub-endothelial and mesangial electrodense deposits, most likely fibrin, parallel these histologic features ${ }^{5}$. Also biochemical markers for endothelial damage have been reported. These include elevated plasma levels of the following compounds: Von Willebrand factor, plasminogen activator (tPA) and plasminogen activator-inhibitor-1 (PAI- 
1) endothelin and cellular fibronectin ". Endothelial dysfunction may also be responsible for the observed imbalance between vasoconstrictor and vasodilator stimuli, such as between prostacyclin (PGI2) and thromboxane (TXA2), but also between plasminogen activator (tPA) and plasminogen activaror-inhibitor-1 (PAI-1) 6, ?.

Epidemiological studies indicate that endothelial dysfunction may either have a more biochemical (i.e. thrombophilia, diabetes mellitus, hypercholesterolemia) or a more mechanical (i.e. hypertension, renovascular disease) background". This supports the view that preeclampsia could be a disease state superimposed upon a preexisting, often subclinical disorder. This concept is in line with the findings that, firstly, fetal growth restriction and preeclampsia in advanced pregnancy are preceded by defective matemal hemodynamic adaptation in the first weeks of pregnancy ${ }^{9} 10$. Secondly, a substantial part of apparentlyhealthy normotensive formerly-precclamptic women had at least a thrombophilic disorder or persistent abnormalities in renal hemodynamics and volume status ${ }^{11,12.13}$. Whether these abnormalities were already present prior to pregnancy or to what extent they predispose for recurrent preeclampsia, remains to be elucidated.

In healthy women, hemodynamics and volume homeostasis vary with the menstrual cycle ${ }^{\text {is. }}$ 15. The reported data provide indirect evidence for mild vasorelaxation in the luteal phase relative to the follicular phase of the menstrual cycle. In this respect, although much less profound, the luteal phase mimics the first weeks of pregnancy ${ }^{16.17}$. Neither the mechanism responsible for these hemodynamic changes nor its functional meaning is fully understood. The pathogenesis of hypertensive complications in pregnancy may begin as early as during implantation as indicated by shallow trophoblast invasion, different trophoblast maturation and abnormal hemodynamic adaptation 9. 10. 18 . This implies that most of the pathogenic cascade evolves sub-clinically over a period of at least 5 months. It is obscure, whether the heterogeneity in predisposing conditions as mentioned above, gives rise to a similar cascade of events in the period between implantation and endothelial dysfunction. Most earlypregnancy changes in maternal hemodynamics are compensations in response to systemic vasorelaxation $16,17.19 .20$. That is to say, cardiac output and the activity of the renin-angiotensin-aldosterone system (RAAS) increase, while plasma volume expands. Theoretically, formerly preeclamptic women with a thrombophilic phenotype ('biochemical' risk-group) and normal cardiovascular function should have a normal menstrual and early-pregnancy hemodynamic compensatory response. Conversely, formerly preeclamptic women with diminished cardiovascular reserves in conjunction with hemodynamic abnormalities such as 
hypertension ('mechanical' risk-group), are more likely to respond to pregnancy either with attenuated initial vasorelaxation or to the latter with abnormal hemodynamic compensations. If the so-called 'biochemical' and 'mechanical' risk groups do indeed differ with respect to hemodynamic cyclicity with the menstrual cycle and/or the adaptive response to pregnancy, it not only would explain the disappointing outcome of a number of recently reported prophylactic strategies in unselected groups of women at risk for preeclampsia ${ }^{21}$. It would also improve our understanding of the pathogenesis of preeclampsia. The latter again is a prerequisite for the development of an effective 'tailor-made' prophylaxis for selected risk groups.

This thesis compiles six separate studies, which were designed to test the following hypotheses;

1. Formerly preeclamptic women have at least one underlying disorder either with a phenotype being thrombophilia or reduced (reno)vascular function (chapter 2).

2. Cyclic changes in hemodynamic and renal function in formerly preeclamptic women differ from those with a history of a normal pregnancy (chapter 3).

3. The early-pregnancy development of a high flow/low resistance circulation is not induced by a rise in metabolic demands (chapter 5 ).

4. Only formerly preeclamptic women with reduced (reno)vascular function respond to pregnancy with initial cardiovascular maladaptation, while those with a thrombophilic phenotype show a normal early-pregnancy adaptive response (chapter 4 and 6).

5. Pre-pregnant cardiovascular and clotting variables in formerly preeclamptic women predict hypertensive complications and fetal growth restriction in the subsequent pregnancy (chapter 7 ).

To test these hypotheses, we studied once, the clotting function, immune and homocysteine status and serially, the central and renal hemodynamic function, vascular compliance and volume homeostasis and its changes throughout the menstrual cycle and in early pregnancy, in both formerly preeclamptic women and normal parous controls. 


\section{References}

1. National High Blood Pressure Education Program Working Group Report on High Blood Pressure in Pregnancy. Am J Obstet Gynecol 1990; 163:1691-1712.

2. Berg CJ, Aurash HK, Koonin LM, Tucker M. Pregnancy-related mortality in the United States, 1987-1990. Obstet Gynecol 1996; 88:161-167.

3. Schuitemaker NWE, Bennebroek Gravenhorst J, Dekker GA, van Dongen PWJ, van Geijn HP. Moedersterfte in Nederland 1988-1992. Nederlands Tijdschrift voor Obstetrie en Gynaecologie 1993; 106:270-271.

4. Roberts JM, Taylor RN, Musci TJ, Rodgers GM, Hubel CA, McLaughlin MK. Preeclampsia: an endothelial cell disorder. Am J Obstet Gynecol 1989; 161:1200-1204.

5. Gabel LW, Spargo BH, Lindheimer MD. Renal pathology in preeclampsia. Baillieres Clin Obstet Gynaecol 1994; 8: 443-468.

6. Friedman SA. Schiff E, Emais JJ, Dekker GA, Sibai BM. Biochemical corroboration of endothelial involvement in severe preeclampsia. Am J Obstet Gynecol 1995: 172; 202-203.

7. van Beek E, Peeters LLH. Pathogenesis of preeclampsia: a comprehensive model. Obstet Gynecol Survey 1998; 53: 233-239.

8. ACOG Technical bulletin. Hypertension in Pregnancy. Number 219, 1996. Int J Gynaecol Obstet 1996; 53:175-183.

9. Duvekot JJ, Cheriex EC, Pieters FAA, Menheere PPCA, Peeters LLH. Maternal volume homeostasis in early pregnancy in relation to fetal growth restriction. Obstet Gynecol 1995; 85: 361367.

10. Duvekot JJ, Cheriex EC, Pieters FA, Peeters LLH. Severely impaired fetal growth is preceded by matemal hemodynamic maladaptation in very early pregnancy. Acta Obstet Gynecol Scand 1995; 74:693-697.

11. van Beek E, Ekhan THA, Schiffers PMH, van Eyck J, Peeters LLH, de Leeuw PW. Persistent abnormalities in plasma volume and renal hemodynamics in patients with a history of preeclampsia. Am J Obstet Gynecol 1998; 179:690-6.

12. van Pampus MG, Dekker GA, Wolf H, Huijgens PC, Koopnan MM, von Blomberg BM, Buller HR. High prevalence of hemostatic abnormalities in women with a history of severe preeclampsia. Am J Obstet Gynecol 1999; 180(5):1 146-50.

13. Kupferminc MJ, Eldor A, Steinman N, Many A, Bar-Am A, Jaffa A, Fait G, Lessing JB. Increased frequency of genetic thrombophilia in women with complications of pregnancy. $N$ Eng J Med 1999; 340:9-13.

14. Beek v. E, Houben AJHM, van Es PN, Willekes C, Korten ECCM, de Leeuw PW, Peeters LLH. Cyclic changes in hemodynamics and renal function in the menstrual cycle. Clin Science 1996; 91: 163-168.

15. Chapman AB, Zamudio S, Woodmansee W, Merouani A, Osorio F, Johnson A, Moore LG, Dahms T, Coffin C, Abraham WT, Schrier RW. Systemic and renal hemodynamic changes in the Iuteal phase of the menstrual cycle minic early pregnancy. Am J Physiol 1997; 273: F777-F782.

16. Duvekot JJ, Cheriex EC, Pieters FAA, Peeters LLH. Early-pregnancy changes in haemodynamics and volume homeostasis are consecutive adjustments triggered by a primary fall in systemic vascular tone. Am J Obstet Gynecol 1993; 169: 1382-1392.

17. Chapman AB, Abraham WT, Zamudio S, Coffin C, Merouani A, Young D, Johnson A, Osoria F, Goldberg C, Moore LG, Dahms T, Schrier RW. Temporal relationships between hormonal and hemodynamic changes in early human pregnancy. Kidney Int 1998: 54: 2056-2063.

18. Zhoe Y, Damsky CH Chiu K, Roberts JM, Fisher SJ. Preeclampsia is associated with abnormal expression of adhesion molecules by invasive cytotrophoblasts. J Clin Invest 1993; 91: 950-960.

19. Schrier RW, Briner VA. Peripheral arterial vasodilatation hypothesis of sodium and water retention in pregnancy: implications for pathogenesis of preeclampsia-eclampsia. Obstet Gynecol $1991 ; 77: 632-9$.

20. Schrier RW, Dürr JJ, Pregnancy: an overfill or underfill state. Am J Kidney Dis 1987; 9:284-9.

21. Sibai BM. Prevention of preeclampsia: a big disappointment. Am J Obstet Gynecol 1998: 179; $1275-1278$. 


\section{Chapter 2}

\section{ASYMPTOMATIC FORMERLY PREECLAMPTIC WOMEN HAVE LATENT HEMODYNAMIC ABNORMALITIES}

Spaanderman MEA, Ekhart THA, van Eyck J, Cheriex EC, de Leeuw PW, Pecters LLH

Departments of Obstetrics and Gynecology, Internal Medicine and Cardiology, Academic Hospital Maastricht and Sophia Hospital Zwolle, The Netherlands.

Am J Obstet Gynecol 2000; 182:101-107. 


\section{Abstract}

Background The majority of women with pregnancy complicated by preeclampsia have hypertension and/or a disorder with a thrombophilic phenotype. In this study we evaluated whether hemodynamics and volume homeostasis in a subgroup of normotensive formerly preeclamptic women with a normal clotting function (defined as "asymptomatic subgroup") are comparable to that in normal parous controls.

Methods In 58 formerly preeclamptic subjects and 11 normal parous controls we measured at least 5 months postpartum, at day $5( \pm 2)$ of the menstrual cycle the following variables: body weight and length, mean arterial pressure, heart rate, cardiac output $(\mathrm{CO})$, plasma volume $(\mathrm{PV})$, glomerular filtration rate, effective renal plasma flow, and in plasma, volume regulatory hormones, clotting factors, antiphospholipid antibodies and homocysteine levels before and after a methionine load. From the measured data, we calculated body mass index, body surface area, cardiac index, left ventricular work (LVW), total peripheral - and renal vascular resistance's, effective renal blood flow and renal filtration fraction.

Results Among formerly preeclamptic women 26 were normotensive thrombophilic (45\%), 14 hypertensive (24\%) and 18 normotensive non-thrombophilic $(31 \%)$. The asymptomatic formerly preeclamptic subjects were more obese than controls. They also had a higher cardiac output and left ventricular work, and a lower plasma volume than the normal parous controls. Therefore, they resemble the second subgroup of formerly preeclamptic subjects with hypertension rather than the controls. The third subgroup of formerly preeclamptic subjects consisted of normotensive women with thrombophilia. The hemodynamic and renal function in this subgroup was similar to that in normal parous controls.

Conclusion On the basis of this study we conclude that hemodynamics and volume homeostasis in the asymptomatic subgroup of formerly preeclamptic women are different from those in normal parous controls. Hemodynamics and volume homeostasis in this subgroup resembles that in of hypertensive 
formerly preeclamptic women. Therefore, we propose to classify the asymptomatic formerly preeclamptic subjects as 'latent' hypertensives. 


\section{Chapter 2}

\section{Introduction}

Increasing evidence supports the concept that systemic arterial vasodilation represents the first detectable systemic hemodynamic change in pregnancy. The latter then initiates a cascade of compensations in the circulation and volume homeostasis 1,2 that include, among others, a rise in cardiac output $(\mathrm{CO})$, hemodilution and activation of the renin-angiotensinaldosterone system. Often, preeclampsia is preceded by abnormalities in these early-pregnancy changes ${ }^{3}$.

Most symptoms in preeclampsia develop secondary to endothelial dysfunction ${ }^{4}$. Conditions such as thrombophilia and hypertension are known to interfere with endothelial function. This may explain why women with these disorders are more prone to develop preeclampsia in pregnancy 5 . In the latter study, the authors reported an approximately $50 \%$ incidence of thrombophilia and about $25 \%$ incidence of chronic hypertension among formerly preeclamptic (ex-PE) women. Whether hemodynamic status and volume homeostasis in the remaining approx. $25 \%$ seemingly healthy, formerly preeclamptic women is indeed entirely normal and thus indistinguishable from that in normal parous controls, is still unsettled. Evidence for latent abnormalities in their hemodynamic - and/or volume regulatory function could mean that preeclampsia is in the majority of cases superimposed upon a pre-existing disorder. This would contribute importantly both to our understanding of the pathogenesis of preeclampsia and to the development of prophylactic strategies.

The objective of the present study was to test the hypothesis that hemodynamics and volume homeostasis in formerly preeclamptic individuals without thrombophilia and without hypertension differs from those in normal parous controls. To this end, we studied 58 formerly preeclamptic women subdivided over a thrombophilic -, a hypertensive - and a seemingly healthy ("asymptomatic") subgroup. These subgroups were compared with one another and with a group of normal parous controls. 


\section{Patients and Methods}

\section{Patients}

In this study 58 formerly preeclamptic non-diabetic women and 11 normal parous controls were enrolled. Participants were at least 5 months post partum. All were Caucasian. None were smoking during pregnancy. Formerly preeclamptic women were recruited at the outpatient clinic at the postpartum follow-up. Most of them had a severe form of preeclampsia, either early in pregnancy or with a rapid onset later on. Controls were recruited by advertisement. All participants gave written informed consent. The hospital's medical-ethical committee approved the study. Preeclampsia and hypertension were defined according to the criteria of the International Society for the Study of Hypertension in Pregnancy (ISSHP) ${ }^{6}$. All experiments were preceded by one week of standardized sodium intake (100 mmol sodium per day), representing the mean sodium intake in our population. The latter required that all participants consulted the hospital's dietitian prior to study. Women's compliance with the diet was evaluated by quantifying 24-hour sodium output on the day before the experiment. None of the women used vitamins, oral contraceptives, nonsteroid anti inflammatory drugs or glucocorticosteroids in the two weeks prior to measurement. Two women used antihypertensive drugs. This medication was discontinued at least one week prior to measurement. On separate days and after an overnight fast, participants were tested for thrombophilia and hemodynamic function.

\section{Methods}

Thrombophilic screening: Anticardiolipin antibodies (ACA) for IgM and IgG were determined spectrophotometrically by enzyme-linked immunoassay ${ }^{7}$. Lupus anticoagulant (LA) was determined by mixing $1: 1$ patient and pooled normal plasma after finding a prolonged partial thromboplastin time. Subsequently, a thromboplastin dilution test was performed by measuring prothrombin time with progressive diluted thromboplastin ${ }^{8}$. Lupus anticoagulant was considered to be present when all assays were positive. The presence of anticardiolipin antibodies and/or lupus anticoagulant was, when higher than $10 \mathrm{GPL}$ for IgG anticardiolipin antibodies and $6 \mathrm{MPL}$ for IgM anticardiolipin antibodies, considered to be indicative of the antiphospholipid syndrome (APS).

Coagulation tests were performed after a flawless venapuncture. Blood was collected in sodium citrate containing glass tubes. Plasma was prepared by two consecutive centrifugation steps, with the second one performed in an Eppendorf centrifuge to eliminate 
platelets. Samples were stored at $-80^{\circ} \mathrm{C}$ prior to assay. Protein $\mathrm{C}$ activity was determined with Coanate protein C (Chromogenix, Mölndal, Sweden) ${ }^{9}$. The normal value of protein C according to the laboratory control group is $70 \%$ to $130 \%$ and has an intra-assay and interassay coefficient of variation of $3.3 \%$ and $4.7 \%$, respectively, Total protein $S$ antigen and free protein $S$ were measured by an enzyme- linked immunosorbent assay (ELISA) (DAKO, Glostrup, Denmark) ${ }^{10}$. The normal range of both total protein $S$ antigen (intra-assay and inter-assay coefficient of variation of $5.1 \%$ and $5.7 \%$ ) and free protein $S$ (intra-assay and inter-assay coefficient of variation $3.4 \%$ and $3.6 \%$ ) is $70 \%$ to $130 \%$ and $65 \%$ to $130 \%$, respectively. Activated protein $\mathrm{C}$ resistance (APCR) was quantified by a chromogenic APCresistance assay ${ }^{11}$. The chromogenic test fully matches DNA analysis for the factor $\mathrm{V}$ Leiden mutation and has a normal range between $0 \%$ and $20 \%{ }^{11}$. Antithrombin activity (AT) was assayed with chromogenic substrate S-2765 (Chromogenix, Mölndal, Sweden) ${ }^{12}$. The normal range of AT is $80 \%$ to $120 \%$.

A methionine-loading test was used to diagnose hyperhomocysteinemia (HHC). Homocysteine was measured by high-performance liquid chromatography with fluorescence detection ${ }^{13}$. In our hands, this test has an intra- and inter-assay coefficient of variation of $3.9 \%$ and $5.9 \%$, respectively. At $8: 30 \mathrm{AM}$, the fasting homocysteine concentration was determined. Six hours after an oral dose of L-methionine $(0.1 \mathrm{~g} / \mathrm{kg}$ body weight), the postload homocysteine concentration was assessed. During the test participants used a standard low-methionine breakfast and lunch. Individuals were considered to have hyperhomocysteinemia when fasting and/or post-load plasma homocysteine levels were more than 2 standard deviations higher than the mean of the laboratory control group.

Measurement of blood pressure and renal hemodynamics: In the mid-follicular period $(5 \pm$ 2) of the menstrual cycle measurements were performed under standardized environmental conditions in a temperature-controlled room $\left(25-26^{\circ} \mathrm{C}\right.$ ) and as little as possible external disturbances. The measurement session started at 08:00 AM, with the insertion of a 20gauge catheter into a vein of the right forearm, to enable determination of renal function as detailed below. A second catheter was inserted into a vein of the contralateral forearm so as to collect blood samples. Participants did not drink caffeine-or alcohol-containing beverages and refrained from smoking and eating for at least 10 hours before the experiment. Throughout the measurement session, subjects were in supine position on a comfortable bed. Arterial blood pressure and heart rate (HR) were recorded continuously by a semi-automatic 
oscillometric device (Dinamap Vital Signs Monitor 1846, Critikon, Tampa, FL, USA), only interrupted during blood sampling and during the echocardiographic measurements (see below). Effective renal plasma flow (ERPF) and glomerular filtration rate (GFR) were measured by continuous infusion of PAH (PAH: para-aminohippurate sodium; MSD, West Point, PA, USA) and inulin (Inutest, Laevosan Gesellschaft, Linz, Austria), respectively ${ }^{14}$, 15. PAH and inulin, measured spectrophotometrically, had intra-assay- and inter-assay coefficient of variation of $4.2 \%$ and $7.3 \%$, and $4.5 \%$ and $8.1 \%$, respectively. Both variables were corrected for body surface area (BSA) and expressed in ml. $\mathrm{min}^{-1} .1 .73 \mathrm{~m}^{-2}$. ERBF, renal vascular resistance (RVR) and filtration fraction $(\mathrm{FF})$ were calculated as follows:

$$
\begin{aligned}
& \text { ERBF }=\text { ERPF/1-hematocrit } \\
& \boldsymbol{R} V R=80.000 \times M A P / E R B F \\
& F F=\text { GFR } / E R P F
\end{aligned}
$$

At least two hours after the initiation of the PAH/inulin infusion, blood samples were collected for the later determination of the circulating levels of inulin and PAH and those of the hormones specified below. Active plasma renin concentration (APRC) was determined by an immunoradiometric assay technique (Nichols Institute Diagnostics, Wychen, The Netherlands) with an intra-assay coefficient of variation of $2.9 \%$ and an inter-assay coefficient of variation of $7.6 \%{ }^{16}$. Angiotensin II (AngII) was assayed by radio-immunoassay (RIA) following Phenyl column extraction (Amersham Int, Amersham, UK) with an intra-assay coefficient of variation of $4.2 \%$ and an inter-assay coefficient of variation of $7.7 \%{ }^{17}$. Aldosterone was assessed by a solid-phase protein binding RIA (Diagnostic Products Corporation, LA, USA) with an intra-assay coefficient of variation of $4.3 \%$ and an inter-assay coefficient of variation of $6.7 \%{ }^{18} . \alpha$-Atrial natriuretic peptide ( $\alpha$ ANP) was analyzed by radioimmunoassay (Nichols Institute Diagnostics, Wychen, The Netherlands) with an intra-assay coefficient of variation of $9 \%$ and inter-assay coefficient of variation of $12 \%{ }^{19}$. Serum $17-\beta$-estradiol and progesterone were determined with a commercially available solid phase radioimmunoassay kit (DPC, Los Angeles, Cal, USA). Sensitivity of the assays are 0.035 and $0.15 \mathrm{nmol} / 1$, respectively. Samples were collected on ice and centrifuged at $4{ }^{\circ} \mathrm{C}$ for $10 \mathrm{~min}$ at $1500 \mathrm{~g}$ immediately after sampling. All samples were stored deep-frozen $\left(-80^{\circ} \mathrm{C}\right)$ prior to assay.

Measurement of plasma volume $(P V)$. After the procedure to quantify renal function, plasma volume was measured. Plasma volume (PV, intra-assay coefficient of variation of $4.2 \%$ ) was 
determined with the Iodine ${ }^{125}$-Albumin $\left({ }^{125}\right.$ I-HSA) indicator dilution method and expressed in $\mathrm{ml}$ per kilogram $(\mathrm{kg})$ lean body mass (LBM). The lean body mass was calculated as specified elsewhere ${ }^{20}$. Plasma volume was obtained by dividing the total injected radioactivity by the virtual volume-specific radioactivity at time zero, which corresponds with the time of bolus injection. The latter was obtained by extrapolation using the specific activity per ml of plasma at 10,20 and 30 minutes after bolus injection.

Echocardiograply to assess cardiac function was performed in semi-left lateral position, after completion of the plasma volume measurement and after approximately 5 minutes of rest, using a cross-sectional, phased array echocardiographic Doppler system (HewlettPackard Sonos 2000 and 2500) '. CO and cardiac index (CI) were calculated according to the formulas:

$$
\begin{array}{ll}
C O & =\text { stroke volume } x H R \\
C I & =C O / B S A
\end{array}
$$

In this formula, heart rate was obtained by taking the mean of the reciprocal of five consecutive R-R intervals on the ECG. Stroke volume (SV) was calculated by multiplying the aortic velocity integral and the aortic area. Aortic flow was measured across the aortic valves from an apical approach. The average area under the aortic velocity curve (aortic velocity integral) of five consecutive ejections was used to calculate stroke volume. Aortic valve diameter necessary for the calculation of the aortic area was measured off-line at the orifice during systole using M-mode. Total peripheral vascular resistance (TPVR) and total peripheral vascular resistance normalized for body surface area (TPVR $i$ ) were calculated as follows:

$$
\begin{aligned}
& T P V R=80 \times M A P / C O \\
& T P V R i=80 \times M A P / C I
\end{aligned}
$$

Left ventricular work (LVW), defined as the energetic expense on blood imposed by the left ventricle per unit of time was calculated using the formula:

$$
L V W=80 \times M A P \times C O
$$

The value used for MAP was obtained during the $\mathrm{CO}$ measurement and was calculated as the mean of three consecutive recordings. 
Statistical analysis: Data are presented as means \pm standard deviation (SD) unless otherwise stated. Differences between groups were tested with the Mann-Whitney-U Test along with Bonferroni correction. A p-value less than 0.05 relative to the control group, was considered statistically significant.

\section{Results}

The allocation of a formerly preeclamptic woman to either the hypertensive - or the thrombophilic subgroup was based on whether or not she had hypertension and if not, whether she had a thrombophilic disorder. Hypertension in this context was defined as a mean systolic - and/or a mean diastolic arterial blood pressure higher then $140 \mathrm{mmHg}$ or higher than $90 \mathrm{mmHg}$, respectively, determined using all of the Dinamap recordings accumulated at the day of the experiment. On the basis of these criteria 14 women were assigned to the hypertensive subgroup. Only two women in this subgroup had been diagnosed before to have hypertension. Among these subjects, 5 were found to have a thrombophilic disorder as well, all but one in conjunction with hyperhomocysteinemia. Of the remaining 44 (normotensive) formerly preeclamptic subjects, $26(59 \%)$ had one $(n=22)$ or more than one $(n=4)$ thrombophilic disorder. They were allocated to the thrombophilic subgroup. The remaining 18 formerly preeclamptic subjects had neither hypertension nor thrombophilia. They were allocated to the asymptomatic subgroup. The demographic characteristics of all participants subdivided over various subgroups are listed in table I.

The three subgroups were comparable with the control group with respect to age, height, parity and urinary sodium excretion. The asymptomatic subgroup differed from controls by a higher body mass index. Obviously, the incidence of - usually iatrogenic - preterm birth was elevated in all formerly preeclamptic women. Prematurity was most obvious in hypertensives, followed by normotensive thrombophilic women and the asymptomatic subgroup.

Table $I I$ lists the subtypes of thrombophilia observed in the formerly preeclamptic participants. Antiphospholipid syndrome, protein $S$ deficiency (prot $S$ def) and hyperhomocysteinemia were most common. All formerly preeclamptic women, which were diagnosed as having antiphospholipid syndrome, were IgG serotypes. In our control group, one woman was diagnosed activated protein $\mathrm{C}$ resistant, based on factor $\mathrm{V}$ Leiden mutation $(9 \%)$. 
Table III lists the hemodynamic variables in the various subgroups. The hemodynamic status in the thrombophilic subgroup was almost identical to that in the control group. In contrast, women in the hypertensive subgroup had a higher cardiac output even when normalized for body surface area (cardiac index). In addition, left ventricular work was higher and a plasma volume per $\mathrm{kg}$ lean body mass lower relative to the control group. Hemodynamically, the asymptomatic subgroup resembled closely the hypertensive subgroup, except for cardiac index. In this group, the plasma volume per $\mathrm{kg}$ lean body mass was lower as compared to controls. After correlation analysis, this phenomenon was found to be independent of the body mass index in this subgroup.

Neurohormones, reproductive hormones and renal hemodynamics are listed in table IV. Only the hypertensives differed from controls by a higher atrial natriuretic peptide, angiotensin II and renal vascular resistance on the one hand, and a lower glomerular filtration rate and effective renal plasma flow, on the other hand. The asymptomatic formerly preeclamptic subjects did not differ significantly from the control group. Plasma levels of progesterone and 17 - $\beta$-estradiol were comparable in all groups.

Table I: Demographic data from the 3 subgroups of formerly preeclamptics (ex-PE) and the group of normal parous controls. Data are presented as means \pm SD. If a value is followed by an arrow, this particular variable is significantly higher $(\uparrow)$ or lower $(\downarrow)$ than the one in the control group.

\begin{tabular}{|c|c|c|c|c|}
\hline 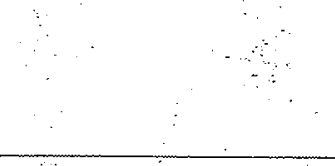 & $\begin{array}{c}\text { controls } \\
(n=11)\end{array}$ & $\begin{array}{l}\text { thrombophilic } \\
(\mathrm{n}=26)\end{array}$ & $\begin{array}{c}\text { ex-PE } \\
\text { asymptomatic } \\
(\mathrm{n}=18)\end{array}$ & $\begin{array}{c}\text { hypertensive } \\
(n=14)\end{array}$ \\
\hline Age (years) & $31 \pm 2$ & $30 \pm 4$ & $30 \pm 3$ & $33 \pm 4$ \\
\hline Height $(\mathrm{cm})$ & $168 \pm 4$ & $167: \pm 7$ & $169 \pm 5$ & $167 \pm 4$ \\
\hline BMI $\left(\mathrm{kg} . \mathrm{m}^{2}\right)$ & $21 \pm 2$ & $24 \pm 4$ & $27 \pm \ddot{6} \uparrow$ & $24 \pm 4$ \\
\hline Parity (median with range) & $1(1-2)$ & $1(1-3)$ & $1(1-2)$ & $1(1-4)$ \\
\hline Amenorrhea at birth (whs) & $39 \pm 1$ & $29 \pm 4 \downarrow$ & $32 \pm 5 \downarrow$ & $28 \pm 5 \downarrow$ \\
\hline Preterm birth < 32 whs $(\%)$ & $0(0 \%)$ & $21(81 \%)$ & $10(56 \%)$ & $11(79 \%)$ \\
\hline $\mathrm{MAP}(\mathrm{mmHg})$ & $84 \div 8$ & $86 \pm 8$ & $87 \pm 7$ & $106 \pm 7 \uparrow$ \\
\hline Natriuresis (mmol $24 \mathrm{~h}^{1}$ ) & $109 \pm 29$ & $99 \pm 33$ & $89 \pm 31$ & $84 \pm 31$ \\
\hline
\end{tabular}

$\mathrm{BMI}=$ body mass index, $\mathrm{MAP}=$ mean arterial blood pressure. 
Table II: Occurrence of the various subtypes of thrombophilic disorders in the thrombophilic - and hypertensive subgroups of formerly preeclamptic women.

\begin{tabular}{lcc}
\hline Type of thrombophilic dișorder & $\begin{array}{c}\text { thrombophilic } \\
(\mathrm{n}=26)\end{array}$ & $\begin{array}{c}\text { hypertensive } \\
(\mathrm{n}=14)\end{array}$ \\
\hline ACA/LA (Antiphospholipid syndrome) & $13(50 \%)$ & $1(7 \%)$ \\
Hyperhomocysteinenui & $5(19 \%)$ & $5(36 \%)$ \\
Protein C deficiency & $2(8 \%)$ & - \\
Activated Protein C Resistance & $3(12 \%)$ & - \\
Protein S deficiency & $7(27 \%)$ & $\cdots$ \\
Anti thrombin deficiency: & - & $\ddots$ \\
\hline
\end{tabular}

$\mathrm{ACA}=$ anticardiolipin antibodies, $\mathrm{LA}=$ lupus anticoagulant

Table III: Hemodynamic data in the 3 subgroups of formerly preeclamptics (ex-PE) and the group of normal parous controls. Data are presented as means $\pm \mathrm{SD}$. If a value is followed by an arrow, this particular variable is significantly higher $(\uparrow)$ or lower $(\downarrow)$ than the one in the control group.

\begin{tabular}{|c|c|c|c|c|c|}
\hline$\quad$ & & $\begin{array}{l}\text { controls } \\
(\mathrm{n}=11)\end{array}$ & $\begin{array}{l}\text { thrombophilic } \\
(\mathrm{n}=26)\end{array}$ & $\begin{array}{c}\text { ex-PE } \\
\text { asymptomatic } \\
(\mathrm{n}=18)\end{array}$ & $\begin{array}{l}\text { hypertensive } \\
(\mathrm{n}=14)\end{array}$ \\
\hline MAP $(\mathrm{nmHg})$ & & $84 \pm 8$ & $86 \pm 8$ & $87 \pm 7$ & $106 \pm 7 \uparrow$ \\
\hline HR (bpm) & & $62 \pm 10$ & $63 \pm 9$ & $66 \pm 8$ & $68 \pm 12$ \\
\hline $\mathrm{CO}\left(\mathrm{L} \cdot \mathrm{min}^{-1}\right)$ & & $4.7 \pm 0.4$ & $5.2 \pm 0.7$ & $5.4 \pm 0.8 \uparrow$ & $5.9 \pm 0.7 \uparrow$ \\
\hline $\mathrm{CI}\left(\mathrm{L} \cdot \mathrm{min}^{-1} \cdot \mathrm{m}^{-2}\right)$ & & $2.8 \pm 0.3$ & $3.0 \pm 0.4$ & $2.9 \pm 0.6$ & $3.4 \pm 0.4 \uparrow$ \\
\hline TPVR $\left(x 10^{3}\right)\left(\right.$ dyne.s. $\left.^{-5}{ }^{-5}\right)$ & & $1.4 \pm 0.2$ & $1.3 \pm 0.2$ & $1.3 \pm 0.2$ & $1.4 \pm 0.2$ \\
\hline TPVR $i\left(x \cdot 10^{3}\right)\left(\right.$ dyne.s.cm $\left.{ }^{-5}\right)$ & & $2.4 \pm 0.4$ & $2.3 \pm 0.5$ & $2.4 \pm 0.4$ & $2.5 \pm 0.3$ \\
\hline LVW $\left(\times 10^{3}\right)\left(\mathrm{mmHg} \cdot \mathrm{L} \cdot \mathrm{min}^{-1}\right)$ & & $31 \pm 4$ & $35 \pm 6$ & $38 \pm 10 \uparrow$ & $50 \pm 9 \uparrow$ \\
\hline$P V(L)$ & & $2.5 \pm 0.2$ & $2.4 \pm 0.2$ & $2.4 \pm 0.3$ & $2.4 \pm 0.3$ \\
\hline PV/LBM $\left(\mathrm{ml} . \mathrm{kg}^{-1}\right)$ & & $\because \quad 56 \pm 5$ & $52 \pm 4$ & $47 \pm 5 \downarrow$ & $51 \pm 5 \downarrow$ \\
\hline
\end{tabular}

MAP = mean arterial blood pressure, $\mathrm{HR}=$ heart rate, $\mathrm{CO}=$ cardiac output, $\mathrm{CI}=$ cardiac index, TPVR = total peripheral vascular resistance, $T P V R i=$ total peripheral vascular resistance index, $\mathrm{LVW}=$ left ventricular work, $\mathrm{PV}=$ plasma volume, $\mathrm{LBM}=$ lean body mass. 
Table IV: Endocrine - and renal variables in the 3 subgroups of formerly preeclamptics (ex-PE) and the group of normal parous controls. Data are presented as means $\pm S D$. If a value is followed by an arrow, this particular variable is significantly higher $(\uparrow)$ or lower $(\downarrow)$ than the one in the control group.

\begin{tabular}{|c|c|c|c|c|c|}
\hline$\because$ & $\therefore$ & $\begin{array}{c}\text { controls } \\
\ddots \\
(n=11)\end{array}$ & $\begin{array}{l}\text { thrombophilic } \\
(n=26)\end{array}$ & $\begin{array}{c}\text { ex-PE } \\
\text { asymptomatic } \\
(\mathrm{n}=18)\end{array}$ & $\begin{array}{c}\text { hypertensive } \\
(n=14)\end{array}$ \\
\hline APRC $\left(\mathrm{mU} \cdot \mathrm{L}^{-1}\right)$ & $\therefore$ & $13.5 \pm 4.5$ & $13.0 \pm 7.8$ & $13.9 \pm 5.9$ & $19.2 \pm 9.9$ \\
\hline AngII $\left(p m o l . L^{-1}\right)$ & & $8.5 \pm 2.4$ & $10.6 \pm 3.3$ & $10,4 \pm 2.7$ & $12.1 \pm 4.5 \uparrow$ \\
\hline Aldo $\left(\right.$ nmol. $\left.L^{-1}\right)$ & & $83 \pm 30$ & $89 \pm 26$ & $1.06 \pm 41$ & $120 \pm 70$ \\
\hline$\alpha$-ANP (ng. $\left.L^{-1}\right)$ & & $88 \pm 31$ & $98 \pm 40$ & $97 \pm 46$ & $160 \pm 48 \uparrow$ \\
\hline GFR $\left(\mathrm{ml} \mathrm{min}^{-1} .1 .73 \mathrm{~m}^{-2}\right)$ & & $125 \pm 8$ & $117 \pm 16$ & $113 \pm 23$ & $105 \pm 19 \downarrow$ \\
\hline $\operatorname{ERPF}\left(\mathrm{ml} \cdot \mathrm{min}^{-1} \cdot 1.73 \mathrm{~m}^{-2}\right)$ & & $562 \pm 78$ & $479 \pm 104$ & $490 \pm 101$ & $444 \pm 123 \downarrow$ \\
\hline $\operatorname{ERBF}\left(\mathrm{ml} \cdot \mathrm{min}^{-1} \cdot 1.73 \mathrm{~m}^{-2}\right)$ & & $877 \pm 127$ & $762 \pm 179$ & $770 . \pm 152$ & $726 \pm 208$ \\
\hline $\operatorname{RVR}\left(\times 10^{3}\right)\left(\right.$ dyne.s. $\left.\mathrm{cm}^{-5}\right)$ & & $7.2 \pm 1.3$ & $9.1 \pm 2.4$ & $8.8 \pm 1.9$ & $12.0 \pm 4.3 \uparrow$ \\
\hline $\mathrm{FF}$ & $\therefore$ & $0.23 \pm 0.02$ & $0.25 \pm 0.03$ & $0.24 \pm 0.04$ & $0.24 \pm 0.04$ \\
\hline
\end{tabular}

$\mathrm{APRC}=$ active plasma renin concentration, $\mathrm{AnglI}=$ angiotensin II, Aldo $=$ aldosterone, $\alpha$-ANP $=$ atrial natriuretic peptide, $G F R=$ glomerular filtration rate, $E R P F=$ effective renal plasma flow, $E R B F=$ effective renal blood flow, $R V R=$ renal vascular resistance, $F F=$ filtration fraction.

\section{Discussion}

Endothelial dysfunction plays a central role in the development of preeclampsia. Women with essential hypertension, renovascular disease, diabetes mellitus and some thrombophilic disorders are prone to develop preeclampsia in pregnancy ${ }^{5}$. Interestingly, in all these conditions the primary abnormality puts extra strain upon the endothelium, either mechanically (shear stress) or (bio)chemically (thrombophilia). The latter suggests that the higher incidence of preeclampsia in these conditions may result from a reduced endothelial tolerance to cope with the pregnancy-related increase in shear stress. Whether the latter is a prerequisite for preeclampsia to develop, is unknown. If so, it is difficult to explain why a large proportion of preeclamptic patients recover without apparent residual symptoms or abnormalities as detailed above. It is still unsettled whether this subgroup of apparently healthy formerly preeclamptic patients is indeed entirely comparable with normal parous controls or else, has some not yet identified subclinical abnormality that interferes with the vasculature's capacity to adapt to pregnancy. Therefore, we studied the hemodynamic -, 
renal - and clotting functions in 58 formerly preeclamptic women and compared the results with those obtained in 11 normal parous controls.

Almost onethird (18 of 58) of the formerly preeclamptic women in this study had neither hypertension nor thrombophilia. In these seemingly healthy formerly preeclamptic subjects renal function and circulating levels of volume regulatory hormones were not different from controls. Although the cardiac index did not differ between the control and a-symptomatic formerly preeclamptic subgroup, the latter cardiac index was achieved at the expense of a higher cardiac load reflected in the higher left ventricular work. In the asymptomatic subgroup of formerly preeclamptic patients, plasma volume per $\mathrm{kg}$ lean body mass was lower as compared to controls. A low plasma volume per $\mathrm{kg}$ lean body mass was also observed in the hypertensive subgroup. Finally, the asymptomatic formerly preeclamptic subgroup was found to be more obese than the control group.

Obesity, chronic hypertension and preeclampsia are related conditions 21,24 . Obesity and preeclampsia could have been related because of the associated hypertension. However, chronic hypertension and overweight contribute independently to the development of preeclampsia ${ }^{24}$. Obesity and total plasma volume are also positively related ${ }^{21}$. Therefore, indexation for body mass is necessary to enable comparison of plasma volume. We observed in both obese and non-obese asymptomatic formerly preeclamptic women and hypertensives a lower plasma volume per $\mathrm{kg}$ lean body mass as compared to controls. It is known that in the early stages of essential hypertension plasma volume is reduced 22 . Therefore asymptomatic formerly preeclamptic women seem to have a condition that can be considered latent - or pre-hypertension. This is supported by the observation that formerly preeclamptic women have an increased likelihood to develop hypertension in the next decades ${ }^{4,23}$.

Thrombophilia not only predisposes for preeclampsia, but also for miscarriage, placental infarcts, placental abruption and stillbirth ${ }^{25}$. Especially women with more than one clotting disorder are at risk. In the present study, about $46 \%$ of the formerly preeclamptic participants had thrombophilia. Similar percentages have been reported earlier for the Dutch population 5 . In thrombophilic formerly preeclamptic women, antiphospholipid syndrome, protein $\mathrm{S}$ deficiency, hyperhomocysteinemia and activated protein $C$ resistance are most common. We diagnosed hyperhomocysteinemia in $36 \%$ of the hypertensive formerly preeclamptic subjects. It is tempting to conclude from this observation that hyperhomocysteinemia accelerates the development of vascular disease. 
Gestational age at birth is the lowest in hypertensive formerly preeclamptics, followed by the normotensive thrombophilic- and latent hypertensive subgroup. Therefore, hemodynamic and hemostatic subdivision of formerly preeclamptic women seems to be related with the onset and severity of preeclampsia.

In summary, formerly preeclamptic women can be subdivided into a hypertensive -, a thrombophilic and an asymptomatic subgroup. The latter subgroup resembles hemodynamically the hypertensive subgroup. Therefore, we propose to categorize the women in the latter group as latent hypertensives. These observations not only confirm the central role of the endothelium in the development of preeclampsia. They also provide evidence for the view that in the majority of cases preeclampsia is superimposed upon a preexisting vascular - or clotting disorder. This offers attractive possibilities to develop prophylactic strategies in women identified with one of these risk conditions. 


\section{References}

1. Duvetor JJ, Cheriex EC, Pieters FAA, Peeters LLH. Early-pregnancy changes in hemodynamics and volume homeostasis are consecutive adjustments triggered by a primary fall in systemic vascular tone. An J Obstet Gynecol 1993;169:1.382-1.392.

2. Davison JM, Noble MCB. Serial changes in 24 hour creatinine clearance during normal menstrual cycles and the first trimester of pregnancy. Br J Obstet Gynaecol 1981;88: 10-17.

3. Duvekot JJ, Cheriex EC, Pieters FAA, Menheere PPCA, Peeters LlH. Maternal volume homeostasis in early pregnancy in relation to fetal growth restriction. Obstet Gynecol 1995;85:361-367.

4. Roberts JM. Endothelial dysfunction in preeclampsia. Semin Reprod Endocrinol 1998;16:5-15

5. van Pampus MG, Detker GA, Wolf H, Huijgens PC, Koopman MM, von Blomberg BM, Buller HR. High prevalence of hemostatic abnomalities in women with a history of severe preeclampsia. Am J Obstet Gynecol 1999; 180(5):1146-50.

6. Perry 1J, Beevers DG. The definition of pre-eclampsia. Br J Obstet Gynaecol 1994;101:587-591.

7. Hauris EN. The second intemational anti-cardiolipin standardization workshop/the Kingston Antiphospholipid Antibody Study (KAPS) group. Am J Clin Pathol 1990;94:476-484.

8. Derksen RHWM, Hasselaar P, Blokzijl L, Gnelig Meyling FHJ, de Groot PhG. Coagulation screen is more specific than the anticardiolipin antibody ELISA in defining a thrombotic subset of lupus patients. Ann Rheum Dis 1988:47:364-371.

9. Vinazzer $\mathrm{H}$, Prangraz U. Protein $\mathrm{C}$ : comparison of different assay's in normal and abnormal plasma samples. Thromb Res 1987:46:1-8.

10. Woodhams BJ. The simultaneous measurement of total and free protein $S$ by EL_ISA. Thromb Res 1988;50:213-220.

11. van Oerle R, van Pampus L. Tans G, Rosing J, Hamulyak K. The clinical application of a new specific functional assay to detect the factor $V$ Leiden mutation associated with activated protein C resistance. Am J Clin Pathol 1997;107:521-526.

12. Tollefsen DM. Laboratory diagnosis of antithombin and heparin cofactor Il deficiency. Semin Thromb Hemost 1990;16:162-8.

13. Ubbink JB, Vermaak WJK, Bissbort S. Rapid high-performance liquid chromatographic assay for total homocysteine levels in human serum. J Chromatoxi 1991:565: 441-446.

14. Cole BR, Giangiacomo J. Ingelfinger JR. Rooson AM. Measurement of renal function without urine collection. A critical evaluation of the constant infusion lechnique for detemination of inulin and para-aminohippurate. N Eng J Med 1972:287:1109-1114.

15. Brun C. A rapid method for the determination of para-aminohippurate acid in kidney function tests. J Lab Clin Chem 1951:37:955-958.

16. Simon D. Hartmann BJ. Badouaille G. Caillot G, Guyenne TT, Corvol P. Pau B, Marchand J. Two-site direct immunoassay specific for active renin. Clin Chem 1991;38:1959-1962.

17. Nussberger J, Brunner DB, Wacber $B$, Brunner HR. True versus imnunoreactive angiotensin II in humas plasma. Hypertension 1985;7(Suppl 1):1-17.

18. Kubasik NP. Warten K. Sine HE. Evaluation of a new conmercial radioassay hit for aldosterone using an iodinated tracer. Clin Biochem 1978;12:59-61. 
19. Rosmalen FMA, Tan ACITL, Tan HS, Benraad BJ. A sensitive radio-immunoassay of atrial natriuretic peptide in human plasma, using a tracer with an immobilized glycouril agent. Clin Chim Acta 1987;165:331-340.

20. Deurenberg P, Weststrate JA, Seidell JC. Body mass index as a measure of body fatness: ageand sex-specific prediction formulas. Br J Nutr 1991;65:105-114.

21. Mujais SK, Tarazi RC, Dustan HP, Fouad FM, Bravo EL. Hypertension in obese patients: hemodynamic and volume studies. Hypertension 1982;4:84-92.

22. Lebel M, Grose JH, Blais R. Increased hematocrit with normal red blood cell mass in early borderline essential hypertension. Clin Exp Hypertens 1989;11:1505-1514.

23. Sibai BM, el Nazer A, Gonzalez Ruiz A. Severe preeclampsia-eclampsia in young primigravid women: subsequent pregnancy outcome and remote prognosis. Am J Obstet Gynecol 1986;155:1011-6.

24. Eskenazi B, Fenster L, Sidney S. A multivariate analysis of risk factors for preeclampsia. JAMA $1991 ; 266: 237-241$

25. Preston FE, Rosendaal FR, Walker ID, Briet E, Berntorp E, Conrad J, Fontcuberta J, Makris M, Mariani G, Noteboom W, Pabinger I, Legnani C, Scharrer I, Schulman S, van der Meer FJ. Increased fetal loss in women with heritable thrombophilia. Lancet 1996;342:913-6. 


\section{Chapter 3}

\section{CHANGES IN HEMODYNAMICS AND VOLUME HOMEOSTASIS WITH THE MENSTRUAL CYCLE IN WOMEN WITH A HISTORY OF PREECLAMPSIA}

Spaanderman MEA, wan Beek E, Ekhart THA, wan Eyck J, Cheriex EC, de Leewn PW, Peeters $L L H$

Departments of Obstetrics and Gynecology, Internal Medicine and Cardiology, Academic Hospital Maastricht and Sophia Hospital Zwolle. The Netherlands.

Am J Obstet Gynecol 2000; 182:1127-34. 


\section{Abstract}

Background

Among formerly preeclamptic women the prevalence of hemodynamic and clotting disorders is raised. In this study we tested the hypothesis that the normal cyclicity in hemodynamics and renal function with the menstrual cycle, as seen in healthy women, is preserved in formerly preeclamptic subjects irrespective of whether or not they had an underlying hemodynamic or clotting disorder.

Methods

We compared the hemodynamic and volume cyclicity during the menstrual cycle in formerly preeclamptic women $(n=39)$ with that in normal parous controls (CONTROLS, $n=10$ ). The formerly preeclamptic participants were subdivided into women with hypertension (HYPERT, $n=10$ ), women with a thrombophilic disorder (THROMB, $n=17$ ) and women without these abnormalities (NONTHROMB, $n=12$ ). We measured at least 5 months postpartum, once during the follicular phase (day $5 \pm 2$ ) and once during the luteal phase (day 22 22 ) of the menstrual cycle, the following variables: body weight and length, mean arterial pressure, heart rate, cardiac output, plasma volume, glomerular filtration rate, effective renal plasma flow, renal volume homeostatic hormones, reproductive hormones and catecholamines. From the measured data, we calculated body mass index, cardiac index, left ventricular work, total peripheral - and renal vascular resistance, effective renal blood flow and renal filtration fraction.

Results HYPERT differed from CONTROLS by a higher basal (follicular phase) value for cardiac output, cardiac output, left ventricular work, renal vascular resistance, atrial natriuretic peptide and norepinephrine. NONTHROMB differed from CONTROLS by a lower basal plasma volume and a higher basal cardiac output and left ventricular work. Women in the THROMB group were comparable with respect to basal hemodynamics and - renal function, except for a higher renal vascular work. In CONTROLS, heart rate, plasma volume, effective renal plasma volume, effective renal blood flow, renin-angiotensin-aldosterone system hormones and norepinephrine in the follicular phase had increased in the luteal phase while the renal vascular resistance and atrial natriuretic 
peptide had decreased. In the three formerly preeclamptic subgroups, this cyclic pattern with the menstrual cycle was preserved for most of these parameters.

Conclusion Although basal hemodynamic - and volume status in formerly preeclamptic women differs from that in normal parous controls, its cyclic pattern with the menstrual cycle is largely preserved. 


\section{ChaPTER 3}

\section{Introduction}

In healthy women, hemodynamics and volume homeostasis vary with the menstrual cycle ${ }^{1 \text {, }}$ ${ }^{2}$. The reported data provide indirect evidence for mild vasorelaxation in the luteal phase relative to the follicular phase of the menstrual cycle. In this respect, although much less profound, the luteal phase mimics the early weeks of pregnancy when systemic vasorelaxation is extensive enough to induce a compensatory rise in cardiac output together with mild hemodilution as a sign of volume expansion and activation of volume regulatory hormones ${ }^{3}$. In contrast, pregnancies complicated by severe fetal growth restriction and/or preeclampsia, are often preceded by defective development of these early pregnancy changes 4.5

Epidemiological studies indicate that disorders with a thrombophilic phenotype or hypertension predispose for preeclampsia ${ }^{6.7}$. Recently another associated subgroup has been described in which the plasma volume was found to be reduced as compared to normal parous controls ${ }^{8}$. These findings might explain the different clinical phenotypes observed before preeclampsia occurs and could be indicative for separate pathophysiological entities which finally all can lead to endothelial damage and the development of preeclampsia.

The defective hemodynamic adaptation in early preeclamptic pregnancy together with the occurrence of vasorelaxation both in the luteal phase and in early pregnancy, raises the question whether the hemodynamic and volume cyclicity during the menstrual cycle in expreeclamptic women is different as compared to that in women with past uneventful pregnancies.

The objective of the present study was to test the hypothesis that the cyclicity in hemodynamic - and volume parameters during the menstrual cycle are different in formerly preeclamptic women as compared to normal parous controls. To this end, we compared in both phases of the menstrual period blood pressure, cardiac function, renal hemodynamics, plasma volume, volume regulatory hormones and catecholamines, between formerly preeclamptic women and normal parous controls. 


\section{Methods}

\section{Selection and patient characteristics.}

In this study 58 formerly preeclamptic women and 14 normal parous controls were enrolled. Only those with a biochemically-confirmed ovulation in the luteal phase measurement session (as detailed below), were included for further analysis. As a consequence, in this paper 39 ovulating formerly preeclamptic non-diabetic Caucasian women and 10 controls were analyzed. Participants were at least 5 months postpartum. Formerly preeclamptic women were recruited at the outpatient clinic at the postpartum follow-up, whereas controls were recruited by advertisement. Preeclampsia and hypertension were defined according to the criteria of the International Society for the Study of Hypertension in Pregnancy 9 Therefore, hypertension was defined as a mean systolic - and/or a mean diastolic arterial blood pressure higher then $140 \mathrm{mmHg}$ or higher then $90 \mathrm{mmHg}$, respectively, using all of the Dinamap recordings accumulated at the day of the experiment. All experiments were preceded by one week of standardized sodium intake (100 mmol sodium per day), representing the mean sodium intake in our population. This required that all participants consulted the hospital's dietitian, prior to study. Measuring 24-hour sodium output on the day before the experiment assessed women's compliance with the diet. None of the women used vitamins, oral contraceptives, antihypertensive drugs, non-steroid anti-inflammatory drugs or glucocorticosteroids in the two weeks prior to the measurements. On separate days and after an overnight fast, participants were tested for thrombophilia and hemodynamic/renal function. Thrombophilia was defined as the condition characterized by the presence of at least one clotting disorders known to be associated with an increased risk to develop venous thrombo-embolism. All participants gave written informed consent. The hospital's medical-ethical committee approved the study.

\section{Experimental procedure}

\section{Methods}

The methodology of the measurements and calculations on the thrombophilic screening and hemodynamic function were described previously ${ }^{23}$.

Thrombophilic screening: In short, anticardiolipin antibodies were determined spectrophotometrically by enzyme-linked immunoassay. Lupus anticoagulant was determined by mixing 1:1 patient and pooled normal plasma after finding a prolonged partial 
thromboplastin time. Subsequently, a thromboplastin dilution test was performed by measuring prothrombin time with progressive diluted thromboplastin. Lupus anticoagulant was considered to be present when all assays were positive. We defined the antiphospholipid syndrome as the condition where anti-cardiolipin antibodies and/or lupus anticoagulant, when higher than $10 \mathrm{GPL}$ for IgG antiphospholipid antibodies and $6 \mathrm{MPL}$ for IgM antiphospholipid antibodies, could be detected in peripheral blood in women with a history of preeclampsia.

Coagulation tests were performed after a flawless venapuncture. Plasma samples were stored at $-80{ }^{\circ} \mathrm{C}$ prior to assay. Protein $\mathrm{C}$ activity was determined with Coamate protein $\mathrm{C}$ (Chromogenix, Mölndal, Sweden). Total protein $S$ antigen and free protein $S$ were measured by an enzyme- linked immunosorbent assay (ELISA) (DAKO, Glostrup, Denmark). A chromogenic activated protein $C$-resistance assay quantified activated protein $C$ resistance. Antithrombin activity was assayed with chromogenic substrate S-2765 (Chromogenix, Mölndal, Sweden).

A methionine-loading test was used to diagnose hyperhomocysteinemia. Homocysteine was measured by high-performance liquid chromatography with fluorescence detection. At 8:30 AM, the fasting homocysteine concentration was determined. Six hours after an oral dose of L-methionine $(0.1 \mathrm{~g} / \mathrm{kg}$ body weight), the post-load homocysteine concentration was assessed. During the test participants used a standard low-methionine breakfast and lunch. Individuals were considered to have hyperhomocysteinemia when fasting and/or post-load plasma homocysteine levels were more than 2 standard deviations (SD) higher than the mean of the laboratory control group.

Measurement of blood pressure and renal hemodynamics: Both in the follicular phase (day 5 \pm 2 ) and luteal phase (day $22 \pm 2$ ) of the menstrual cycle (random order), measurements were performed under standardized environmental conditions in a temperature-controlled room $\left(25-26^{\circ} \mathrm{C}\right)$ and with as minimal external disturbances as possible. Participants did not drink caffeine- or alcohol-containing beverages and refrained from smoking and eating for at least 10 hours before the experiment. The measurement session started at 8:00 AM, with the insertion of a 20 -gauge catheter into a vein of the right forearm, to enable determination of renal function as detailed below ${ }^{23}$. A second catheter was inserted into a vein of the contralateral forearm for sampling of blood. Throughout each measurement session, subjects were in supine position on a comfortable bed. Arterial blood pressure and heart rate were recorded 
repeatedly at two minutes interval by a semi-automatic oscillometric device (Dinamap Vital Signs Monitor 1846, Critikon, Tampa, FL, USA), throughout the measurement session. Effective renal plasma flow and glomerular filtration rate were measured by continuous infusion of PAH (PAH: para-aminohippurate sodium; MSD, West Point, PA, USA) and inulin (Inutest, Laevosan Gesellschaft, Linz, Austria), respectively. PAH and inulin were measured spectrophotometrically. Renal hemodynamics were corrected for body surface area (BSA) and expressed in ml.min ${ }^{-1} .1 .73 \mathrm{~m}^{-2}$. Effective renal blood flow (ERBF), renal vascular resistance (RVR) and filtration fraction (FF) were calculated as follows:

$$
\begin{aligned}
& \text { ERBF }=\text { ERPF/1-hematocrit } \\
& \boldsymbol{R} V \boldsymbol{R}=80.000 \times M A P / E R B F \\
& F F=G F R / E R P F
\end{aligned}
$$

At least two hours after the initiation of the PAH/inulin infusion, three blood samples were taken for determination of inulin and PAH. In addition, blood was collected for assay of active plasma renin concentration, angiotensin II, aldosterone, $\alpha$ atrial natriuretic peptide, sex-hormones and catecholamines. Active plasma renin concentration was determined by an immunoradiometric assay technique (Nichols Institute Diagnostics, Wychen, The Netherlands). Angiotensin II was assayed by radioimmunoassay (RIA) following Phenyl column extraction (Amersham Int, Amersham, UK). A solid-phase protein binding RIA (Diagnostic Products Corporation, LA, USA) assessed aldosterone. $\alpha$-Atrial natriuretic peptide was analyzed by radioimmunoassay (Nichols Institute Diagnostics, Wychen, The Netherlands). Norepinephrine (intra-assay coefficient of variation (CV) $4.5 \%$, inter-assay CV $8.1 \%$ ), epinephrine (intra-assay CV $4.1 \%$, inter-assay CV $8.6 \%$ ) and dopamine (intraassay CV $3.9 \%$, inter-assay CV $7.1 \%$ ) were assessed by chromatograph after liquid-liquid extraction and derivatization with a selective fluorescent agent ${ }^{10}$. Serum 17 - $\beta$-estradiol and progesterone were determined with a commercially available solid phase radioimmunoassay kit (DPC, Los Angeles, Cal, USA). Sensitivity of the latter assays are 0.035 and $0.15 \mathrm{nmol} / \mathrm{l}$, respectively. Ovulation was confirmed when mid-luteal serum progesterone exceeded 15 $\mathrm{pg} / \mathrm{l}{ }^{22}$. Samples were collected on ice and centrifuged at $4{ }^{\circ} \mathrm{C}$ for $10 \mathrm{~min}$ at $1500 \mathrm{~g}$ immediately after sampling. All samples were stored deep-frozen $\left(-80^{\circ} \mathrm{C}\right)$ prior to assay.

Measurement of plasma volume. After the procedure to quantify renal function, plasma volume was measured. Plasma volume was determined with the Iodine ${ }^{125}$-Albumin $\left(^{125} \mathrm{I}\right.$ - 
HSA) indicator dilution method and expressed in $\mathrm{ml}$ per kilogram ( $\mathrm{kg}$ ) lean body mass $(\mathrm{LBM})^{2 \hat{3}}$.

Echocardiography to assess cardiac function was performed in semi-left lateral position, after completion of the PV measurement and after 5 minutes of rest, using a cross-sectional, phased array echocardiographic Doppler system (Hewlett-Packard Sonos 2000 and 2500) ${ }^{23}$. Cardiac output $(\mathrm{CO})$ and cardiac index $(\mathrm{Cl})$ were calculated according to the formulas:

$$
\begin{array}{ll}
C O & =\text { stroke volume } x H R \\
C I & =C O / B S A
\end{array}
$$

In this formula, heart rate (HR) was obtained by taking the mean of five consecutive R-R intervals on the ECG. Stroke volume was calculated by multiplying the aortic velocity integral and the aoric area. Aortic flow was measured across the aortic valves from an apical approach. The average area under the aortic velocity curve (aortic velocity integral) of five consecutive ejections was used to calculate stroke volume. Aortic valve diameter necessary for the calculation of the aortic area, was measured off-line at the orifice during systole using M-mode. Total peripheral vascular resistance (TPVR) and total peripheral vascular resistance index (TPVRi) were calculated as follows:

$$
\begin{aligned}
& \text { TPVR }=80 \times M A P / C O \\
& \text { TPVRi }=80 \times M A P / C I
\end{aligned}
$$

Left ventricular work (LVW), defined as the energetic expense on blood imposed by the left ventricle per unit of time was calculated using the formula:

$$
L \boldsymbol{W}=80 \times \operatorname{MAP} x \mathrm{CO}
$$

The value used for mean arterial blood pressure (MAP) was obtained during the cardiac output measurement and was calculated as the mean of three consecutive recordings.

Statistical analysis: Data are presented as means \pm SD unless otherwise stated. Differences between groups were tested with the Mann-Whitney-U Test along with Bonferroni correction.

Differences within groups between the follicular phase and luteal phase were evaluated by Wilcoxon Matched-Pairs Signed-Ranks test. Correlations, when calculated, between concomitantly measured potentially related variables, were tested by Spearman's Rank correlation analysis. In the comparisons a p-value less than 0.05 was considered statistically 
significant. The calculated minimum detectable changes of the mean of variables within controls ( $\mathrm{n}=10, \alpha=0.05, \beta=0.10$ ), assuming a normal distribution of the data were $10 \%$ (mean arterial pressure), 9\% (heart rate), 14\% (stroke volume), 11\% (cardiac output), 11\% (cardiac index), $14 \%$ (total peripheral vascular resistance), $9 \%$ (plasma volume), $8 \%$ (glomerular filtration rate), 4\% (effective renal plasma flow), $7 \%$ (effective renal blood flow), and $15 \%$ (renal vascular resistance), respectively.

\section{Results}

The allocation of a formerly preeclamptic woman to either the hypertensive (HYPERT) - or the normotensive subgroup was based on whether or not she had hypertension. If not, then she was allocated to the normotensive thrombophilic group (THROMB) or the normotensive nonthrombophilic group (NONTHROMB) based on whether she had a thrombophilic disorder or not. On the basis of these criteria 10 of 39 women were assigned to the HYPERT subgroup. Two women in this subgroup had been diagnosed as having hypertension prior to the study. Among the hypertensive subjects, three were found to have a thrombophilic disorder as well, all in conjunction with hyperhomocysteinemia $(30 \%)$. Of the remaining 29 (normotensive) formerly preeclamptic subjects, $17(44 \%)$ had one $(n=16)$ - or more than one $(n=1)$ thrombophilic disorder(s). They were allocated to the THROMB subgroup. The remaining 12 formerly preeclamptic subjects had neither hypertension nor thrombophilia. They were allocated to the NONTHROMB subgroup. The demographic characteristics of all participants subdivided over the various subgroups are listed in table I. As compared to controls, the formerly preeclamptic subgroups did not differ with respect to age, height, parity and urinary sodium excretion. Formerly preeclamptic females in the NONTHROMB subgroup had a higher body mass index than the controls. Obviously, mean arterial blood pressure was higher in the HYPERT subgroup as compared to controls.

Among the 39 formerly preeclamptic participants $51 \%(20 / 39)$ had at least one disorder associated with thrombophilia. In the subjects allocated to the THROMB subgroup, antiphospholipid syndrome $(7 / 17,41 \%)$ and protein $S$ deficiency $(6 / 17,35 \%)$ were most common, followed by hyperhomocysteinemia $(3 / 17,18 \%)$, activated protein $\mathrm{C}$ resistance $(1 / 17,6 \%)$ and protein $\mathrm{C}$ deficiency $(1 / 17,6 \%)$. All formerly preeclamptic women, which were diagnosed as having antiphospholipid syndrome, were IgG serotypes. We did not identify women with antithrombin deficiency. 
Table II lists the systemic hemodynamic data measured in this study, with those from the follicular phase being defined as basal values. Baseline systemic hemodynamics in the THROMB subgroup were comparable to those in the control group. Basal mean arterial blood pressure, cardiac output, cardiac index and left ventricular work were higher in the HYPERT subgroup as compared to controls. In the NONTHROMB subgroup basal values of cardiac output and left ventricular work were higher and plasma volume lower as compared to the control group. After correlation analysis, plasma volume was found to be independent of the body mass index in this subgroup, but also for the other subgroups. With respect to the cyclicity, luteal plasma volume was found to have increased relative to value in the follicular phase, both in controls and in all 3 formerly preeclamptic subgroups. After analysis, the mean rise in plasma volume between the control group and the THROMB -, NONTHROMB - and HYPERT subgroups, respectively, was found to be comparable. Luteal heart rate was consistently higher in the controls and in the THROMB subgroup, but not in the NONTHROMB - and HYPERT subgroups. In neither group did any of the other hemodynamic variables listed in table II vary with the menstrual cycle.

Table I: Demographic data (follicular phase) from the 3 subgroups of formerly preeclamptic women (formerly PE) and the group of normal parous controls. If a value is followed by an arrow, this particular variable is higher $(\uparrow)$ or lower $(\downarrow)$ than the one in the control group.

\begin{tabular}{|c|c|c|c|c|}
\hline & $\begin{array}{l}\text { controls } \\
(n=10)\end{array}$ & $\begin{array}{c}\text { THROMB } \\
(n=17)\end{array}$ & $\begin{array}{l}\text { formerly PE } \\
\text { NONTHROMB } \\
(\mathrm{n}=12)\end{array}$ & $\begin{array}{c}\text { HYPERT } \\
(\mathrm{n}=10)\end{array}$ \\
\hline Age (years) & $31 \pm 2$ & $31 \pm 4$ & $29 \pm 3$ & $33 \pm 4$ \\
\hline Height (cm) & $168 \pm 3$ & $166 \pm 7$ & $167 \pm 5$ & $166 \pm 4$ \\
\hline $\mathrm{BMI}\left(\mathrm{kg} \cdot \mathrm{m}^{-2}\right)$ & $22 \pm 2$ & $24 \pm 4$ & $28 \pm 5 \uparrow$ & $22 \pm 3$ \\
\hline Parity (median with range) & $1(1-2)$ & $1(1-3)$ & $1(1-2)$ & $1(1-4)$ \\
\hline $\mathrm{MAP}(\mathrm{mmHg})$ & $83 \pm 8$ & $84 \pm 8$ & $.88 \pm 6$ & $107 \pm 6 \uparrow$ \\
\hline Natriuresis (nmol. $24 \mathrm{~h}^{-1}$ ) & $108 \pm 26$ & $97 \pm 37$ & $97 \pm 33$ & $81 \pm 23$ \\
\hline
\end{tabular}

$\mathrm{BMI}=$ body mass index, $\mathrm{MAP}=$ mean arterial blood pressure. 
Table II: Hemodynamic data obtained in the follicular phase (FP) and luteal phase (LP) of the menstrual period (MP). An arrow that follows a particular value indicates this variable to be higher $(\uparrow)$ or lower $(\downarrow)$ than the one in the control group in the corresponding menstrual period phase. The symbol * indicates the luteal phase value in a particular subgroup to be different from that in the follicular phase.

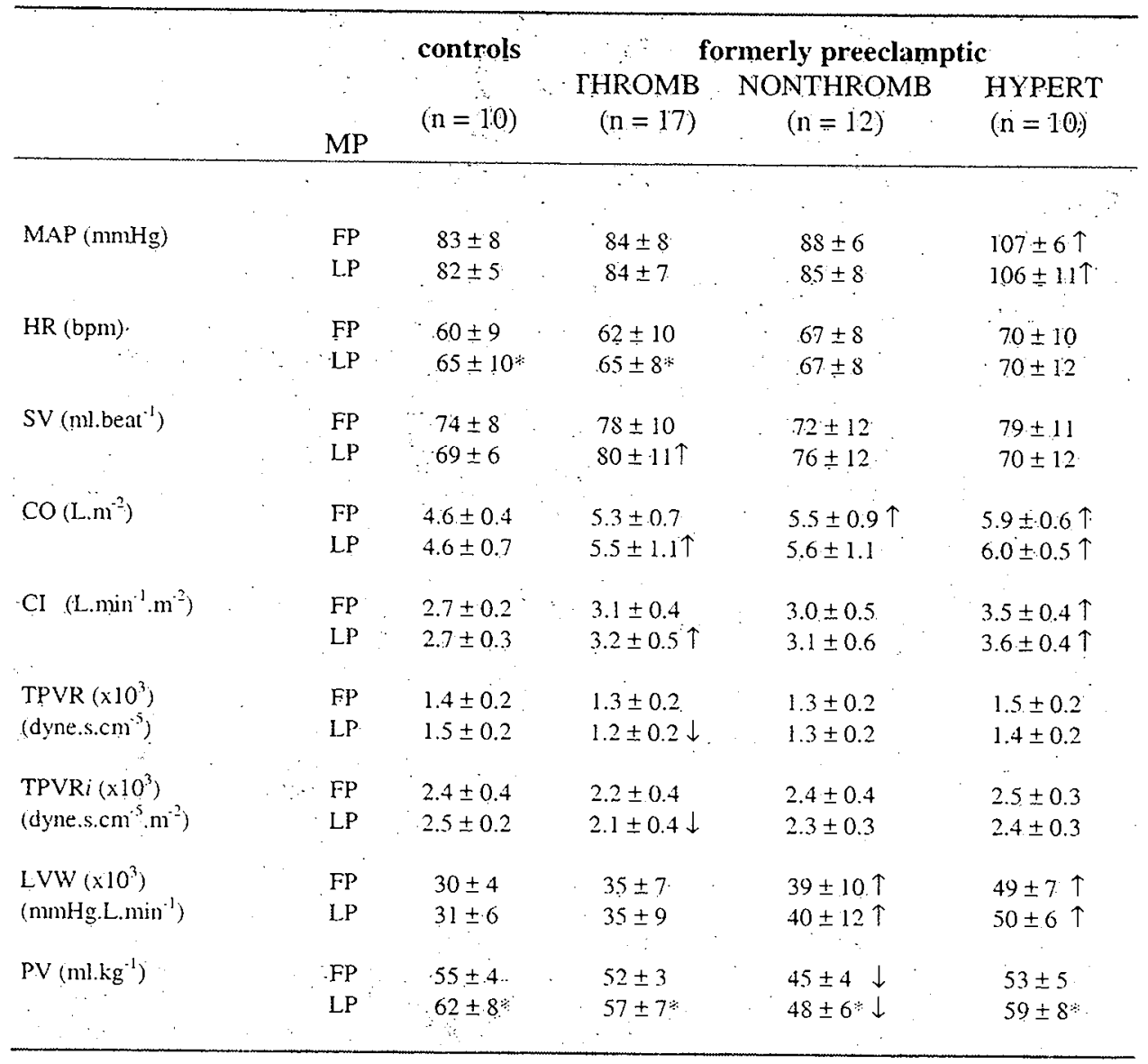

$\mathrm{MAP}=$ mean arterial blood pressure, $\mathrm{HR}=$ heart rate, $\mathrm{SV}=$ stroke volume, $\mathrm{CO}=$ cardiac output $\mathrm{CI}$ $=$ cardiac index, TPVR $=$ total peripheral vascular resistance, $T P V R i=$ total peripheral vascular resistance index, LVW = left ventricular work, $\mathrm{PV}=$ plasma volume. 
Table III: Renal hemodynamics as determined in the follicular phase (FP) and luteal phase (LP) of the menstrual period (MP). An arrow that follows a particular value indicates this variable to be higher $(\uparrow)$ or lower $(\downarrow)$ than the one in the control group in the corresponding menstrual period phase. The symbol * indicates the luteal phase value in a particular subgroup to be different from that in the follicular phase.

\begin{tabular}{|c|c|c|c|c|c|}
\hline & MP & $\begin{array}{l}\text { controls } \\
(n=10)\end{array}$ & $\begin{array}{l}\text { THROMB } \\
(n=17)\end{array}$ & $\begin{array}{l}\text { merly preeclamptic } \\
\text { NONTHROMB } \\
\qquad(n=12)\end{array}$ & $\begin{array}{l}\text { HYPERT } \\
(n=10)\end{array}$ \\
\hline $\begin{array}{l}\text { GFR } \\
\left(\mathrm{ml} \cdot \min { }^{-1} \cdot 1.73 \mathrm{~m}^{-2}\right)\end{array}$ & $\begin{array}{l}\text { FP } \\
\text { LP. }\end{array}$ & $\begin{array}{l}125 \pm 8 \\
130 \pm 12\end{array}$ & $\begin{array}{l}115 \pm 13 \\
119 \pm 18\end{array}$ & $\begin{array}{l}114 \pm 24^{\circ} \\
122 \pm 27^{*}\end{array}$ & $\begin{array}{l}111 \pm 10 \\
120 \pm 18\end{array}$ \\
\hline $\begin{array}{l}\text { ERPF } \\
\left(\mathrm{ml} \text { min }{ }^{-1} 1.73 \mathrm{~m}^{-2}\right)\end{array}$ & $\begin{array}{l}\mathrm{FP} \\
\mathrm{LP}\end{array}$ & $\begin{array}{l}565 \pm 77 \\
596 \pm 64 *\end{array}$ & $\begin{array}{c}495 \pm 71 \\
516 \pm 77 \downarrow\end{array}$ & $\begin{array}{l}500 \pm 98 \\
519 \pm 111\end{array}$ & $\begin{array}{l}480 \pm 105 \\
557 \pm 133\end{array}$ \\
\hline $\begin{array}{l}\text { ERBF } \\
\left(\mathrm{ml} \cdot \min { }^{-1} .1 .73 \mathrm{~m}^{-2}\right)\end{array}$ & $\begin{array}{l}\text { FP } \\
\mathrm{LP}\end{array}$ & $\begin{array}{l}881 \pm 127 \\
935 \pm 105\end{array}$ & $\begin{array}{l}777 \pm 129 \\
809 \pm 132\end{array}$ & $\begin{array}{l}791 \pm 144 \\
820 \pm 163\end{array}$ & $\begin{array}{l}770 \pm 169 \\
897 \pm 205\end{array}$ \\
\hline $\begin{array}{l}\operatorname{RVR}\left(\times 10^{3}\right) \\
\left(\text { dyne } s \mathrm{~cm}^{-5}, 1.73 \mathrm{~m}^{-2}\right)\end{array}$ & $\begin{array}{l}\mathrm{FP} \\
\mathrm{LP}\end{array}$ & $\begin{array}{l}7.2 \pm 1.3 \\
6.7 \pm 0.9\end{array}$ & $\begin{array}{l}8.4 \pm 1.6 \uparrow \\
7.9 \pm 1.5\end{array}$ & $\begin{array}{l}8.6 \pm 1.5 \uparrow \\
8.2 \pm 1.7\end{array}$ & $\begin{array}{c}10.9 \pm 2.6 \uparrow \\
9.2 \pm 2.6 \% \uparrow\end{array}$ \\
\hline $\begin{array}{l}\text { FF } \\
\text { (GFR/ERPF) } \quad \therefore\end{array}$ & $\begin{array}{l}\text { FP } \\
\text { LP }\end{array}$ & $\begin{array}{c}0.22 \pm 0.03 \\
0.22 \pm 0.03\end{array}$ & $\begin{array}{l}0.23 \pm 0.03 \\
0.23 \pm 0.03\end{array}$ & $\begin{array}{l}0.23 \pm 0.02 \\
0.24 \pm 0.03\end{array}$ & $\begin{array}{l}0.24 \pm 0.04 \\
0.22 \pm 0.05\end{array}$ \\
\hline $\begin{array}{l}\text { Sodium excretion } \\
\left(\text { mmol. } 24 \mathrm{~h}^{-1}\right)\end{array}$ & $\begin{array}{l}\text { FP } \\
\text { LP }\end{array}$ & $\begin{array}{l}108 \pm 26 \\
123 \pm 32\end{array}$ & $\begin{array}{l}97 \pm 37 \\
89 \pm 39 \downarrow\end{array}$ & $\begin{array}{l}97 \pm 33 \\
92 \pm 25\end{array}$ & $\begin{array}{l}81 \pm 23 \\
84 \pm 30 \downarrow\end{array}$ \\
\hline
\end{tabular}

GFR = glomerular filtration rate, $E R P F=$ effective renal plasma flow,$E R B F=$ effective renal blood flow, $\mathrm{RVR}=$ renal vascular resistance, $\mathrm{FF}=$ filuration fraction .

The renal hemodynamic data are listed in table III. All basal data points were comparable between groups except for a higher renal vascular resistance in all formerly preeclamptic subgroups relative to the controls. The cyclicity in renal hemodynamics differed between groups. In the control group luteal effective renal plasma flow and effective renal blood flow had increased and the renal vascular resistance had decreased relative to the follicular phase. In the HYPERT subgroup these changes were supplemented with a luteal rise in glomerular filtration rate and fall in filtration fraction relative to the follicular phase. In the NONTHROMB subgroup only the luteal rise in glomerular filtration rate reached significance whereas in the THROMB subgroup none of the renal variables had changed significantly between the follicular phase and luteal phase. In the HYPERT and THROMB subgroups, the luteal natriuresis was lower than that in the follicular phase in spite of a presumed similar sodium intake. 
Table $\mathbf{N}$ : Endocrine variables as determined in the follicular phase (FP) and luteal phase (LP) of the menstrual period (MP). An arrow that follows a particular value indicates this variable to be higher $(\uparrow)$ or lower $(\downarrow)$ than the one in the control group in the corresponding menstrual period phase. The symbol * indicates the luteal phase value in a particular subgroup to be different from that in the follicular phase.

\begin{tabular}{|c|c|c|c|c|c|c|}
\hline$\because$ & & & controls & for & nerly preeclamptic & \\
\hline 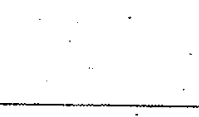 & & MP & $(n=10)$ & $\begin{array}{l}\text { THROMB } \\
(\mathrm{n}=17) .\end{array}$ & $\begin{array}{l}\text { NONTHROMB } \\
\therefore \quad(n=12)\end{array}$ & $\begin{array}{l}\text { HYPERT } \\
(n=10)\end{array}$ \\
\hline $\begin{array}{l}\mathrm{APRC} \\
\left(\mathrm{mU}: \mathrm{L}^{-1}\right)\end{array}$ & & $\begin{array}{l}\text { FP } \\
\text { LP }\end{array}$ & $\begin{array}{l}13.7 \pm 4.5 \\
21.7 \pm 7.3^{*}\end{array}$ & $\begin{array}{l}12.1 \pm 6.9 \\
23.7 \pm 11.6^{*}\end{array}$ & $\begin{array}{l}14.0 \pm 5.3 \\
21.2 \pm 5.5 \%\end{array}$ & $\begin{array}{l}18.3 \pm 9.4 \\
25.9 \pm 10.4\end{array}$ \\
\hline $\begin{array}{l}\text { Angiotensin II } \\
\left(\text { pmol. } L^{-1}\right)\end{array}$ & $\therefore$ & FP & $\begin{array}{c}8.7 \pm 2.4 \\
137 \pm 10.4^{*}\end{array}$ & $\begin{array}{c}9.9 \pm 3.7 \\
12.9 \pm 5.1:\end{array}$ & $\begin{array}{l}10.2 \pm 2.4 \\
13.0 \pm 4.3^{*}\end{array}$ & $\begin{array}{l}10.7 \pm 3.7 \\
15.7 \pm 6.0^{*}\end{array}$ \\
\hline $\begin{array}{l}\text { Aldosterone } \\
\left(\text { nmol. } L^{-1}\right)\end{array}$ & . & $\begin{array}{l}\text { FP } \\
\text { LP }\end{array}$ & $\begin{array}{c}85 \pm 30 \\
203 \pm 141 \%\end{array}$ & $\begin{array}{r}82 \pm 23 \\
233 \pm 106\end{array}$ & $\begin{array}{c}107 \pm 39 \\
285 \pm 175 \% \\
\end{array}$ & $\begin{array}{l}109 \pm 68 \\
183 \pm 105\end{array}$ \\
\hline $\begin{array}{l}\alpha \text { ANP } \\
\left(\mathrm{ng} . \mathrm{L}^{-1}\right)\end{array}$ & & $\begin{array}{l}\text { FP } \\
\text { LP }\end{array}$ & $\begin{array}{l}93 \pm 26 \\
84 \pm 21 *\end{array}$ & $\begin{array}{l}97 \pm 34 \\
77 \pm 29 \%\end{array}$ & $\begin{array}{r}105 \pm 50 \\
98 \pm 31\end{array}$ & $\begin{array}{l}141 \pm 46 \uparrow \\
126 \pm 73^{*}\end{array}$ \\
\hline $\begin{array}{l}\text { Norepinephrine } \\
\left(\text { nmol.L }{ }^{-1}\right)\end{array}$ & $\therefore$ & $\begin{array}{l}\text { FP } \\
\mathrm{LP}\end{array}$ & $\begin{array}{c}0.63 \pm 0.20 \\
1.02 \pm 0.20\end{array}$ & $\begin{array}{l}0.84 \pm 0.47 \\
1.25 \pm 0.68\end{array}$ & $\begin{array}{l}0.86 \pm 0.19 \\
1.01 \pm 0.24\end{array}$ & $\begin{array}{l}1.28 \pm 0.64 \uparrow \\
1.27 \pm 0.85\end{array}$ \\
\hline $\begin{array}{l}\text { Epinephrine } \\
\left(\text { nmol. } L^{-1}\right)\end{array}$ & & $\begin{array}{l}\text { FP } \\
\mathrm{LP} \\
\because\end{array}$ & $\begin{array}{l}0.06 \pm 0.04 \\
0.05 \pm 0.03\end{array}$ & $\begin{array}{l}0.06 \pm 0.03 \\
0.06 \pm 0.03\end{array}$ & $\begin{array}{l}0.06 \pm 0.03 \\
0.07 \pm 0.07\end{array}$ & $\begin{array}{l}0.10 \pm 0.09 \\
0.06 \pm 0.05 \\
\cdots\end{array}$ \\
\hline $\begin{array}{l}\text { Dopamine } \\
\left(\text { mmol. } L^{-1}\right)\end{array}$ & & $\begin{array}{l}\text { FP } \\
\text { LP }\end{array}$ & $\begin{array}{l}0.21 \pm 0.12 \\
0.21 \pm 0.10\end{array}$ & $\begin{array}{l}0.27 \pm 0.13 \\
0.22 \pm 0.11\end{array}$ & $\begin{array}{l}0.18 \pm 0.07 \\
0.23 \pm 0.10\end{array}$ & $\begin{array}{l}0.18 \pm 0.09 \\
0.19 \pm 0.10\end{array}$ \\
\hline $\begin{array}{l}\text { 17ß-Estradiol } \\
\text { (nmol. } L^{-1} \text { ) }\end{array}$ & & $\begin{array}{l}\text { FP. } \\
\text { LP }\end{array}$ & $\begin{array}{l}0.13 \pm 0.09 \\
0.25 \pm 0.11 *\end{array}$ & $\begin{array}{l}0.14 \pm 0.05 \\
0.34 \pm 0.12\end{array}$ & $\begin{array}{l}0.15 \pm 0.04 \\
0.31 \pm 0.10\end{array}$ & $\begin{array}{l}0.16 \pm 0.07 \\
0.35 \pm 0.11 \%\end{array}$ \\
\hline $\begin{array}{l}\text { Progesterone } \\
\left.\text { (nmol. } \mathrm{L}^{-1}\right)\end{array}$ & & $\begin{array}{l}\text { FP } \\
\text { LP }\end{array}$ & $\begin{array}{c}1.3 \pm 0.5 \\
30.1 \pm 1.2\end{array}$ & $\begin{array}{c}2.2 \pm 1.1 \\
29.7 \pm 9.2\end{array}$ & $\begin{array}{c}2.3 \pm 1.4 \\
26.5 \pm 9.6\end{array}$ & $\begin{array}{c}1.7 \pm 0.8 \\
29.6 \pm 10.9\end{array}$ \\
\hline
\end{tabular}

$\mathrm{APRC}=$ active plasma renin concentration, $\alpha \mathrm{ANP}=\alpha$ atrial natriuretic peptide

The endocrine data are listed in table IV. Basal $\alpha$ atrial natriuretic peptide and norepinephrine were higher in the HYPERT subgroup than in the control group. With respect to the cyclicity we noted a luteal rise in the hormones of the renin-angiotensinaldosterone system and a fall in $\alpha$ atrial natriuretic peptide in all groups except for NONTHROMB women. Except for the HYPERT subgroup, in all other groups luteal norepinephrine was found to have increased relative to the follicular phase. The difference between the luteal and follicular value for the other neurohormones was inconsistent. 
Finally, baseline levels and cyclic change in 17- $\beta$-estradiol and progesterone were comparable in all groups.

\section{Discussion}

Endothelial dysfunction plays a central role in the development of preeclampsia ${ }^{11}$. Endothelial function can be jeopardized either biochemically (i.e. thrombophilia, diabetes mellitus) or mechanically (i.e. hypertension, renovascular disease) ${ }^{7,12}$. Preeclampsia seems to be superimposed upon a preexisting disorder and may be the clinical expression of "endothelial decompensation" which represents the common endpoint of these two different pathophysiologic pathways. We therefore subdivided our group of formerly preeclamptic subjects into a normotensive thrombophilic (THROMB) - and hypertensive (HYPERT) subgroup, thus separating them from a group of normotensive formerly preeclamptic women without thrombophilia (NONTHROMB). Since in healthy females menstrual changes in hemodynamics and renal function largely mimic early pregnancy changes and preeclampsia often is preceded by hemodynamic and renal maladaptation, these finding raised the question whether cyclic menstrual changes in these functions, as seen in healthy women, would be preserved in the above mentioned formerly preeclamptic subgroups. To answer this question, we studied mid follicular and mid luteal of the menstrual cycle, clotting, metabolic, renal and cardiovascular function in formerly preeclamptic women and controls and compared the data in the various formerly preeclamptic subgroups with those found in a reference group of normal parous controls.

With respect to the general characteristics, the three subgroups were comparable with the control group, except for a higher body mass index in the NONTHROMB subgroup. In most women in the THROMB subgroup, thrombophilia was caused by antiphospholipid syndrome, protein-S-deficiency and hyperhomocysteinemia, an observation in line with reports by others ${ }^{6}$. Comparison of all basal hemodynamic, renal and endocrine data in the three formerly preeclamptic subgroups relative to the control group indicated that in the HYPERT subgroup, the higher mean arterial blood pressure was paralleled by a higher cardiac output and cardiac index, but a comparable total peripheral vascular resistance at the expense of a higher left ventricular work load. In this group renovascular resistance was increased and circulating levels of $\alpha$ atrial natriuretic peptide and norepinephrine elevated. It is unlikely that the higher cardiac index was secondary to the awareness of having hypertension as in only 2 of the 10 women in the HYPERT subgroup the diagnosis "hyper- 
tension" was made at the time of the study and the raised blood pressure was seen during both measurement sessions ${ }^{1.3}$. Most baseline values for central and renal hemodynamics and endocrine status in the THROMB subgroup resembled those in the control group. This indicates that the altered endothelial function in response to thrombophilia does not seem to influence appreciably cardiovascular function. In the NONTHROMB subgroup the relative overweight and the lower plasma volume were most conspicuous.

With respect to the central and renal hemodynamic cyclicity with the menstrual cycle, we found that, in the luteal phase, most variables had changed modestly in the control group. In controls, the observed luteal fall in renal vascular resistance was paralleled by a rise in heart rate, effective renal plasma- and blood flow and plasma volume. Most of these changes are paralleled by endocrine and autonomic nervous stimuli; the cyclic changes in almost all these stimuli were significant. In the luteal phase the renin-angiotensin-aldosterone-system hormones had increased and the $\alpha$ atrial natriuretic peptide decreased relative to the follicular phase. These changes are in agreement with previous observations reported by others and are compatible with a state of vasorelaxation giving rise to volume expansion as a result of activation of the sympathetic system and the renin-angiotensin-aldosterone-system with adaptive suppression of $\alpha$ atrial natriuretic peptide $1,2,14$. In contrast to controls, HYPERT not only had higher basal circulating norepinephrine levels, also its luteal rise remained absent. Otherwise, their cyclic changes in renal and endocrine variables were comparable to those in controls. In the normotensive formerly preeclamptic groups, we observed a trend towards a decrease in renal vascular resistance and a rise in renal perfusion and clearance. Hormonal changes were similar as in controls. These observations indicate that most hemodynamic, renal and hormonal changes with the menstrual cycle in normal parous women are preserved in formerly preeclamptic individuals.

Although it is known that in the early stages of essential hypertension plasma volume is reduced, we did not find such an abnormality in our hypertensive formerly preeclamptic patients ${ }^{15}$. However we did observe a reduced plasma volume in the NONTHROMB group. Therefore NONTHROMB seem to have a condition that can be considered latent - or prehyperiension. The lower plasma volume could then be viewed upon as a compensatory mechanism to minimize a rise in blood pressure. Why plasma volume is not reduced in the HYPERT subgroup, is less easy to explain. Perhaps this group already has more advanced renal lesions which interfere with volume control. 
A lower plasma volume can be secondary to an increased vascular tone. However plasma volume may also be reduced when the total volume of the venous bed is relatively small, a condition which either could be genetically or acquired during the early phases of vascular development ${ }^{16}$. About $2 / 3$ of the plasma volume is located within the venous compartment and can be mobilized in response to a fall in arterial tone ${ }^{17}$. In order to compensate for the luteal decrease in afterload, both the renin-angiotensin-aldosterone-system and the sympathetic nerve system will be activated $17,18,19$. It is conceivable that an inadequacy of the resulting volume retention to balance the increased demands for venous retum will lead to a higher sympathetic tone as a second line compensation. The latter not only leads to a higher cardiac preload, but also to a higher heart rate and mean arterial blood pressure ${ }^{17,19}$. The $\alpha$ atrial natriuretic peptide level provides an indirect estimate for vascular filling state 20 . The cyclic change in $\alpha$ atrial natriuretic peptide in all groups supports the development of a state of relative vascular underfill in the luteal phase. On the other hand, $\alpha$ atrial natriuretic peptide also correlates positively to right atrial pressure ${ }^{21}$ A rise in sympathetic tone can be expected to raise cardiac preload and with it, increase of right atrial pressure. Therefore, we postulate that a subnormal size of the venous compartment with inadequate capacity to raise venous return in response to a rise in flow demands, will induce a rise in sympathetic tone. When sustained, the latter leads to a higher atrial pressure and with it an increase in $\alpha$ atrial natriuretic peptide. The observation of higher, in hypertensive formerly preeclamptic basal norepinephrine levels relative to controls supports the view that in these individuals a balance between venous return and cardiac output is only possible at the expense of a higher sympathetic tone.

The type of difference between the subgroups suggests that two preexisting states appear to be associated with an increased risk to develop preeclampsia: 1. thrombophilia which is associated with chronically elevated biochemical strain put upon the endothelium and 2. marginal size of the vascular compartment in conjunction with a chronically elevated cardiac output, a condition that limits the ability of the vasculature to respond to prolonged increased demands.

In summary, although basal hemodynamics and volume status differed between formerly preeclamptic subgroups and controls, the cyclicity with the menstrual cycle in the three subgroups of formerly preeclamptic women, was preserved. 


\section{References}

1. Beek v. E, Houben AJHM, van Es PN, Willekes C, Korten ECCM, de Leeuw PW, Peeters LLH. Cyclic changes in hemodynamics and renal function in the menstrual cycle. Clin Science 1996; 91: 163-168.

2. Chapman AB, Zamudio S, Woodmansee W, Merouani A, Osorio F, Johnson A, Moore LG, Dahms $T$, Coffin C, Abraham WT, Schrier RW. Systemic and renal hemodynamic changes in the luteal phase of the menstrual cycle mimic early pregnancy. Am J Physiol 1997; 273: F777F782.

3. Duvekot JJ, Cheriex EC, Pieters FAA, Peeters LLH. Early-pregnancy changes in haemodynamics and volume homeostasis are consecutive adjustments triggered by a primary fall in systemic vascular tone. Am J Obstet Gynecol 1993; 169: 1382-1392.

4. Duvekot JJ, Cheriex EC, Pieters FAA, Menheere PPCA, Peeters LLH. Matemal volume homeostasis in early pregnancy in relation to fetal growth resuriction. Obstet Gynecol 1995; 85:361-367.

5. Duvekot JJ, Cheriex EC, Pieters FAA, Peeters LLH. Severely impaired fetal growth is preceded by maternal hemodynamic maladaptation in very early pregnancy. Acta Obstet Gyn Scan 1995; 74: 693-697.

6. Dekker GA, de Vries JIP, Doelitzsch PM, Huijgens PC, von Blomberg BME, Jacobs C, van Geijn HP. Underlying disorders associated with severe early-onset preeclampsia. Am J Obstet Gynecol 1995;173:1042-8.

7. Beek v. E, Peeters LLH. Pathogenesis of preeclampsia: a comprehensive model. Obstet Gynecol Survey 1998; 53: 233-239.

8. Beek v., E, Ekhart THA, Schiffers PMH, van Eyck J, Peeters LLH, de Leeuw PW. Persistent abnormalities in volume homeostasis and renal hemodynamics in patients with a history of preeclampsia. Am J Obstet Gynecol 1998;179:690-6.

9. Perry IJ, Beevers DG. The definition of pre-eclampsia. Br J Obstet Gynaecol 1994; 101: $587-$ 591.

10. Van der Hoom FA, Boomsma F, Man in 't Veld AJ, Schalekamp MADH. Determination of catecholamines in human plasma by high-performance liquid chromatography: comparison between a new method with fluorescence detection and an established method with electrochemical detection. J Chromatography 1989;487:17-28.

11. Roberts JM. Endothelial dysfunction in preeclampsia. Semin Reprod Endocrinol 1998;16:5-15

12. Ness RB, Roberts JM. Heterogenous causes constituting the single syndrome of preeclampsia, a hypothesis and its implications. Am J Obstet Gynecol 1996; 175:1365-1370.

13. Rostrup M, Mundall HH, Westheim A, Eide I. Awareness of high blood pressure increases arterial plasma catecholamines, platelet noradrenaline and adrenergic responses to mental stress. J Hypertension 1991;9:159-166.

14. Hoyer J. Endothelial vasorelaxation and mechanosensitive ion channels in hypertension. Nephrol Dial Transplant 1997;22:6-8.

15. Lebel M. Grose JH, Blais R. Increased hematocrit with normal red blood cell mass in early borderline essential hypertension. Clin Exp Hypertens A. 1989; 11:1505-1514.

16. Barker DJP. Fetal origins of coronary heart disease. BMJ 1995;311:171-174.

17. Guyton AC. Cardiac output, venous return and their regulation. In :Guyton AC, ed. Textbook of medical physiology. Philadelphia: Saunders, 1986:272-286. 
18. Henrich WL, Berl T, McDonald KM, Anderson RJ, Schrier RW. Angiotensin II, renal nerves, and prostaglandins in renal hemodynamics during hemorrhage. Am J Physiol 1978; 235:F46F51.

19. Schobel HP, Fischer T, Heuszer K, Geiger H, Schmieder RE. Preeclampsia-A state of sympathetic overactivity. N Eng J Med 1996;335:1480-5.

20. Leunissen KML, Menheere PPCA, Cheriex EC, van den Berg BW, Noordzij TC, van Hooff JP. Plasma alpha-human atrial natriuretic peptide and dry weight in chronic hemodialysis. Nephr Dial Transpl 1989; 4:382-386.

21. Hirata $Y$, Ishii $M$, Matsuoka $H$, Sugimoto $T$, lizuka $M$, Uchida $Y$, Serizawa $T$, Sato $H$, Kohmoto O, Mochizuki T, Sugimoto T, Miyata A, Kangawa K, Matsuo H. Plasma concentrations of $\alpha$-human atrial natriuretic polypeptide and cyclic GMP in patients with heart disease. Am Heart J 1987; 113:1463-1469.

22. Collins JA. Diagnostic assessment of the ovulatory process. Seminars in Reproductive Endocrinology 1990;8(3):145-155.

23. Spaanderman MEA, Ekhart THA, van Eyck J, Cheriex EC, de Leeuw PW, Peeters LLH. Asymptomatic ex-preeclamptic women have latent hemodynamic abnormalities. Am J Obstet Gynecol 2000;182:101-107. 


\section{Chapter 4}

\section{THE EFFECT OF PREGNANCY ON THE COMPLIANCE OF LARGE ARTERIES AND VEINS IN NORMAL PAROUS CONTROLS AND FORMERLY PREECLAMPTICS}

Spaanderman MEA, Willekes C, Hoeks APG, Ekhart THA, Peeters LLH.

Department of Obstetrics and Gynecology, Physiology and Biophysics, University Hospital Maastricht, The Netherlands.

Am J Obstet Gynecol 2000:183;1278-86 


\section{Abstract}

Background Early pregnancy is characterized by a fall in total peripheral vascular resistance. In this study we tested the hypothesis that this phenomenon is accompanied by a rise in the compliance of the large arteries and veins.

Methods

In 42 formerly preeclamptic women (ex-PE) and 10 normal parous controls (CONTR), we measured the following variables midfollicular (FP) and midluteal (LP) during the menstrual cycle and again at 5 (AM5) and at 7 (AM7) wecks amenorrhea: cardiac output (CO), mean arterial pressure (MAP), carotid ( $\mathrm{CaC}$ ) and femoral artery compliance $(\mathrm{FeC})$ and venous compliance (VeC). The total peripheral vascular resistance (TPVR) was obtained as the ratio of MAP and CO. After screening for thrombophilia and hypertension, ex-PE's were subdivided into a hypertensive subgroup (HYPERT), a thrombophilic subgroup (THROMB) and a subgroup of subjects without these abnormalities (NONTHROMB).

Results In parallel to the early pregnancy fall in TPVR, FeC and VeC increases in CONTR. Except for $\mathrm{VeC}$, these changes were also observed in the THROMB ex-PE subjects. In the HYPERT and NONTHROMB subjects arterial and venous compliance failed to increase, in spite of a drop in TPVR.

Conclusion These data support the concept that in normal pregnancy the fall in TPVR is paralleled by improved macrovascular compliance. The latter adaptive change does not occur in normotensive nonthrombophilic and hypertensive ex-PE women. 


\section{Chapter 4}

\section{Introduction}

The current idea about the hemodynamic adaptation to pregnancy is, that systemic arterial vasodilation represents the trigger for a caseade of compensatory changes such as a rise in cardiac output ( $\mathrm{CO}$ ), activation of the renin-angiotensin-aldosterone system and resetting of the osmoreceptor ${ }^{1,2,3}$. In rat pregnancy the compliance of the descending aorta was found to increase in concert with this early-pregnancy hemodynamic adaptation ${ }^{23}$. Data obtained in human pregnancy suggest that the aortic compliance and venous distensibility only. increases at the end of the first trimester ${ }^{5,6,7}$. Therefore, it is still unsettled whether or not the human pregnancy-related rise in the compliance of the large vessels develops independently or in response to the institution of the high-flow/low-resistance circulation in the first weeks of pregnancy.

Pregnancies complicated by intra uterine growth retardation have been associated with absent early pregnancy vasorelaxation ${ }^{2}, 3$. Furthermore, various. studies have shown that pregnancies of women with either a vascular disorder such as hypertension or a clotting disorder with a thrombophilic phenotype; are at risk to become complicated by preeclampsia $4,21,22$. Whether absent vasorelaxation in early preeclamptic pregnancy occurs in both subgroups, is unknown. Theoretically, the vasorelaxation can be expected only to be blunted in the subgroup of women with reduced vascular elasticity; as is the case in those with hypertension. At any rate, exploration of potential differences in the pathogenesis of preeclampsia between these two subgroups is expected to improve our understanding of this syndrome.

The objectives of this study were (1). to evaluate whether the compliance of the large arteries and veins increases in early human pregnancy in concert with the drop in total peripheral vascular resistance (TPVR), and if so, to determine whether the magnitude of the rise in vascular compliance correlates with that of the drop in TPVR, (2). to evaluate whether the effect of pregnancy on the vasçular compliance differs between women with a history of preeclampsia and normal parous controls, and between women with a preexistent vascular disorder and those with thrombophilia. To this end, we determined longitudinally during the menstrual cycle and the first weeks of subsequent pregnancy $\mathrm{CO}$, arterial blood pressure, the dynamic function of the carotid and femoral artery and forearm veins, along with a number of biochemical and endocrine variables, in parous controls and in formerly preeclamptic women. 


\section{Methods}

\section{Selection and patient characteristics.}

In this study 42 ex-preeclamptic non-diabetic women and 10 normal parous controls were enrolled. Participants were at least 5 months postpartum. EX-PE women were recruited at the outpatient clinic during the postpartum follow-up; whereas controls were recruited by advertisement. All participants gave written informed consent. The hospital's medicalethical committee approved the study. PE and hypertension were defined according to the criteria of the International Society for the Study of Hypertension in Pregnancy (ISSHP) ${ }^{8}$. That is to say, hypertension was defined as a mean systolic blood pressure above $140 \mathrm{mmHg}$, and/or a mean diastolic arterial blood pressure above $90 \mathrm{mmHg}$, using all of the Dinamap recordings accumulated on the day of the experiment. None of the women used vitamins, oral contraceptives, antihypertensive drugs, NSAID's or glucocorticosteroids in the two weeks prior to the measurements. On separate days and after an overnight fast, participants were tested for thrombophilia; and hemodynamic and vascular function.

\section{Experimental procedure}

\section{Methods}

Thrombophilic screening: Anticardiolipin antibodies (ACA; IgM and IgG) were determined spectrophotometrically by enzyme-linked immunoassay ${ }^{9}$. Lupus anticoagulant (LA) was determined by mixing $1: 1$ patient and pooled normal plasma after finding a prolonged partial thromboplastin time. Subsequently, a thromboplastin dilution test was performed by measuring prothrombin time with progressive diluted thromboplastin ${ }^{10}$. LA was considered tọ be present when all assays were positive: The presence of LA and\% an ACA titer over 10 GPL (IgG): or over $6 \mathrm{MPL}$ (IgM) was considered indicative of the antiphospholipid syndrome (APS).

Coagulation tests were performed after a flawless venapuncture. Blood was collected in sodium citrate containing glass tubes. Plasma was prepared by two consecutive. centrifugation steps, with the second one performed in an Eppendiorf centrifuge to eliminate platelets. Samples were stored at $-80^{\circ} \mathrm{C}$ prior to assay. Protein $\mathrm{C}$ activity was determined with Coamate protein C (Chromogenix, Mölndal, Sweden) ${ }^{11}$. The normal value of protein $C$ according to the laboratory control group is $7.0 \%$ to $130 \%$ and has an intra-assay and interassay coefficient of variation (CV) of $3.3 \%$ and $4.7 \%$, respectively. Total protein $S$ antigen 
and free protein $S$ were measured by an enzyme-linked immunosorbent assay (ELISA) (DAKO, Glostrup, Denmark) ${ }^{12}$. The normal range for both total protein $S$ antigen (intraassay and inter-assay $\mathrm{CV}$ of $5.1 \%$ and $5.7 \%$, respectively) and free protein $S$ (intra-assay and inter-assay $\mathrm{CV} 3: 4 \%$ and $3.6 \%$, respectively) is $7.0 \%$ to $130 \%$ and $65 \%$ to $130 \%$, respectively. Activated protein $C$ resistance (APCR) was quantified by a chromogenic APCresistance assay ${ }^{13}$. The chromogenic test fully matches $\mathrm{DNA}$ analysis for the factor $\mathrm{V}$ Leiden mutation and has a normal range between $0 \%$ and $20 \%{ }^{14}$. Antithrombin activity (AT) was assayed with chromegenic substrate S-2765 (Chromogenix, Mölndal, Sweden) ${ }^{15}$. The normal range of AT is $80 \%$ to $120 \%$.

A methionine-loading test was used to diagnose hyperhomocysteinemia (HHC). Homocysteine was measured by high-performance liquid chromatography with fluorescence detection ${ }^{16}$. In our hands, this test has an intra- and inter-assay coefficient of variation (CV) of $3.9 \%$ and $5.9 \%$, respectively. At $8: 30 \mathrm{AM}$, the fasting homocysteine concentration was determined. Six hours after an oral dose of L-methionine $(0.1 \mathrm{~g} / \mathrm{kg}$ body weight), the postload homocysteine concentration was assessed. During the test participants used a standard low-methionine breakfast and lunch. Individuals were considered to have hyperhomocysteinemia when fasting and/or post-load plasma homocysteine levels were more than 2 standard deviations (SD) higher than the mean of the laboratory control group.

Measurement of hemodynamics and vascular compliance: Both in the FP (day $5 \pm 2$ ) and LP (day $22 \pm 2$ ) of the menstrual cycle (random order) and again in early pregnancy at 5 and 7 weeks amenorrhea, measurements were performed under standardized environmental conditions in a temperature-controlled room $\left(25-26^{\circ} \mathrm{C}\right)$ and with external disturbances as minimized as possible. Participants did not drink caffeine- or alcohol-containing beverages and refrained from smoking and eating for at least 10 hours before the experiment. The measurement session started at 8:00 AM. Throughout each measurement session, subjects were in supine position on a comfortable bed. Arterial blood pressure and heart rate (HR, beats. $\min ^{-1}$ ) were recorded at two minutes interval by a semi-automatic oscillometric device (Dinamap Vital Signs Monitor 1846, Critikon, Tampa, FL, USA), throughout the measurement session. At 8:15 AM, after a 15-minute rest, carotid and femoral artery compliance was assessed non-invasively. Arterial wall displacement was visualized by a two-dimensional real time B-mode imager attached to a vessel wall moving detector system (Pie Medical, Maastricht, The Netherlands). Based on the B mode image, an M-line 
perpendicular to the artery is selected. The received radio frequency (RF) signals covering the artery of interest are stored in a personal computer system for off-line analysis. Analysis of the RF signals from sample windows covering the anterior and posterior walls provides the artery distension waveform. Three recordings of five consecutive heartbeats were used to establish the changes in arterial diameter during the cardiac cycle as a function of time. From the recorded data the mean absolute distension ( $\Delta d$ ) from diastole to systole and relative distension ( $\Delta d . d^{-1}$ ) were calculated. The measurement of the carotid and femoral artery $\Delta \mathrm{d} . \mathrm{d}$ ${ }^{-1}$ and $\mathrm{d}$ is associated with an intra- and interobserver $\mathrm{CV}$ of 8 and $12 \%$, respectively, for $\Delta d$ $d^{-1}$ and $2.8-4.5 \%$ and $2.0-3.0 \%$, respectively, for $d^{17}$.

The distensibility coefficient (DC, in $\left.\mathrm{kPa}^{-1}\right)$ and compliance $\left(\mathrm{CC}, \mathrm{mm}^{2} \cdot \mathrm{kPa}^{-1}\right)$ were calculated as follows:

$$
\begin{aligned}
& D C=2 \cdot \Delta d \cdot d^{-1} \cdot \Delta p^{-l} \\
& C C=\pi \cdot d \cdot \Delta d \cdot 2 \cdot \Delta p^{-1}
\end{aligned}
$$

The brachial pulse pressure (systolic minus diastolic pressure) is taken as $\Delta p$ and was calculated by taking the mean of three sets of Dinamap recordings measured during establishment of the vascular images.

Venous compliance ( $\mathrm{VeC}$ ), representing venous visco-elastic properties, was defined as the plethysmographically determined slope of the relationship of intravenous volume- and pressure changes (Periflow, JSI, Beerse, Belgium) ${ }^{20}$. Intravenous pressure was measured by means of a 20 -gauge catheter in the left forearm fossa cubiti. A pressure transducer was placed $5 \mathrm{~cm}$ below the sternal angle (HP, Böblingen, Germany). Forearm volume changes were measured using a silastic strain gauge filled with mercury, which is connected to a venous occlusion plethysmograph. Measurement started 30 minutes after venapunction at 09:30 AM. During the first pressure step, the upper arm cuff was inflated to a cuff pressure of $25 \mathrm{mmHg}$. It was kept inflated for three minutes. This interval was chosen to reach steady-state in arm volume and pressure. During the subsequent two minutes, the cuff was deflated in order to minimize accumulation of interstitial fluid due to capillary filtration. Changes in volume and intravenous pressure during each subsequent inflational pressure step (starting at $25 \mathrm{mmHg}$, followed by $30,35,40,45$ and ending at $50 \mathrm{mmHg}$ ) were taken at the end of the three minutes of cuff-inflation and after deflation of the cuff. Venous compliance was defined as the slope of the relationship between the changes in forearm. 
volume $\left(\delta \mathrm{V}\left(\mathrm{ml} .100 \mathrm{ml}^{-1}\right.\right.$ forearm volume $\left.)\right)$ on the ordinate and corresponding venous pressure $(\delta \mathrm{P}(\mathrm{mmHg}))$ on the abscissa calculated by linear regression analysis and has a $\mathrm{CV}$ of $11.4 \% 20$.

Finally, blood was collected for assay of sex-hormones. Serum 17- $\beta$-estradioli and progesterone were determined with a commercially available solid phase radioimmunøassay kit (DPC, Los Angeles, Cal, USA). Sensitivity of the latter assays are 0.035 and $0.15 \mathrm{nmol} / \mathrm{l}$, respectively. Samples were collected on ice and centrifuged at $4{ }^{\circ} \mathrm{C}$ for $10 \mathrm{~min}$ at $1500 \mathrm{~g}$ immediately after sampling. All samples were stored deep-frozen $\left(-80^{\circ} \mathrm{C}\right)$ prior to assay.

Measurement of plasma volume $(P V)$ : After the procedure to quantify vascular function, $\mathrm{PV}$ was measured. During the FP, plasma volume (PV, intra-assay $\mathrm{CV}$ of $4.2 \%$ ) was determined with the Iodine ${ }^{125}$-Albumin $\left({ }^{125} \mathrm{I}-\mathrm{HSA}\right.$ ) indicator dilution method and expressed in ml per kilogram (kg): lean body mass (LBM). The LBM was calculated as specified elsewhere ${ }^{18}$. PV was obtained by dividing the total injected radioactivity by the virtual volume-specific radioactivity at time zero ${ }^{19}$. The latter, which corresponds with the time of bolus injection, was obtained by extrapolation using the specific activity per $\mathrm{ml}$ of plasma at 10,20 and 30 minutes after bolus injection.

Echocardiography to assess cardiac function was performed in semi-left lateral position, after completion of the PV measurement and after 5 minutes of rest, using a cross-sectional, phased array echocardiographic Doppler system (Hewlett-Packard Sonos 2000 and 2500) ${ }^{2}$. $\mathrm{CO}$ and cardiac index $(\mathrm{CI})$ defined as $\mathrm{CO}$ per $\mathrm{m}^{2}$ body surface area (BSA), were calculated according to the formulas ${ }^{4}$ :

$$
\begin{aligned}
& \text { CO = stroke volume. } H R \\
& C I=C O \cdot B S A^{-1} \quad\left(B S A=0.007184 . \text { height }^{0.725} \cdot \text { weight }^{0.425}\right) .
\end{aligned}
$$

In this formula, HR was obtained by taking the mean of the reciprocal of five consecutive R$\mathrm{R}$ intervals on the ECG. Stroke volume $(\mathrm{SV}, \mathrm{ml}$ ) was calculated by multiplying the aortic velocity integral and the aortic area. Aortic flow was measured across the aortic valves from an apical approach. The average area under the aortic velocity curve (aortic velocity integral) of five consecutive ejections was used to calculate SV. Aortic valve diameter necessary for the calculation of the aortic area, was measured off-line at the orifice during systole using $M$ mode. TPVR (dyne. $\mathrm{s}^{-1} \cdot \mathrm{cm}^{-5}$ ) was calculated as follows:

$$
\text { TPVR }=80 \cdot M A P \cdot C O^{-1}
$$


The value used for mean arterial pressure (MAP, $\mathrm{mmHg}$ ) was obtained during the $\mathrm{CO}$ measurement using the Dinamap apparatus and was calculated as the mean of three consecutive recordings.

Statistical analysis: Data are presented as means with SD unless stated otherwise. Intragroup differences were tested with Wilcoxon Signed-Raniks Matched-Pairs test along with Bonferroni correction, using the value observed in the follicular phase as the reference. Differences between groups were tested with the Mann-Whitney-U Test along with Bonferroni correction.

Correlation, when çalculated, between concomitantly measured potentially related variables, was tested by Spearman's Rank Correlation Analysis. The calculated minimum detectable changes of the mean of variables within controls $(n=10, \alpha=0.05, \beta=0.10)$, assuming $a$ normal distribution of the data were $7 \%$ (mean arterial pressure), 15\% (heart rate), $10 \%$ (stroke volume), $11 \%$ (cardiac output), $11 \%$ (total peripheral vascular resistance), $23 \%$ (carotis compliance coefficient), 16\% (carotis distensibility coefficient), $46 \%$ (femoral compliance coefficient), $59 \%$ (femoral distensibility coefficient) and $16 \%$ (venous compliance), respectively. In all analyses, a p-value lẹss than 0:05, when appropriate relative to the control group, was considered statistically significant.

\section{Results}

The demographic characteristics of all participants divided over various subgroups are listed in table I. From the 42 ex-PE subjects, eleven women were assigned to the HYPERT subgroup. Among them, three had alșo a thrombophilic disorder (see table II). Eighteen of the remaining 31 (normotensive) ex-PE subjects had at least one thrombophilic disorder(s) and, therefore, were allocated to the THROMB subgroup. The rest group of eleven ex-PE subjects had neither hypertension nor thrombophilia. They were allocated to the NONTHROMB subgroup. The 3 ex-PE subgroups and the controls were comparable with respect to age, height, $\mathrm{BMI}$, parity and the time elapsed between delivery of the previous pregnancy and first measurement session. Ex-PE females in the NONTHROMB subgroup had a lower PV than the controls. By definition, MAP was higher in the HYPERT subgroup than in the controls.

Table II lists the distribution of thrombophilic disorders over the THROMB and HYPERT subgroups. The incidence of at least one thrombophilic disorder in the total group of ex-PE subjects was $50 \%$ (21/42). In the THROMB subgroup, APS and protein $S$ deficiency (prot $S$ 
def) were most common. All formerly preeclamptic women; which were diagnosed as having anti-phospholipid syndrome, were IgG serotypes. One subject in this subgroup had more than one thrombophilic disorder.

Central hemodynamic data are listed in table MII. During the menstrual cycle HYPERT subjects had a higher $\mathrm{CO}$ and $\mathrm{Cl}$ as compared to controls. In all subgroups except for the NONTHROMB, MAP had decreased and HR increased in early pregnancy relative to the FP. reference value. The concomitantly determined TPVR had decreased - and SV increased in all groups. The latter was associated with an increase in $\mathrm{CO}$ and $\mathrm{CI}$ in all groups except for the HYPERT.

Tables IV and V list the results on vascular dynamics in all participants. Only the HYPERT subgroup had a higher pulse pressure during carotid artery parameter assessment (icarotid. PP) at 5 and 7 weeks and a higher pulse pressure during femoral artery parameter assessment (femoral PP) in the FP and at 5 weeks. Intergroup differences in carotid and femoral artery. diameter and the intra-group changes with pregnancy were in general small. Only in the HYPERT subgroup in the FP (only carotid) and at 5 and 7 weeks, the carotid and femoral CC and DC were smaller than in the control group. Only in controls, carotid DC had changed with pregnancy, while femoral CC and DC had increased in controls and THROMB subjects, but not in NONTHROMB and HYPERT women. Only in the controls, the VeC (Table V) had increased in early pregnancy.

In all groups absolute values in the FP and changes in early pregnancy in 17/-estradiol and progesterone were comparable (Table VI).

Only in controls, the absolute change in TPVR correlated with femoral compliance $(r=0.81$, $\left.r^{2}=0.66, p=0.03\right)$. Only in HYPERT, we noticed a correlation between the rise in progesterone and the fall in TPVR $\left(r=0.85, r^{2}=0.72, p=0.004\right)$. In the FP of normotensive formerly preeclamptic groups PV correlated with venous compliance $\left(r=0.63, r^{2}=0.39, p=\right.$ 0.0004). 
Table I: Demographic data (FP) from the 3 subgroups of ex-preeclamptics and the group of normal parous controls. If a value is followed by an arrow, this particular variable is higher ( $\uparrow$ ) or lower $(\downarrow)$ than the one in the control group $(\mathrm{p}<0.05)$.

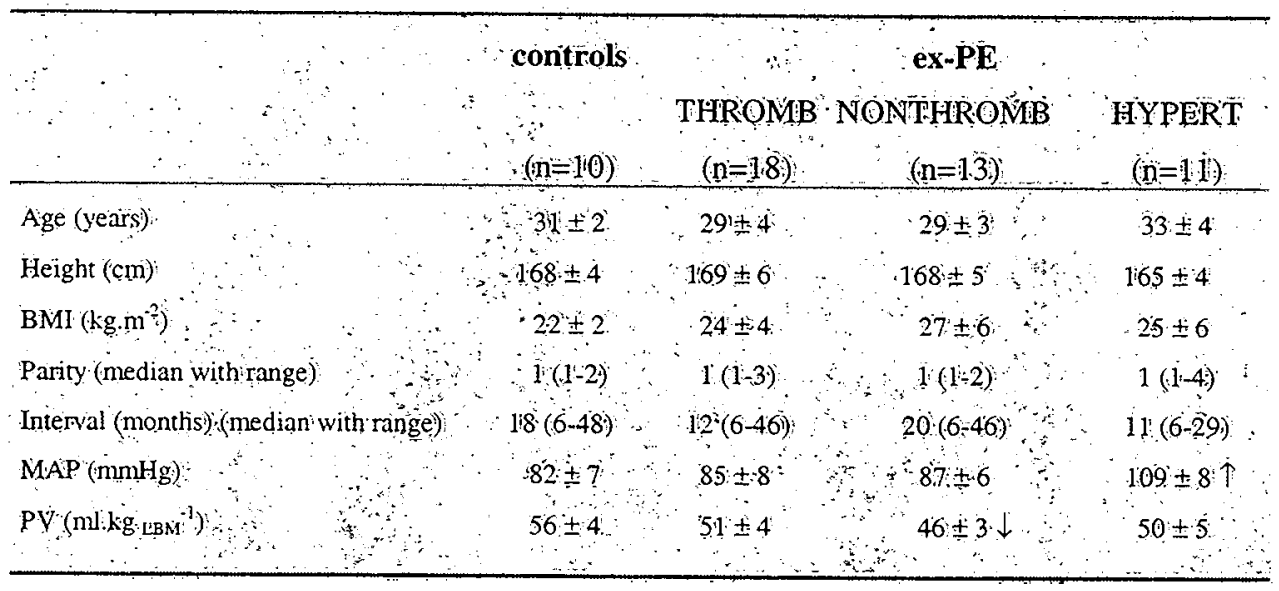

Interval $=$ time elapsed between delivery previous pregnancy and first measurement session

Table II: Occurrence of the various subtypes of thrombophilic disorders in the thrombophilic - and hypertensive subgroups of ex-PE-women.

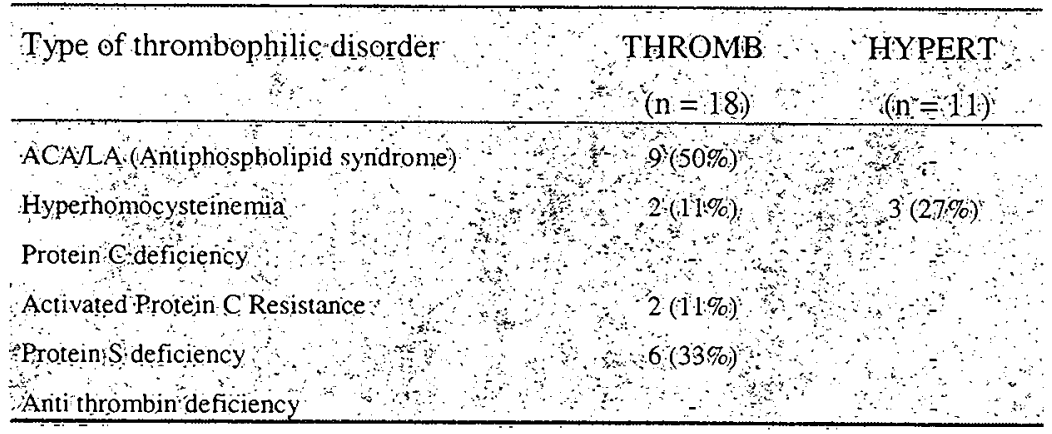


Table III: Hemodynamic data obtained in the FP and LP of the menstrual cycle (MC) and at 5 and 7 weeks amenorrhea (AM5 and AM7, respectively). An arrow indicates higher $(\uparrow)$ or lower $(\downarrow)$ than the one in the control group in the corresponding MC phase $(\mathrm{p}<0.05)$. The symbol $*$ indicates the value in a particular subgroup to be different from that in the FP $(p<0.05)$.

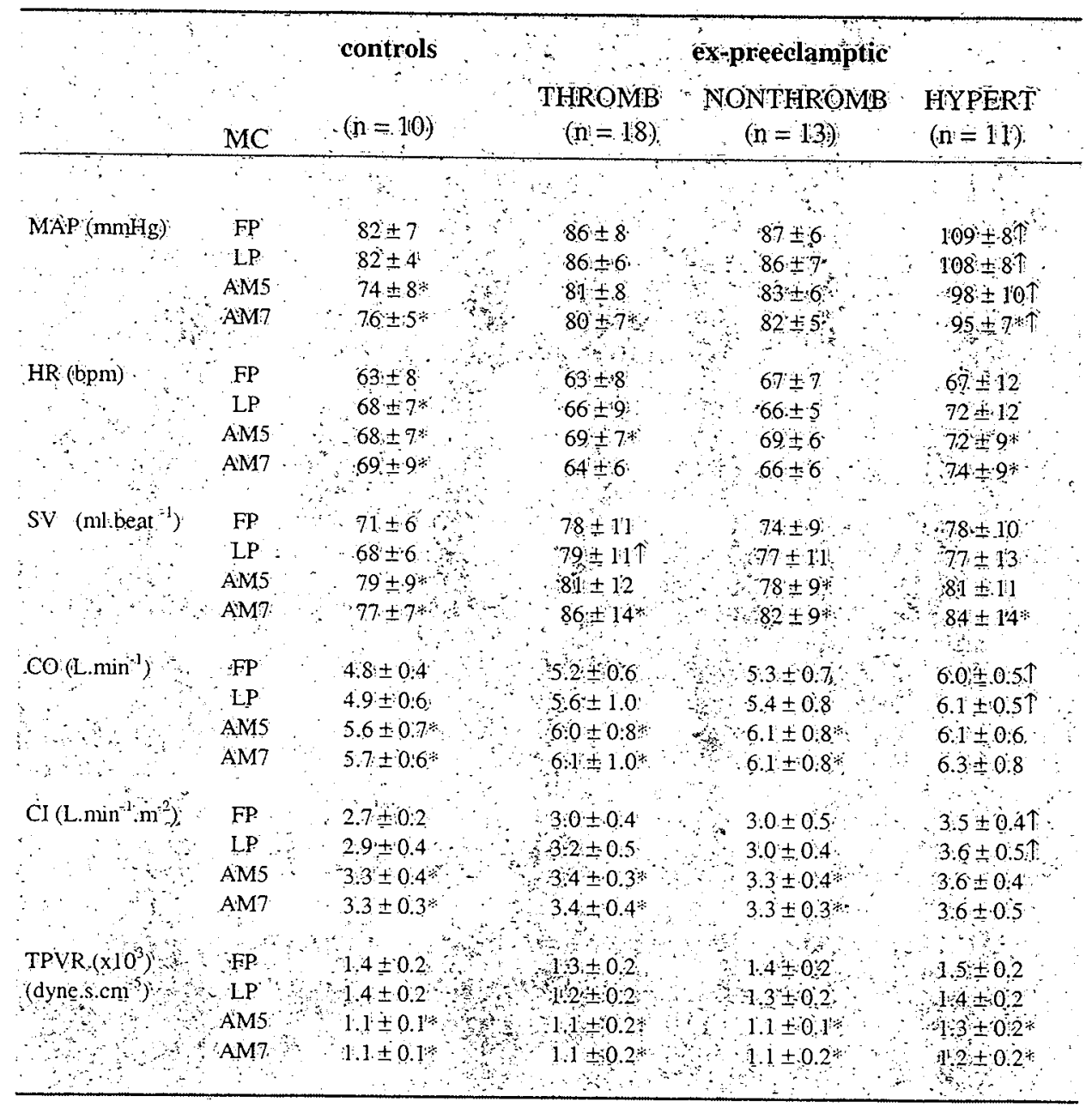


Table IV: Carotid vascular data obtained in the FP and LP of the menstrual cycle (MC) and at 5 and 7 weeks amenorrhea (AM5 and AM7, respectively). An arrow indicates higher $(\uparrow)$ or lower $(\downarrow)$ than the one in the control group in the corresponding $\mathrm{MC}$ phase $(\mathrm{p}<0.05)$. The symbol $*$ indicates the value in a particular subgroup to be different from that in the FP $(\mathrm{p}<0.05)$,

\begin{tabular}{|c|c|c|c|c|c|}
\hline$\therefore \quad \because$ & 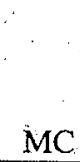 & $\begin{array}{c}\text { controls } \\
\because \because \\
(n=10)\end{array}$ & $\begin{array}{l}\text { THROMB } \\
(n=18)\end{array}$ & $\begin{array}{c}\text { ex-preeclamptic } \\
\text { NONTHROMB } \\
(n=13)\end{array}$ & $\begin{array}{l}\text { HYPERT } \\
(\mathrm{n}=11)\end{array}$ \\
\hline .9 & & & & & \\
\hline $\begin{array}{c}\text { Carotis MAP (mmHg) } \\
\because \cdots \\
\therefore \\
\quad \because \quad\end{array}$ & $\begin{array}{l}\text { FP } \\
\text { LP } \\
\text { AMM } \\
\text { AM7 }\end{array}$ & $\begin{array}{l}82 \pm 6 \\
83 \pm 6 \\
75 \pm 4 \\
78 \pm 6\end{array}$ & $\begin{array}{r}88 \pm 5 \\
86 \pm 7 \\
85 \pm 8 \\
81 \pm 4\end{array}$ & $\begin{array}{r}89 \pm 6 \\
89 \pm 6 \\
\quad 83 \pm 5 \\
\because 82 \pm 6\end{array}$ & $\begin{array}{l}103 \pm 7 \uparrow \\
106 \pm 6 \uparrow \\
97 \pm 7 \uparrow \\
95 \pm 7 \geqslant\end{array}$ \\
\hline $\begin{array}{l}\text { Carotis PP }(\Delta \mathrm{mmHg}) \\
\therefore \quad \therefore \quad\end{array}$ & $\begin{array}{l}\text { FP } \\
\text { LP } \\
\text { AML5 } \\
\text { AM7 }\end{array}$ & $\begin{array}{l}41 \pm 2 \\
44 \pm 4 \\
45 \pm 5 \\
42 \pm 6\end{array}$ & $\begin{array}{r}46 \pm 6 \\
48 \pm 8 \\
45 \pm 7 \\
48 \pm 6\end{array}$ & $\begin{array}{r}\because 45 \pm 4 \\
\quad 48 \pm 6 \\
\quad 49 \pm 8 \\
\therefore \quad 51 \pm 9\end{array}$ & $\begin{array}{l}48 \pm 10 \\
50 \pm 7 \\
54 \pm 7 \uparrow \\
52 \pm 12 \uparrow\end{array}$ \\
\hline Carotis $\varnothing(\mathrm{mmm})$ & $\begin{array}{l}\text { FP } \\
\mathrm{LP} \\
\text { AMS } \\
\text { AM? }\end{array}$ & $\begin{array}{l}6.7 \pm 0.3 \\
6: 5 \pm 0.3 \\
6: 5 \pm 0.3 \\
6.6 \pm 0.3\end{array}$ & $\begin{array}{r}6.7 \pm 0.3 \\
6.7 \pm 0.2 \\
6.6 \pm 0.3 \\
66 \pm 0.2\end{array}$ & $\begin{array}{l}6.8 \pm 0.5 \\
6.8 \pm 0.31 \\
6.7 \pm 0.2 \\
6.7 \pm 0.3\end{array}$ & $\begin{array}{l}6.8 \pm 0.2 \\
6.9 \pm 0.2 \uparrow \\
6.6 \pm 0.3 \\
6.5 \pm 0.4\end{array}$ \\
\hline Carotis CC (mmm kPa & $\begin{array}{l}\text { FP } \\
\text { LP } \\
\text { AMS } \\
\text { AM7 }\end{array}$ & $\begin{array}{l}1.08 \pm 0.26 \\
0.97 \pm 0.24 \\
1.07 \pm 0.22 \\
1.18 \pm 0.35\end{array}$ & $\begin{array}{l}1.04 \pm 0.23 \\
1.00 \pm 0.19 \\
1.12 \pm 0.10 \\
1.06 \pm 0.16\end{array}$ & $\begin{array}{l}0.98 \pm 0.27 \\
1.05 \pm 0.27 \\
1.10 \pm 0.27 \\
1.05 \pm 0.18\end{array}$ & $\begin{array}{l}0.80 \pm 0.051 \\
0.85 \pm 0.21 \\
0.71 \pm 0.101 \\
0.79 \pm 0.19 \downarrow\end{array}$ \\
\hline $\begin{array}{c}\text { Carotis } \mathrm{BC}-\left(\mathrm{k} \mathrm{Pa}^{-1}\right) \\
\therefore\end{array}$ & $\begin{array}{l}\text { FP } \\
\text { LP } \\
\text { AM5 } \\
\text { AM7 }\end{array}$ & $\begin{array}{l}30.5 \pm 7.9 \\
28.8 \pm 6.3 \\
32.0 \pm 6.4 \\
36.0 \pm 9.4\end{array}$ & $\begin{array}{l}29.5 \pm 5.9 \\
28.3 \pm 6.1 \\
33.0 \pm 4.5 \\
30.8 \pm 4.4\end{array}$ & $\begin{array}{l}28.0 \pm 9.1 \\
28.9 \pm 8.1 \\
31.9 \pm 8.4 \\
29.9 \pm 6: 5\end{array}$ & $\begin{array}{l}22.6 \pm 1.3 \downarrow \\
23.1 \pm 4.2 \\
21.1 \pm 4.2 \downarrow \\
23.2 \pm 4.6 \downarrow\end{array}$ \\
\hline
\end{tabular}


Table V: Femoral and venous vascular data obtained in the FP and LP of the menstrual cycle (MC) and at 5 and 7 weeks amenorrhea (AM5 and AM7, respectively). An arrow indicates higher ( $\uparrow$ ) or lower $(\downarrow)$ than the one in the control group in the corresponding MC phase $(p<0.05)$. The symbol * indicates the value in a particular subgroup to be different from that in the FP $(p<0.05)$.

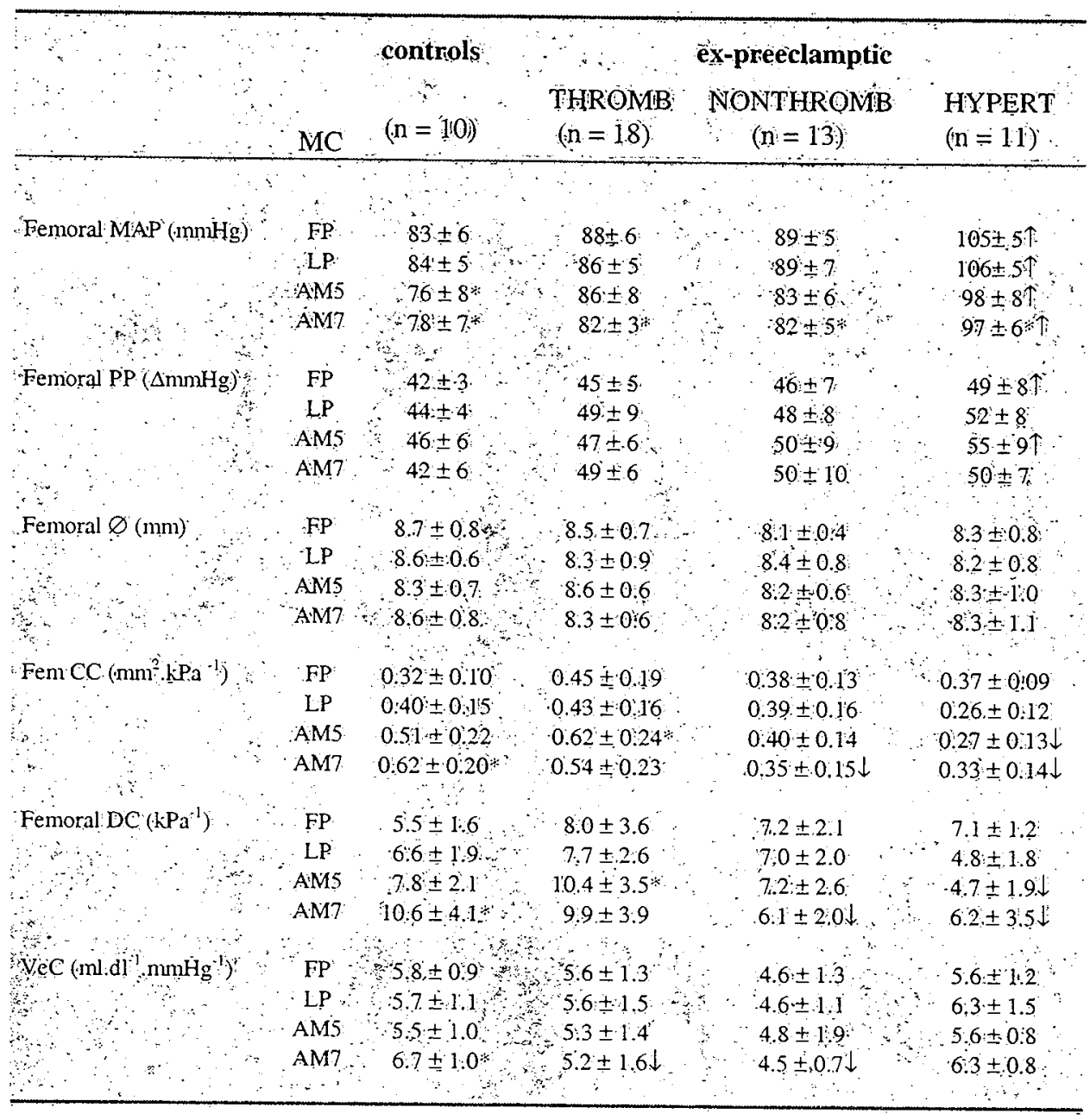


Table VI: Sex-hormones data obtained in the FP and LP of the menstrual cycle (MC) and at 5 and 7 weeks amenorrhea (AM5 and AM7, respectively). An arrow indicates higher $(\uparrow$ ) or lower $(\downarrow)$ than the one in the control group in the corresponding $\mathrm{MC}$ phase $(\mathrm{p}<0.05)$. The symbol $*$ indicates the value in a particular subgroup to be different from that in the FP $(\mathrm{p}<0.05)$.

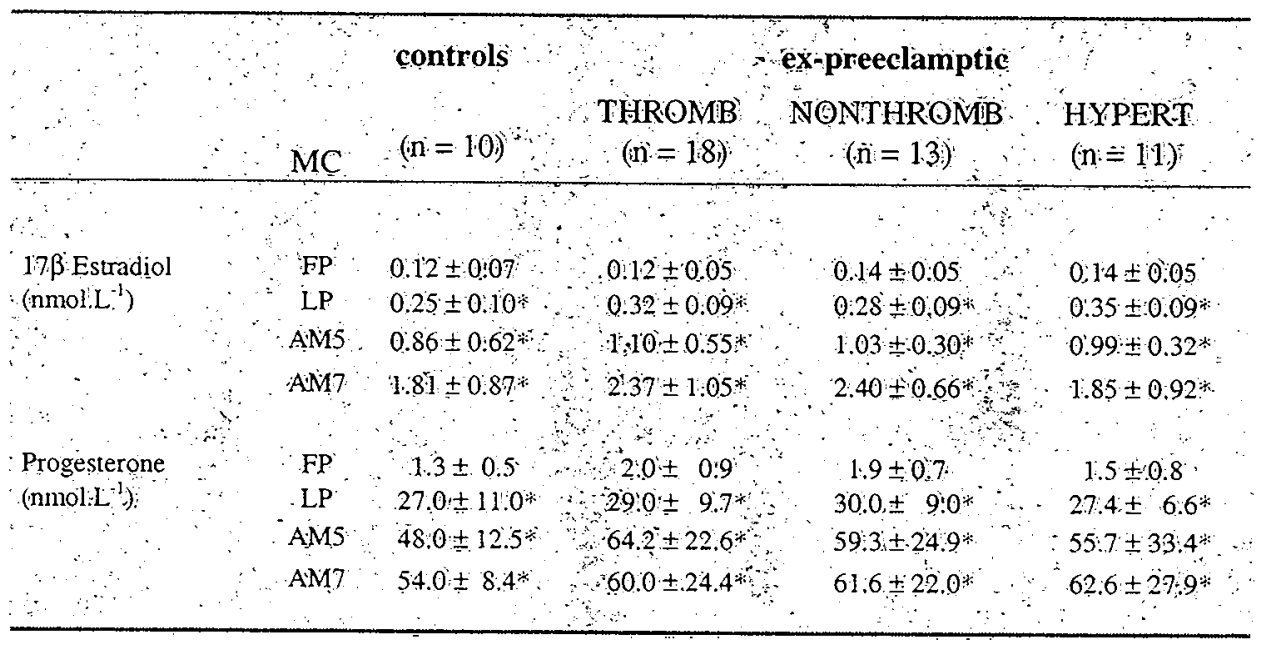

\section{Discussion}

This study was designed to determine whether the institution of a high-flow/low resistance circulation in the first weeks of pregnancy is accompanied by a rise in the compliance of the large vessels. In addition, we wanted to find out whether the pregnancy-induced change in this macrovascular compliance differs between women with and those without an increased risk to develop a hypertensive complication during pregnancy. To this end, we studied longitudinally in 42 high-risk women and 10 low-risk controls in the menstrual cycle and subsequent early pregnancy total peripheral vascular resistance and the compliance of both capacitive (predominantly elastic wall properties; carotid artery) and conductive arteries (predominantly muscular wall properties; femoral artery) and forearm veins. We chose the two functionally different arteries as vasorelaxation was expected to affect the compliance of a muscular artery more than that of an elastic artery. Measurements were performed in the follicular-and luteal phases of the menstrual cycle and again at 5 and 7 weeks pregnancy. The high-risk participants were subdivided into three subgroups, depending on the type of preexistent disorder $4,21,22$.

The general characteristics in the three subgroups selected were comparable with those in the control group, except for a lower plasma volume in the NONTHROMB subgroup and 
obviously, a higher blood pressure in the HYPERT group. The incidence of the various thrombophilic disorders in the THROMB subgroup was in line with reports by others ${ }^{21,22}$. In all groups, total peripheral vascular resistance had decreased by 20 to $25 \%$ in early pregnancy, an abrupt decline already reached by 5 weeks, which is consistent with previous studies ${ }^{2}$. However, only in controls, this phenomenon was paralleled by a gradual increase in carotid distension coefficient, femoral artery and forearm venous compliance. Except for venous compliance and çarotid distension coefficient, these changes were also discernible in THROMB ex-PE subjects. Interestingly, both NONTHROMB and HYPERT ex-PE subgroup failed to respond to pregnancy with a rise in vascular compliance. Previous reports showed a rise in aortic compliance in the first trimester of human pregnancy, which was maintained until term ${ }^{5,7}$. In the present study, this adaptive change was already noticeable in the early part of the first trimester of pregnancy. Our observation that this phenomenon develops very early in pregnancy, is supported by similar observations in the conscious pregnant rat ${ }^{23}$. The magnitude in response to pregnancy of the femoral and carotid arterial compliance suggests that the arterial compliance increases as a result of relaxation of the muscular layer of the vessel wall. Theoretically, the impact on vascular impedance of a given rise in vascular compliance increases progressively moving downstream in the vascular tree from the aorta to the microcirculation. This may explain why the early-pregnancy fall in total peripheral vascular resistance seemed to occur earlier and to be larger than the rise in femoral artery compliance. It should be emphasized that other phenomena are also influencing the vascular compliance in early pregnancy. The vascular filling state, the decreased mean arterial blood pressure and the rise in heart rate tend to lower vascular compliance. It is likely that both decrement in vascular resistance and increment in compliance share a common, still obscure, mechanism triggered by the endocrine environment of pregnancy. In-vitro studies support the involvement of a lower myogenic vascular tone and reactivity ${ }^{24}$. However, the exact pathway is still to be unraveled.

The rise in both arterial and venous compliance, as occurring in controls, supports the view that a systemically acting vascular relaxant can be considered a strong candidate initiating these changes. This relaxant initiates a cascade of responses. Centrally, both cardiac preload and afterload will fall. These changes trigger volume retention and the institution of a highflow/low-resistance circulation, respectively. The rise in heart rate indicates that the sympathetic tone in the circulation is elevated in this period, in order to warrant an adequate rise in cardiac output to meet the peripheral demands. Possibly, when the venous 
compartment is relatively small and contracted, as indicated by a lower plasma volume and also its correlation with venous compliance, autonomic responses can be expected to interfere with a normal rise arterial and venous vascular compliance.

Interestingly, NONTHROMB and HYPERT subjects did not respond to pregnancy with a rise in femoral compliance. The defective response may be caused by a weak pregnancyrelated stimulus or by blunted responsiveness of the target tissue, for instance by a mechanism mentioned above. The changes in circulating steroid levels were comparable in controls and all ex-PE subgroups. Therefore, in both NONTHROMB and HYPERT subjects, reduced responsiveness of the vascular smooth muscle appears to be the most plausible explanation for the lack of increase in arterial compliance.

In summary, these data support the concept that in normal pregnancy the fall in total peripheral vascular resistance is paralleled by improved macrovascular compliance. The latter adaptive change does not occur in normotensive nonthrombophilic and hypertensive formerly preeclamptic women. 


\section{References}

1. Schrier RW, Briner VA. Peripheral arterial vasodilatation hypothesis of sodium and water retention in pregnancy: implications for pathogenesis of preeclampsia-eclampsia. Obstet Gynẹcol 1991;77:632-9.

2. Duvekot JJ, Cheriex EC, Pieters FAA, Peeters LLH. Early-pregnancy changes in haemodynamics and volume homeostasis are consecutive adjustments triggered by a primary fall in systemic vascular tone. Am J Obstet Gynecol 1993; 169: 1382-92.

3. Duvekot JJ, Cheriex EC, Pieters FA, Peeters LLH. Severly impaired fetal growth is preceded by matemal maladaptation in very early pregnancy. Acta Obstet Gynecol Scand 1:995;74(9):693-7.

4. Spaanderman MEA, Ekhart THA, van Eyck J, Cheriex EC, de Leeuw PW, Peeters. LLH. Asymptomatic ex-preeclamptic women have latent hemodynamic abnormalities. Am J Obstet Gynecol 2000; 182;101-7.

5. Hart MV, Morton MJ, Hosenpud JD, Metcalfe J. Aortic function during normal human pregnancy. Am J Obstet Gynecol 1986; 154:887-891.

6. Sakai K, Imaizumi T, Maeda H, Nagata H, Tsukinori K, Takeshita A, Nakano H. Venous distensibility during pregnancy. Comparisons between normal pregnancy and preeclampsia. Hypertension 1994; 24(4):461-6.

7. Poppas A, Schroff SG, Korcarz CE, Hibbard JU, Berger DS, Lindheimer MD, Lang RM. Serial assessment of the cardiovascular system in normal pregnancy. Role of arterial compliance and pulsatile arterial load. Circulation 1997; 95 (10): 2407-15.

8. Perry IJ, Beevers DG. The definition of pre-eclampsia. Br J Obstet Gynaecol 1994; 101: 587 591.

9. Harris EN. The second international anti-cardiolipin standardization workshop/the Kingston Antiphospholipid Antibody Study (KAPS) group. Am J Clin Pathol 1990;94: 476-484.

10. Derksen RHWM, Hasselaar P, Blokzijl L, Gmelig Meyling FHJ, de Groot PhG. Coagulation screen is more specific than the anticardiolipin antibody ELISA in defining a thrombotic subset of lupus patients. Ann Rheum Dis 1988; 47:364371.

11. Vinazzer H, Prangraz U. Protein $C$ : comparison of different assays in normal and abnormal plasma samples. Thromb Res 1987; 46: 1-8.

12. Woodhams BJ. The simultaneous measurement of total and free protein $S$ by ELISA. Thromb Res 1988; 50: 213-220.

13. Nicolaes GAF, Thomassen MCLGD, van Oerle R, Hamulyak K, Hemker HC, Tans G, Rosing J. A prothrombinase-based assay for detection of resistance to activated protein C. Thromb Res 1996; 76: 404-410.

14. van Oerle R, van Pampus $L$, Tans G, Rosing J, Hamulyak K. The clinical application of a new specific functional assay to detect the factor $\mathrm{V}$ Leiden mutation associated with activated protein C resistance. Am J Clin Pathol 1997; 107: 521-526.

15. Tollefsen DM. Laboratory diagnosis of antithrombin and heparin cofactor II deficiency. Semin Thromb Hemost 19.90; 16: 162-8.

16. Ubbink JB, Vermaak WJK, Bissbort S. Rapid high-performance liquid chromatographic assay for total homocysteine levels in human serum. J Chromatogr 1991; 565: 441-446.

17. Kool MJ, van Merode T, Reneman RS, Hoeks AP, Struyker-Boudier HA, van Bortel LM. Evaluation of reproducibility of a vessel wall movement detector system for assessment of large artery properties. Cardiovasc Res 1994; 28(5):610-4. 
18. Deurenberg $P$, Weststrate JA, Seidell JC. Body mass index as a measure of body fatness: ageand sex-specific prediction formulas $1991 ; \mathrm{Br}$ J Nutr 65: 105-114.

19. International Committee for Standardization in Haematology. Recommended methods for measurement of red-cell and plasma volume: J Nucl Med 1980;21:793-800.

20. Kooman JP, Wijnen JA, Draaijer P, van Bortel LM, Glad ziwa U, Peltenburg HG, StruykerBoudier HA, van Hooff JP, Leunissen KM. Compliance and reactivity of the peripheral venous system in chronic intermittent hemodialysis. Kidney Int 1992; 41(4):1041-8.

21. Dekker GA, de Vries. JIP, Doelitzsch PM, Huijgens PC, von Blomberg BME, Jacobs C, van Geijn HP. Underlying disorders associated with severe early-onset preeclampsia. Am J Obstet Gynecol 1995;173:1042-8.

22. Kupferminc MJ, Eldor A, Steinman N, Many A, Bar-Am A, Jaffa A, Fait G, Lessing JB. Increased frequency of genetic thrombophilia in women with complications of pregnancy. $N$ Eng. J Med 1999; 340:9-13.

23. Slangen BFM, van Ingen Schenau DS, van Gorp AW, De Mey JGR, Peeters LLH. Aortic distensibility and compliance in conscious pregnant rats. Am J Physiol 1997; 272:H1260-1265.

24. Meyer MC, Osol G, McLaughlin M. Flow decreases myogenic reactivity of mesenteric arteries from pregnant rats. J Soc Gynecol Invest 1997; 293-297. 


\title{
Chapter 5
}

\section{THE CARDIAC OUTPUT INCREASES INDEPENDENT OF BASAL METABOLIC RATE IN EARLY HUMAN PREGNANCY}

\author{
Spaanderman MEA, Meertens $M$, van Bussel M, Ekhart THA, Peeters LLH.
}

Department of Obstetrics and Gynecology,

Academic Hospital Maastricht, The Netherlands.

Am J Physiol 2000;278:H1585-H1588. 


\section{Abstract}

Background Early pregnancy is characterized by the institution of a high-flow lowresistance circulation. In this study we tested the hypothesis that these hemodynamic changes develop independent of changes in basal metabolic rate.

Methods In 12 healthy women, we determined and calculated once during the follicular phase (FP, day 5 \pm 2 ) and at $6,8,10$ and 12 weeks of pregnancy, the following variables: body weight and length, body mass index (BMI), fat free mass (ffm), mean arterial pressure (MAP), heart rate (HR), stroke volume (SV), cardiac output (CO), total peripheral vascular resistance (TRVR), resting energy expenditure (REE), REE/ffm ( $R E E_{\text {ffin }}$ ) and respiratory quotient (RQ).

Results At 6 weeks gestational age HR and CO had increased while MAP and TPVR had decreased. These changes persisted throughout the study period. Meanwhile, REE, REE ffm, RQ, ffm and body weight did not change consistently. The changes with pregnancy in hemodynamics did not correlate with those in basal metabolic rate.

Conclusion In early pregnancy the institution of a high-flow low-resistance circulation develops without a concomitant rise in basal metabolic rate. These findings support the concept that the hemodynamic changes in early pregnancy develop independent of concomitant changes in basal metabolic rate. 


\section{Chapter 5}

\section{Introduction}

In pregnancy, systemic arterial vasodilation represents one of the first detectable changes in systemic hemodynamics. This vasodilation than initiates a cascade of compensations in the circulation and volume homeostasis that include, among others, a rise in cardiac output

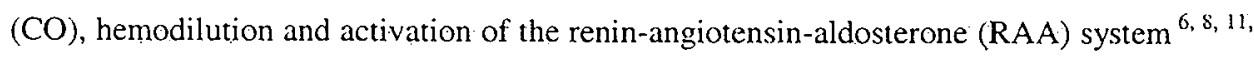
$12,13,21$. Neither the mechanism responsible for the initial hemodynamic change in early pregnancy nor its functional meaning in this period of pregnancy is understood. Insight in the interrelation between the early pregnancy increase in $\mathrm{CO}$ and a concomitant change in metabolic rate would improve our understanding of the mechanism and functional meaning of the early pregnancy vasorelaxation. Although in late pregnancy basal metabolism is elevated, the available data on change in metabolic rate in early pregnancy are scarce and inconclusive $4,19,20$. Moreover, to the best of our knowledge, the metabolic rate in early pregnancy has never been measured simultaneously with $\mathrm{CO}$ in a longitudinally study. Therefore, it is still obscure whether or not CO increased before or after a rise in metabolic rate in the first trimester of pregnancy.

The objective of the present study was to test the hypothesis that in early pregnancy the CO increases independent of concomitant changes in metabolic rate. To this end, we measured serially in 12 women during the follicular phase of the menstrual cycle and in subsequent early pregnancy, blood pressure, cardiac output and resting energy expenditure. 


\section{Methods}

\section{Selection and patient characteristics}

In this study 12 non-smoking healthy women were enrolled. Participants were recruited by advertisement. None of the women used oral contraceptives or other medication. Measurements were performed in the FP (follicular phase; day $5 \pm 2$ ) and at 6, 8, 10 and 12 weeks of pregnancy. The gestational age at the time of measurement was verified by ultrasound biometry of the embryo (series 150, Pie Medical, Maastricht, NL) prior to the fịst measurement session in pregnancy. Gestational age was blinded for the individuals that determined metabolic and hemodynamic parameters.

\section{Experimental procedure}

\section{Metabolism}

After an overnight fast, each experimental session was started with the measurement of fat free mass (FFM, kg) and resting energy expenditure (REE, kcal. kcal.24 $\mathrm{h}^{-1}$ ). Mean arterial blood pressure (MAP, $\mathrm{mmHg}$ ) and heart rate $(\mathrm{HR}, \mathrm{bpm})$ were recorded intermittently throughout the measurement session by a semi-automatic oscillometric device (Dinamap Vital Signs Monitor 1846, Critikon, Tampa, FL, USA). FFM was determined by bioelectrical impedance (BIA-101, RJL Systems, Detroit, MI, USA), a method associated with $0.3 \mathrm{~kg}$ variation between consecutive days ${ }^{22}$. REE, which comprises the sleeping metabolic rate supplemented with the energy cost of being awake, was determined by indirect calorimetry using a computerized open-circuit ventilated hood system (Oxycon B, Jaeger, Breda, $\mathrm{Nl}$ ). In a horizontal position, each participant breathes inside a canopy that forms a gastight barrier between the room air and the respirable air. Using a continuous inflation and suction pump, a constant flow of exhaled air and room air is drawn from and to the canopy. The gas composition and the velocity of the air flow are measured at the outlet of the air suction pump. In steady state, differences in gas composition between the canopy and room air varies as a function of the oxygen consumption $\left(\mathrm{VO}_{2}, \mathrm{~L} \cdot \mathrm{min}^{-1}\right)$ and carbon dioxide production $\left(\mathrm{VCO}_{2}, \mathrm{~L} \cdot \mathrm{min}^{-1}\right)^{23}$. From these values, the respiratory quotient (RQ) was calculated, according to the formula: 
Twenty-four hour resting energy expenditure is calculated using the abbreviated Weir formula ${ }^{25}$ and expressed in $\mathrm{kcal}^{2} 24 \mathrm{~h}^{-1}$ and $\mathrm{kcal} .24 \mathrm{~h}^{-1} \mathrm{~kg}$ fat free mass $\mathrm{s}^{-1}$ :

$$
\begin{aligned}
& \boldsymbol{R E E}\left(\mathrm{kcal} .24 \mathrm{~h}^{-1}\right) \quad=(3.9+1.1 \mathrm{RQ}) \times \mathrm{VO}_{2} \times 1440 \\
& R E E_{f f m}\left(k c a l .24 h^{-1} \cdot \mathrm{kg}^{-1}\right)=(3.9+1.1 R Q) \times V O_{2} \times 1440 / F F M
\end{aligned}
$$

In our laboratory, the determination of RQ and that of REE has an intra-individual CV of $6 \%$ and $1.2 \%$, respectively ${ }^{23}$.

\section{Hemodynamics}

Echocardiography to assess cardiac output was performed in semi-left lateral position, immediately after completion of the REE measurement after approximately 5 minutes of rest, using a crọss-sectional, phased array echocardiographic Doppler system (HewlettPackard Sonos 2000 and 2500) ${ }^{12}$.

$\mathrm{CO}$ was calculated according to the formula:

$$
\operatorname{CO}\left(\text { L.min }{ }^{-1}\right) \quad=\text { stroke volume } x H R
$$

In this formula, HR was obtained by taking reciprocal of the mean of five consecutive R-R intervals on the ECG. Stroke volume $(\mathrm{SV}, \mathrm{ml})$ was calculated by multiplying the aortic velocity integral and the aortic area. Aortic flow was measured across the aortic valves from an apical approach. SV was calculated using the average area under the aortic velocity curve (aortic velocity integral) of five consecutive ejections. Aortic valve diameter necessary for the calculation of the aortic area, was measured during systole by $\mathrm{M}$-mode, off-line and at the orifice. Total peripheral vascular resistance (TPVR) was calculated as follows:

$$
\text { TPVR (dyne.s. } \left.\mathrm{cm}^{-5}\right)=80 \times \mathrm{MAP} / \mathrm{CO}
$$

The value used for MAP was obtained during the $\mathrm{CO}$ measurement and was calculated as the mean of three consecutive recordings.

Statistical analysis: Data are presented as means \pm SD unless otherwise stated. Differences relative to the value obtained during the follicular phase were evaluated with ANOVA for repeated measures. Correlations between concomitantly measured variables in the different phases were tested by Spearman's rank correlation analysis. A p-value less than 0.05 was considered statistically significant. 


\section{Results}

The demographic characteristics of the participants are listed in table I. In all subjects, the course of pregnancy was uneventful.

REE, REE $E_{f m}$ and RQ did not change consistently in the study period between the FP and the $12^{\text {th }}$ week of pregnancy (Table II). Body weight and FFM varied little and inconsistently between the 5 measurement sessions. Meanwhile, $\mathrm{CO}$ and $\mathrm{HR}$ had increased, and TPVR and MAP had decreased consistently in the study period, a change already noticed by the $6^{\text {th }}$ week (Table IL, Figure I).

The CO per unit REE and per unit $\mathrm{REE}_{\mathrm{ffm}}$ increased significantly over the study period ( $\mathrm{p}=$ $0.04, r=0.90, r^{2}=0.80$ and $p=0.02, r=0.94, r^{2}=0.89$, respectively). Within one measurement session, HR did not change appreciably between the period of REE measurement and the subsequent period of $\mathrm{CO}$ determination.

Neither the change in REE, nor that in REE ffm in the course of the five measurement sessions correlated with the observed concomitant changes in $\mathrm{CO}\left(r=-0.29, \mathrm{r}^{2}=0.09\right.$ and $r$ $=-0.44, r^{2}=0.19$, respectively) .

Table I: Demographic data (follicular phase).

\begin{tabular}{lr}
\hline Age (years) & $29 \pm 3$ \\
Height (cm) & $168 \pm 7$ \\
BMI (kg.m $\left.{ }^{-2}\right)$ & $23 \pm 3$ \\
Parity (\% nulliparous) & 50 \\
MAP (mmHg) & $91 \pm 12$ \\
\hline
\end{tabular}

Table II: Metabolic data and body- and fat free mass are from the follicular phase (FP) of the menstrual cycle and at $6,8,10$ and 12 weeks of pregnancy. An asterisk indicates a significant difference as compared to the FP.

\begin{tabular}{|c|c|c|c|c|c|}
\hline$\because$ & Follicular & $6 \mathrm{wks}$ & $8 \mathrm{wks}$ & 10 wks & 12 wks \\
\hline Weight & $65 \pm 10$ & $65 \pm 10$ & $65 \pm 11$ & $65 \pm 11$ & $65 \pm 12$ \\
\hline FFM & $45 \pm 5$ & $46 \pm 4$ & $44 \pm 5$ & $45 \pm 5$ & $45 \pm 5$ \\
\hline REE & $1496 \pm 165$ & $1536 \pm 141$ & $1451 \pm 215$ & $1486 \pm 201$ & $1426 \pm 117$ \\
\hline$R E E_{\text {ffin }}$ & $33.5 \pm 3.4$ & $33.2 \pm 2.9$ & $315 \pm 4.0$ & $32.8 \pm 3.4$ & $32.8 \pm 1.5$ \\
\hline$R Q$ & $0.88 \pm 0.04$ & $0.88 \pm 0.06$ & $0.87 \pm 0.04$ & $0.92 \pm 0.06$ & $0.89 \pm 0.04$ \\
\hline
\end{tabular}

$\mathrm{REE}=$ resting energy expenditure $\left(\mathrm{kcal} .24 \mathrm{~h}^{-1}\right), \mathrm{FFM}=$ fat free mass $(\mathrm{kg}), \mathrm{RQ}=$ respiratory quotient 
Table III: Hemodynamic data are from the follicular phase (FP) of the menstrual cycle and at 6,8 , 10 and 12 weeks of pregnancy. An asterisk indicates a significant difference as compared to the FP.

\begin{tabular}{|c|c|c|c|c|c|}
\hline & Follicular & $6 \mathrm{wks}$ & $8 \mathrm{wks}$ & $10 \mathrm{wks}$ & $12 \mathrm{wks}$ \\
\hline $\mathrm{HR}$ & $66 \pm 5$ & $72 \pm 5 *$ & $70 \pm 6$ & $67 \pm 8$ & $71 \pm 7^{*}$ \\
\hline SV & $79 \pm 7$ & $85 \pm 12$ & $85 \pm 12$ & $84 \pm 11$ & $80 \pm 8$ \\
\hline $\mathrm{CO}$ & $5.2 \pm 0.6$ & $6.0 \pm 0.7 *$ & $5.9 \pm 1: 0$ & $5.8 \pm 0.8$ & $6,1 \pm 0.4$ \\
\hline MAP & $92 \pm 11$ & $87 \pm 7 *$ & $87 \pm 7$ & $88 \pm 6 *$ & $85 \pm 6$ \\
\hline TPVR & $1434 \pm 284$ & $1188 \pm 242^{*}$ & $1213 \pm 272 *$ & $1192 \pm 228 *$ & $1174 \pm 111 *$ \\
\hline
\end{tabular}

$\mathrm{HR}=$ heart rate $(\mathrm{BPM}), \mathrm{SV}=$ stroke volume $(\mathrm{ml}), \mathrm{CO}=$ cardiac output $\left(\mathrm{L} \cdot \mathrm{min}^{-1}\right), \mathrm{MAP}=$ mean arterial pressure $(\mathrm{mmHg})$, TPVR $=$ total peripheral vascular resistance $\left(\right.$ dyne. $\left..5 . \mathrm{cm}^{-5}\right)$.

Figure I: Percent change, relative to the follicular phase (FP), in cardiac output (CO, solid bars) and resting energy expenditure (REE, open bạrs). Data are presented in means and SE and originate from the FP of the menstrual cycle and at 6,8,10 and 12 weeks of pregnancy. An asterisk indicates a significant difference as compared to the FP.

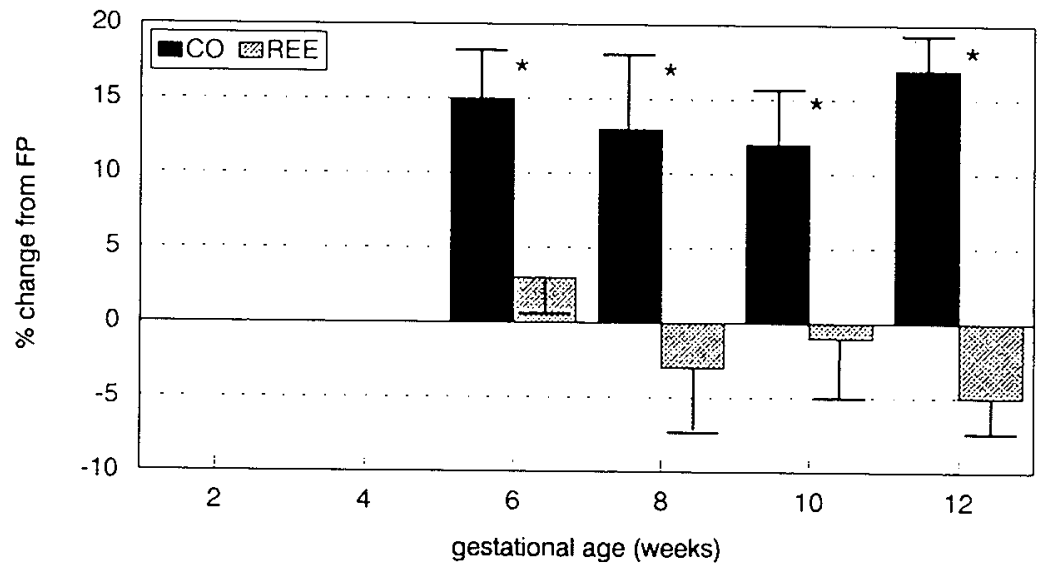




\section{Discussion}

Early pregnancy is characterized by the development of a high-flow low-resistance circulation $6,7,9,13,13,21$. However, at present the exact mechanism responsible for this effect is still obscure. A rise in metabolic rate could be one of the possible triggers for these circulatory adjustments. Conversely, when the metabolic rate does not increase, the highflow low resistance circulation is associated with a $\mathrm{CO}$ rise in excess of metabolic demands. In this study, we explored the possible interrelationship between systemic vasorelaxation and metabolic rate in twelve healthy women, by measuring $\mathrm{CO}$ together with REE during five consecutive sessions in the first weeks of pregnancy when hemodynamic changes are the largest. In our study, the institution of a high-flow low-resistance circulation in early pregnancy develops without a concomitant rise in basal metabolic rate.

Reports on REE in early pregnancy are rather conflicting with some studies reporting an increment, others a fall in basal metabolic rate in early pregnancy ${ }^{9}, 20$. Some of these differences in can be explained by the methods employed, the procedure to standardize measurement conditions and the role of fat mass with REE. In fact, suppression of REE in early pregnancy is mainly observed in women with a low body mass index and also, in advanced pregnancy, the largest increase in REE occurs in women with the highest body mass indices ${ }^{4,20}$. During the first 12 weeks of pregnancy we did not find an appreciable change in REE and RQ. Conversely, the concomitantly measured CO had already increased by the $6^{\text {th }}$ week of pregnancy. Meanwhile, the time-dependent change in CO and that in REE did not correlate. Also the CO per unit REE and $\mathrm{REE}_{\mathrm{ffm}}$ was found to increase with advancing amenorrhea. All these phenomena support the development of a hyperdynamic circulation in the first weeks of pregnancy. To maintain the balance in Starling forces within the capillary bed, the institution of a hyperdynamic circulation should be paralleled by the opening of protective arteriovenous shunts and with it a fall in arteriovenous oxygen difference over the circulation, an effect which has been observed by others in both human and animal pregnancy $2,5,14,18$. Opening of these arteriovenous fistulae is considered to be primarily systemic rather than placental, since intervillous circulation has not been established until the end of the first trimester ${ }^{16}$.

Obviously, these results should be interpreted in the context of the methods employed, particularly with respect to potential pitfalls. We performed the $\mathrm{CO}$ measurement immediately after the REE determination, a choice made for logistic reasons. These observations can only be considered 'simultaneously made', if the participants were really in 
a steady state. The latter was highly probable, since REE is a continuously measured variable that can only be determined reliable when RQ had been stable for at least 15 minutes. The steady-state conditions during the REE measurement was maintained during the subsequent CO measurement, a condition verified on the basis of maintained steady-state in HR and MAP values throughout the latter period until completion of data acquisition.

These findings indicate that the early pregnancy systemic vasorelaxation develops independent of changes in basal metabolism. How this initial change in pregnancy is induced remains to be established. Prolonged changes in steroid environment giving rise to an altered balance between vasoconstrictive and vasodilatory stimuli, are thought to be responsible for the initial arterial relaxation 15, 17. The support for this concept comes from observations during the menstrual cycle and in the (pseudo)pregnant rat. During the luteal phase of the menstrual cycle, the hemodynamics and renal function changes slightly in the direction similar to that observed in early pregnancy ${ }^{8}$. In rat pseudopregnancy, initial adaptations in hemodynamic and volume homeostasis are similar to those observed in normal rat pregnancy $1,3,24$. Moreover, although not found by all investigators, suppletion of sex steroid hormones in ovariectomized rats to a level observed in pregnancy can alter vascular sensitivity to vasodilatory stimuli comparable to that seen in normal pregnancy ${ }^{10,15}$. This indicates that neither trophoblastic hormones, nor the placenta itself, are needed to induce these hemodynamic changes.

In conclusion, early pregnancy is characterized by the development of a hyperdynamic circulation. This adaptive change seems to be the result of a primary relaxation of the arterial vasculature together with the opening of protective arteriovenous shunts. 


\section{References}

1. Atherton JC, Bu'lock D, Pirie SC. The effect of pseudopregnancy on glomerular filtration rate and salt and water reabsorption in the rat. J Physiol (Lond) 1982; 324:11-20.

2. Bader RA, Bader ME, Rose DJ, Braunwald E. Hemodynamics at rest and during exercise in normal pregnancy as studied by cardiac catheterization. J Clin Invest 1955; 34:1524-36.

3. Baylis C. Glomerular ultrafiltration in the pseudopregnant rat. Am J Physiol 1982; 243:F300-5.

4. Bronstein MN, Mak RP, King JC. Unexpected relationship between fat mass and basal metabolic rate in pregnant women. Br J Nutr 1996; 75:659-68.

5. Burwell CS, Strayhorn WD, Flickinger D, Corlette MB. Circulation during pregnancy. Arch Intern Med 1938; 62:979-1003.

6. Capeless EL, Clapp JF. Cardiovascular changes in early phase of pregnancy. Am J Obstet Gynecol 1989; 161:1449-53.

7. Chapman AB, Abraham WT, Zamudio S, Coffin C, Merouani A, Young D, Johnson A, Osorio F, Goldberg C, Moore LG, Dahms T, Schrier RW. Temporal relationships between hormonal and hemodynamic changes in early human pregnancy. Kidney Int 1998; 54:2056-63.

8. Chapman AB, Zamudio S, Woodmansee W, Merouani A, Osorio F, Johnson A, Moore LG, Dahms T, Coffin C, Abraham WT, Schrier RW. Systemic and renal hemodynamic changes in the luteal phase of the menstrual cycle mimic early pregnancy. Am J Physiol 1997; 273: F777F782.

9. Clapp JF, Seaward BL, Sleamaker RH, Hiser J. Maternal physiologic adaptations to early human pregnancy. Am J Obstet Gynecol 1988; 159:1456-60.

10. Conrad KP, Mosher MD, Brinck-Johnsen T, Colpoys MC. Effects of 17 beta-estradiol and progesterone on pressor responses in conscious ovariectomized rats. Am J Physiol 1994; 266:R1267-72.

11. Davison JM, Noble MCB. Serial changes in 24 hour creatinine clearance during normal menstrual cycles and the first trimester of pregnancy. Br J Obstet Gynaecol 1981; 88: 10-17.

12. Duvekot JJ, Cheriex EC, Pieters FAA, Peeters LLH. Early-pregnancy changes in hemodynamics and volume homeostasis are consecutive adjustments triggered by a primary fall in systemic vascular tone. Am J Obstet Gynecol 1993; 169:1382-1392.

13. Easterling TR, Benedetti TJ, Schmucker BC, Millard SP. Maternal hemodynamics in normal and pre-eclamptic pregnancies: a longitudinal study. Obstet Gynecol 1990; 76:1061-69.

14. Gilson GJ, Mosher MD, Conrad KP. Systemic hemodynamics and oxygen transport during pregnancy in chronically instumented, conscious rats. Am J Physiol 1992; 263:H1911-8.

15. Grewal M, Cuevas J, Chaudhuri G, Nathan L. Effects of calcitonin gene-related peptide on vascular resistance in rats: role of sex steroids. Am J Physiol 1999; 276:H2063-8.

16. Jaffe R, Jauniaux E, Hustin J. Maternal circulation in the first-trimester human placenta: myth or reality? Am J Obstet Gynecol 1997; 176:695-705.

17. Magness RR, Phernetton TM, Zheng J. Systemic and uterine blood flow distribution during prolonged infusion of 17beta-estradiol. Am J Physiol 1998; 275:H731-43.

18. Metcalfe J, Ueland K. Maternal cardiovascular adjustments to pregnancy. Prog Cardiovasc Dis $1974 ; 16: 364-374$.

19. Pernoll ML, Metcalfe J, Schlenker TL, Welch JE, Matsumoto JA. Oxygen consumption at rest and during exercise in pregnancy. Respir Physiol 1975; 25:285-93. 
20. Prentice AM, Goldberg GR, Davies HL, Murgatroyd PR, Scott W. Energy-sparing adaptations in human pregnancy assessed by whole-body calorimetry. Br J Nutr 1989; 62:5-22.

21. Robson SC, Hunter S, Boys RJ, Dunlop W. Serial study of factors influencing changes in cardiac output during human pregnancy. Am J Physiol 1989; 256:H1060-5.

22. Schols AMWJ, Dingemans ANC, Soeters PB, Wouters EFM. Within day variation of bioelectrical resistance measurements in patients with chronic obstructive pulmonary disease. Clin Nutr 1990; 9:266-271.

23. Schols AMWJ, Schoffelen PFM, Ceulemans H, Wouters EFM, Saris WHM. Measurement of resting energy expenditure in patients with chronic obstructive pulmonary disease in a clinical setting. J Parent Enter Nutr 1992; 16:364-368.

24. Slangen BFM, Out ICM, Verkeste CM, Smits JFM, Peeters LLH. Hemodynamic changes in pseudopregnancy in chronically instrumented, conscious rats. Am J Physiol 1997; 272:H695700 .

25. Weir JB. New methods for calculating metabolic rate with special reference to protein metabolism. J Physiol 1949; 109:1-9. 


\section{Chapter 6}

\section{MALADAPTATION TO PREGNANCY: A ROLE FOR ATRIAL NATRIURETIC PEPTIDE?}

Spaanderman MEA, Ekhart THA, van Eyck $J$, de Leeuw PW, Peeters LLH

Departments of Obstetrics and Gynecology and Intemal Medicine,

Academic Hospital Maastricht and Sophia Hospital Zwolle, The Netherlands.

Submitted 


\section{Abstract}

Background: The majority of women with a history of preeclampsia have either an underlying thrombophilic or vascular disorder. In this study we tested the hypothesis that only the latter condition predisposes for abnormal hemodynamic adaptation to pregnancy.

Methods: $\quad 37$ formerly preeclamptic subjects were subdivided into a hypertensive (HYPERT, $n=10$ ), a normotensive thrombophilic (THROMB, $n=13$ ) and a normotensive nonthrombophilic subgroup (NONTHROMB, $n=14$ ). In these women and in ten normal parous controls, we measured the following variables at least 5 months postpartum at day $5( \pm 2)$ of the menstrual cycle, and again at 5 and 7 weeks amenorrhea in the next pregnancy: Mean arterial pressure, heart rate, cardiac output, central cardiovascular dimensions, plasma volume, glomerular filtration rate, effective renal plasma flow, 17- $\beta$ estradiol, progesterone, the hormones of the renin-angiotensin-aldosterone (RAAS) axis, catecholamines and $\alpha$-atrial natriuretic peptide.

Results: The early-pregnancy rise in cardiac output, renal variables, RAAS activity and plasma volume was comparable in all groups. However, the HYPERT and NONTHROMB subgroups differed from both THROMB and controls, by a higher cardiac output, lower renal hemodynamics and a lower plasma volume in the pre-pregnant state. In addition, only the women in these two subgroups responded to pregnancy by a rise in circulating $\alpha$-atrial natriuretic peptide. In addition, at 7 weeks, in the subjects belonging to the HYPERT and NONTHROMB subgroups plasma volume was the lowest and correlated inversely with the concomitant circulating level of $\alpha$-atrial natriuretic peptide.

Conclusion: The hemodynamic adaptation to pregnancy in the HYPERT and NONTHROMB subgroups differs from that in THROMB and controls by an early-pregnancy rise in $\alpha$-atrial natriuretic peptide. As a consequence, the early-pregnancy plasma volume expansion in the NONTHROMB and HYPERT subgroups is less than in normal parous controls. 


\section{Chapter 6}

\section{Introduction}

In the last decade evidence is accumulating supporting the concept that preeclampsia and HELLP syndrome (Hemolysis, Elevated Liver enzymes, Low Platelets) are pregnancyrelated syndromes that develop in women with a pre-existent vascular, metabolic or clotting disorder 1,2. The pathogenesis of these syndromes may begin as early as at the time of implantation as indicated by poor trophoblast invasion, and abnormal hemodynamic adaptation with common endpoint endothelial dysfunction ${ }^{3,4}$. It follows that most of the pathogenetic cascade evolves subclinically over a period of at least 5 months. It is obscure, whether the heterogeneity in predisposing conditions as mentioned above, gives rise to a similar cascade of events in the period between defective implantation and the appearance of clinical symptoms caused by endothelial dysfunction. Most early-pregnancy changes in maternal hemodynamics are compensations triggered by systemic vasorelaxation ${ }^{5.6,7}$. These changes include the rise in cardiac output, renin-angiotensin system (RAAS) activity and plasma volume. Theoretically, formerly preeclamptic women with a thrombophilic phenotype and normal cardiovascular function can be expected to have a normal early-pregnancy hemodynamic compensatory response. Alternatively, formerly preeclamptic women with diminished cardiovascular reserves in conjunction with hypertension or "latent" hypertension, are more likely to show abnormal early-pregnancy changes ${ }^{8}$. If the pathogenetic cascade between these two most important risk groups is indeed different in early pregnancy, it not only explains the modest yield of various recently reported prevention strategies executed in unselected groups of women at risk for preeclampsia ${ }^{9}$. It also increases our understanding of the pathogenesis of preeclampsia and may provide valuable information about possibilities for preventive measures in selected risk groups.

The objective of this study was to test the hypothesis that the adaptation to pregnancy in women with a history of preeclampsia depends upon the predisposing condition. That is to say, the adaptation to pregnancy differs between women likely to have a pre-existent cardiovascular disorder and women with a thrombophilic phenotype. To this end, we divided a group of formerly preeclamptic women into subgroups with or without hypentension. The normotensive group was further subdivided into females with or without thrombophilia. These three groups were compared with a group of normal parous controls. 


\section{Methods}

\section{Selection and patient characteristics.}

Sixty-three formerly preeclamptic, non-diabetic women and 15 normal parous controls were enrolled in this study. Data acquisition was initiated at least 5 months postpartum. Inclusion for further analysis required a pregnancy occurring within one year after the pre-pregnant measurement session. Furthermore, only ongoing singleton pregnancies (gestational age $>16$ weeks) were included. As a consequence, from the group of 63 formerly preeclamptics and 15 controls having completed the non-pregnant measurement sessions, only 37 formerly preeclamptic women and 10 controls could be included for final analysis. All subjects were Caucasian and the ones who smoked $(n=9)$, refrained from smoking during pregnancy. Formerly preeclamptic women were recruited from our outpatient clinic at the time of postpartum follow-up. Controls were recruited by advertisement. Preeclampsia and (pregnancy-induced) hypertension were defined according to the criteria of the National High Blood Pressure Education Program Working Group Report on High Blood Pressure in Pregnancy ${ }^{10}$. All experiments were preceded by one week of standardized sodium intake (100 mmol sodium per day), representing the mean sodium intake in our population. To this end, all participants consulted the hospital's dietitian, prior to study. Measuring 24-hour sodium output on the day before the experiment assessed women's compliance with the diet. None of the participants used vitamin supplements or any other medication in the two weeks prior to measurement. Women on antihypertensive drugs ( $n=2$, labetalol) discontinued this medication at least one week prior to the study session but not in early pregnancy. On separate days and after an overnight fast, participants were tested for thrombophilia and hemodynamic function. Thrombophilia was defined as the condition characterized by the presence of at least one clotting disorder known to be associated with an increased risk to develop venous thrombo-embolism. All participants gave written informed consent. The hospital's medical-ethical committee approved the study.

\section{Experimental procedure}

\section{Methods}

The methodology of the measurements and calculations on the thrombophilic screening and hemodynamic function were described previously ${ }^{8}$. 
Thrombophilic screening: In short, anticardiolipin antibodies were determined spectrophotometrically by enzyme-linked immunoassay. Lupus anticoagulant was determined by mixing 1:1 patient and pooled normal plasma after finding a prolonged partial thromboplastin time. Subsequently, a thromboplastin dilution test was performed by measuring prothrombin time with progressively diluted thromboplastin. Lupus anticoagulant was considered to be present when all assays were positive. We defined the antiphospholipid syndrome as the condition where anti-cardiolipin antibodies, when higher than $10 \mathrm{GPL}$ for IgG and $6 \mathrm{MPL}$ for IgM antiphospholipid antibodies, respectively, could be detected in peripheral blood in women with a history of preeclampsia/HELLP syndrome. Coagulation tests were performed after a venous puncture. Plasma samples were stored at $-80^{\circ} \mathrm{C}$ prior to assay. Protein $\mathrm{C}$ activity was determined with Coamate protein $\mathrm{C}$ (Chromogenix, Mölndal, Sweden). Total protein $S$ antigen and free protein $S$ were measured by an enzyme- linked immunosorbent assay (ELISA) (DAKO, Glostrup, Denmark). Activated protein C resistance was quantified by a chromogenic activated protein C-resistance assay. Antithrombin activity was assayed with chromogenic substrate S-2765 (Chromogenix, Mölndal, Sweden). A methionine-loading test was used to diagnose hyperhomocysteinemia. Homocysteine was measured by high-performance liquid chromatography with fluorescence detection. Individuals were considered to have hyperhomocysteinemia when fasting and/or post-load plasma homocysteine levels were more than 2 standard deviations higher than the mean of the laboratory control group.

Measurement of blood pressure and renal hemodynamics: In the mid-follicular phase (day 5 \pm 2 ) of the menstrual period and at 5 and 7 weeks in the subsequent pregnancy, measurements were performed under standardized environmental conditions in a temperature-controlled room $\left(25-26^{\circ} \mathrm{C}\right)$ and with as minimal external disturbances as possible. Participants did not drink caffeine- or alcohol-containing beverages and refrained from smoking and eating for at least 10 hours before the experiment. The measurement session started at 8:00 AM, with the insertion of a 20-gauge catheter into a vein of the right forearm, to enable determination of renal function as detailed below ${ }^{8}$. A second catheter was inserted into a vein of the contralateral forearm for sampling of blood. Throughout each measurement session, subjects were in supine position on a comfortable bed. Mean arterial blood pressure (MAP) and heart rate (HR) were recorded repeatedly at two minutes interval by a semi-automatic oscillometric device (Dinamap Vital Signs Monitor 1846, Critikon, Tampa, FL, USA), throughout the measurement session. Effective renal plasma flow (ERPF) 
and glomerular filtration rate (GFR) were measured by continuous infusion of PAH (PAH: para-aminohippurate sodium; MSD, West Point, PA, USA) and inulin (Inutest, Laevosan Gesellschaft, Linz, Austria), respectively. PAH and inulin were measured spectrophotometrically. Renal hemodynamics were corrected for body surface area (BSA) and expressed in $\mathrm{ml}^{-\mathrm{min}^{-1}} .1 .73 \mathrm{~m}^{-2}$. Effective renal blood flow (ERBF) was obtained by dividing the effective renal plasma flow by (1-hematocrit). Renal vascular resistance (RVR, dyne.s.cm $\mathrm{cm}^{-5} \cdot 1.73^{-2}$ ) was obtained by dividing mean arterial blood pressure by the effective renal blood flow. The ratio of glomerular filtration rate and effective renal plasma flow was taken to obtain the filtration fraction (FF).

At least two hours after the initiation of the PAH/inulin infusion, three blood samples were taken for determination of inulin and PAH. In addition, blood was collected for assay of active plasma renin concentration, angiotensin II, aldosterone, $\alpha$-atrial natriuretic peptide, 17- $\beta$ estradiol, progesterone and catecholamines. Active plasma renin concentration was determined by an immunoradiometric assay technique (Nichols Institute Diagnostics, Wychen, The Netherlands). Angiotensin II was assayed by radioimmunoassay (RLA) following Phenyl column extraction (Amersham Int, Amersham, UK). A solid-phase protein binding RIA (Diagnostic Products Corporation, LA, USA) assessed aldosterone. In our laboratory, by the methods employed, the tests do not cross-react with progesterone. $\alpha$-Atrial natriuretic peptide was analyzed by radioimmunoassay (Nichols Institute Diagnostics, Wychen, The Netherlands). Norepinephrine, epinephrine and dopamine were assessed by chromatograph after liquid-liquid extraction and derivatization with a selective fluorescent agent. Finally, serum 17- $\beta$-estradiol and progesterone were determined with a commercially available solid phase radioimmunoassay kit (DPC, Los Angeles, Cal, USA). Samples were collected on ice and centrifuged at $4{ }^{\circ} \mathrm{C}$ for $10 \mathrm{~min}$ at $1500 \mathrm{~g}$ immediately after sampling. All samples were stored deep-frozen $\left(-80^{\circ} \mathrm{C}\right)$ prior to assay. Urinary sodium concentration was measured by standard chemical procedures in a urine sample collected over the 24 hours preceding the measurement session.

Venous compliance, representing venous visco-elastic properties, was defined as the plethysmographically determined slope of the relationship of intravenous volume- and pressure changes (Periflow, JSI, Beerse, Belgium) 11, 12. The measurement procedure has been detailed previously and has a cocfficient of variation of $11.4 \%{ }^{11}$. 
Measurement of plasma volume. Since 2 of the 3 measurements took place in early pregnancy, plasma volume was determined with the dextran-70 indicator dilution method and expressed in $\mathrm{ml}$ per kilogram $\left(\mathrm{kg}\right.$ ) lean body mass $(\mathrm{LBM})^{13}$. Plasma volume was obtained by dividing the total injected dextran-70 by the virtual volume-specific dextran-70 concentration at time zero. The latter was obtained by extrapolation using the dextran-70 concentration determined at 10,20 and 30 minutes after bolus injection ${ }^{8,13}$.

Echocardiography to assess cardiac function was performed in semi-left lateral position, after completion of the plasma volume measurement and after 5 minutes of rest, using a cross-sectional, phased array echocardiographic Doppler system (Hewlett-Packard Sonos 2000 and 2500$)^{8}$. Cardiac output (CO, L. $\mathrm{min}^{-1}$ ) was calculated by multiplying strike volume $(\mathrm{ml})$ and heart rate (HR, beats per minute). In this formula, heart rate (HR) was obtained by taking the reciprocal of the mean of five consecutive R-R intervals on the ECG. Stroke volume was calculated by multiplying the aortic velocity integral and the aortic area. Aortic flow was measured across the aortic valves from an apical approach. The average area under the aortic velocity curve (aortic velocity integral) of five consecutive ejections was used to calculate stroke volume. Aortic valve diameter necessary for the calculation of the aortic area, was measured off-line at the orifice during systole using $\mathrm{M}$-mode. Cardiac index (CI, L. $\min ^{-1} \cdot \mathrm{m}^{-2}$ ) was calculated by dividing cardiac output by body surface area. Total peripheral vascular resistance (TPVR, dyne.s. $\mathrm{cm}^{-5}$ ) was calculated by dividing mean arterial blood pressure by cardiac output. The value used for mean arterial blood pressure (MAP) was obtained during the cardiac output measurement and was calculated as the mean of three consecutive recordings. Left atrial diameter was measured by 2-D echocardiography. Finally, we determined the ultrasonic diameter of the inferior vena cava ${ }^{7}$.

Statistical analysis: Data are presented as means \pm standard deviation unless otherwise stated. Differences between groups were tested with the Mann-Whitney-U Test, differences within groups between the follicular phase and other measurement sessions by Wilcoxon Matched-Pairs Signed-Ranks test, both tests with Bonferroni correction. Correlations, when calculated, between concomitantly measured potentially related variables, were tested by Spearman's Rank correlation analysis. The minimum detectable changes in the variables studied, between consecutive observations was calculated for the control group $(\mathrm{n}=10, \alpha=$ $0.05, \beta=0.10$ ), assuming a normal distribution. The obtained values were $5 \%$ for mean arterial pressure, $10 \%$ for heart rate, $8 \%$ for stroke volume, $15 \%$ for cardiac output, $15 \%$ for 
total peripheral vascular resistance, $9 \%$ for plasma volume, $12 \%$ for giomerular filtration rate, $16 \%$ for effective renal plasma flow, $15 \%$ for effective renal blood flow, $18 \%$ for renal vascular resistance and $38 \%$ for atrial natriuretic peptide. Similarly, we calculated the minimum detectable difference in these variables between the control group and the subgroups ( $\mathrm{n}=10, \alpha=0.05, \beta=0.10$ ), also assuming a normal distribution of the data. This led to the following percentages; $19 \%$ for mean arterial pressure, $22 \%$ for heart rate, $12 \%$ for stroke volume, $12 \%$ for cardiac output, $19 \%$ for total peripheral vascular resistance, $10 \%$ for plasma volume, $8 \%$ for glomerular filtration rate, $20 \%$ for effective renal plasma flow, $21 \%$ for effective renal blood flow, $27 \%$ for renal vascular resistance and $49 \%$ for atrial natriuretic peptide. In all analyses, we considered a p-value of less than 0.05 statistically significant.

\section{Results}

Among the 37 formerly preeclamptics, 10 subjects had hypertension and were assigned to the HYPERT subgroup. Among these hypertensive subjects, three were found to have a thrombophilic disorder as well, all in conjunction with hyperhomocysteinemia (30\%). Of the remaining 27 normotensive formerly preeclamptic subjects, 13 had one $(n=12)$ or more $(n=1)$ thrombophilic disorder(s). They were assigned to the THROMB subgroup. The other 14 had neither hypertension nor thrombophilia. They were assigned to the NONTHROMB subgroup. The demographic characteristics of all participants are listed in Table 1. The 3 subgroups of formerly preeclamptics and the controls were comparable with respect to age, height, parity and urinary sodium output. The subjects in the NONTHROMB subgroup had a higher body mass index. Obviously, mean arterial blood pressure was higher in the HYPERT subgroup as compared to controls.

Among the 37 formerly preeclamptic participants, $43 \%$ (16/37) had at least one thrombophilic disorder. In the subjects allocated to the THROMB subgroup, the antiphospholipid syndrome $(5 / 13,38 \%)$ and protein $S$ deficiency $(4 / 13,31 \%)$ were most common, followed by hyperhomocysteinemia $(2 / 13,15 \%)$, APC resistance $(2 / 13,15 \%)$ and protein $\mathrm{C}$ deficiency $(1 / 13,8 \%)$. All formerly preeclamptic women, which were diagnosed as having the anti-phospholipid syndrome, were IgG serotypes. We did not identify women with antithrombin deficiency. 
Table I: Demographic data (follicular phase) from the 3 subgroups of formerly preeclamptic women and the group of nomal parous controls. If a value is followed by an arrow, this particular variable is higher $(\uparrow)$ or lower $(\downarrow)$ than the one in the control group $(\mathrm{p}<0.05)$.

\begin{tabular}{|c|c|c|c|c|}
\hline$\cdots$ & controls & \multicolumn{3}{|c|}{ formerly preeclamptic } \\
\hline $\begin{array}{r}\ddots \\
\ddots \\
\end{array}$ & $\begin{array}{c}\ddots \\
(n=10)\end{array}$ & $\begin{array}{l}\text { THROMB } \\
(n=13) \\
\end{array}$ & $\begin{array}{l}\text { NONTHROMB } \\
(\mathrm{n}=14)\end{array}$ & $\begin{array}{l}\text { HYPERT } \\
(\mathrm{n}=10)\end{array}$ \\
\hline Age (years) & $31 \pm 2$ & $29 \pm 4$ & $29 \pm 3$ & $33 \pm 4$ \\
\hline Height $(\mathrm{cm})$ & $168 \pm 4$ & $168 \pm 5$ & $168 \pm 6$ & $165 \pm 5$ \\
\hline Body mass index $\left(\mathrm{kg} \cdot \mathrm{m}^{-2}\right)$ & $22 \pm 2$ & $22 \pm 3$ & $27 \pm 6 \uparrow$ & $26 \pm 7$ \\
\hline Parrity (median with range) & $1(1-2)$ & $1(\mathrm{I}-3)$ & $1(1-2)$ & $1(1-4)$ \\
\hline Mean arterial pressure $(\mathrm{mmHg})$ & $79 \pm 6$ & $82 \pm 6$ & $84 \pm 7$ & $104 \pm 9 \uparrow$ \\
\hline Natriuresis $\left(\operatorname{mmol} 24 \mathrm{~h}^{-1}\right)$ & $115 \pm 25$ & $94 \pm 32$ & $89 \pm 33$ & $99 \pm 22$ \\
\hline
\end{tabular}

The data regarding systemic hemodynamics are listed in Table II. Data collected during the follicular phase were defined as 'baseline'. Baseline systemic hemodynamics in the THROMB subgroup did not differ from those in the control group. On the other hand, in both the NONTHROMB and HYPERT subgroups, baseline cardiac output was higher and baseline plasma volume lower than in the control group. Baseline cardiovascular dimensions and venous compliance did not differ between groups. In early pregnancy, all groups responded with a rise in stroke volume, cardiac output, cardiac index and plasma volume, and a fall in total peripheral vascular resistance and mean arterial blood pressure. Heart rate had increased in all groups except HYPERT. Venous compliance had only increased in the HYPERT and control groups. At 7 weeks, venous compliance was lower in the NONTHROMB subgroup as compared to controls. Except for an increase in left atrial diameter in the NONTHROMB subgroup at 7 weeks gestational age, none of the central cardiovascular dimensions differed between groups or had changed consistently with pregnancy in the various groups.

The renal hemodynamic data are listed in Table III. Baseline renal data in THROMB and controls were comparable. In contrast, the NONTHROMB and HYPERT subgroup differed from controls by a lower glomerular filtration rate (only in NONTHROMB), effective renal plasma flow and effective renal blood flow, and a higher renal vascular resistance. 
Table II: Hemodynamic and vascular data obtained in the follicular phase (FP) of the menstrual period (MP) and at 5 and 7 weeks amenorrhea (AM5 and AM7). An arrow indicates higher ( $\uparrow$ ) or lower $(\downarrow)$ than the one in the control group in the corresponding phase $(p<0.05)$. The symbol * indicates the value in a particular subgroup to be different from that in the follicular phase $(p<0.05)$.

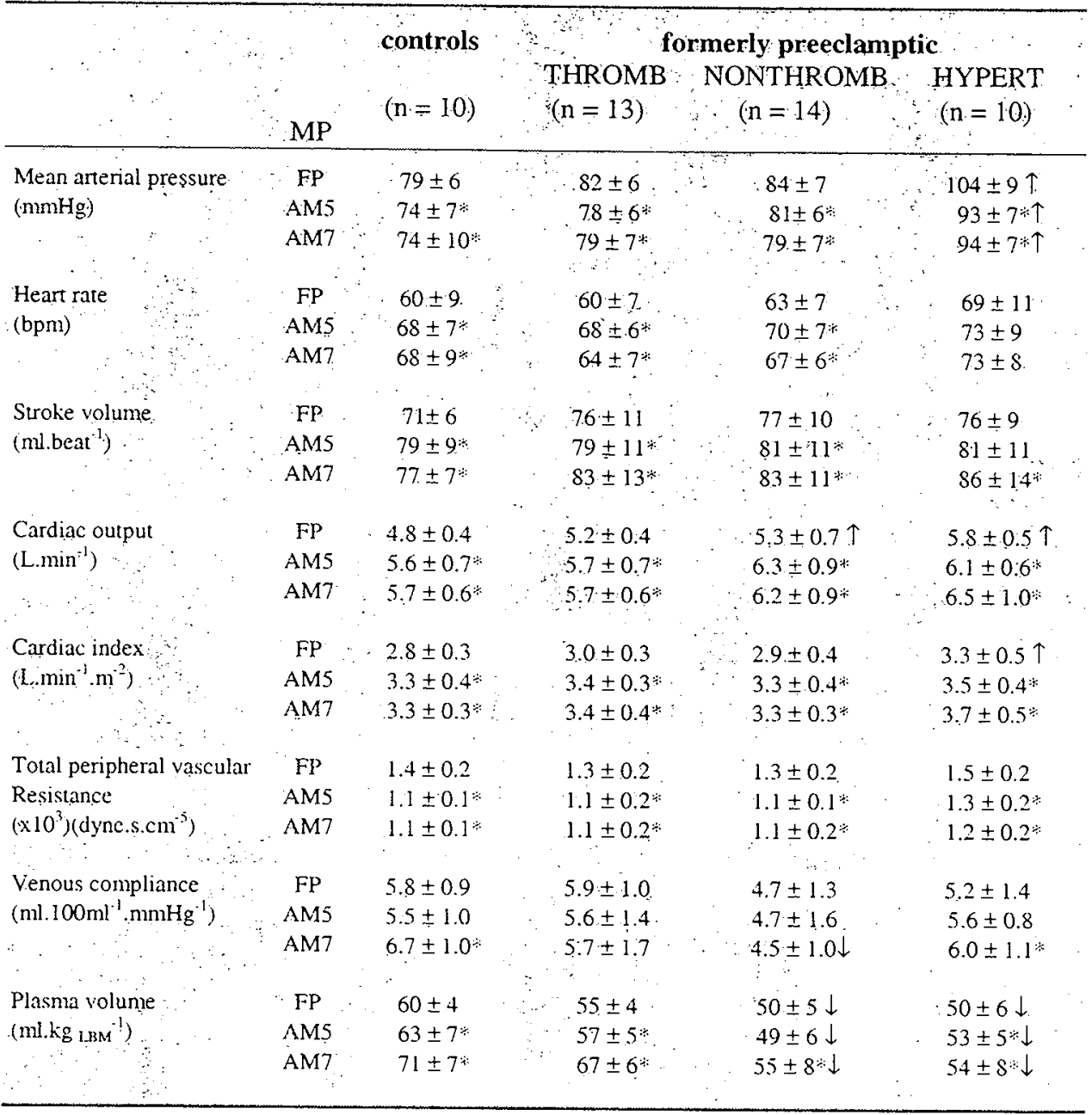

In early pregnancy, glomerular filtration rate, effective renal plasma and blood flow had increased, while renal vascular resistance and filtration fraction (all groups except NONTHROMB) had decreased. Throughout the measurement period, renal vascular resistance was consistently higher and effective renal blood flow was consistently lower in the NONTHROMB and HYPERT subgroups as compared to the control group. 
Table III: Renal hemodynamics obtained in the follicular phase (FP) of the menstrual period (MP) and at 5 and 7 weeks amenorrhea (AM5 and AM7). An arrow indicates higher $(\uparrow)$ or lower $(\downarrow)$ than the one in the control group in the corresponding phase $(p<0.05)$. The symbol * indicates the value in a particular subgroup to be different from that in the follicular phase $(p<0.05)$.

\begin{tabular}{|c|c|c|c|c|c|}
\hline$\therefore$ & $\mathrm{MP}$ & $\begin{array}{l}\text { controls } \\
(n=10)\end{array}$ & $\begin{array}{r}\text { forn } \\
\text { THROMB } \\
(n=13)\end{array}$ & $\begin{array}{l}\text { nerly preeclamp } \\
\text { NONTHROMB } \\
\qquad(n=14)\end{array}$ & $\begin{array}{l}\text { HYPERT } \\
(n=10)\end{array}$ \\
\hline $\begin{array}{l}\text { Glomerular filtration rate } \\
\left(\text { ml.min }{ }^{-1} .1 .73 \mathrm{~m}^{2}\right)\end{array}$ & $\begin{array}{l}\text { FP } \\
\text { AM5 } \\
\text { AM7 }\end{array}$ & $\begin{array}{l}124 \pm 7 \\
145 \pm 11 \% \\
157 \pm 14^{*}\end{array}$ & $\begin{array}{l}115 \pm 20 \\
137 \pm 24 \\
156 \pm 27\end{array}$ & $\begin{array}{l}111 \pm 11 \downarrow \\
130 \pm 7 * \downarrow \\
141 \pm 11 * \downarrow\end{array}$ & $\begin{array}{l}113 \pm 23 \\
136 \pm 21 \\
146 \pm 28\end{array}$ \\
\hline $\begin{array}{l}\text { Effective renal plasma flow } \\
\left(\text { ml.min }{ }^{-1} .1 .73 \mathrm{~m}^{-2}\right) \\
\vdots\end{array}$ & $\begin{array}{l}\text { FP } \\
\text { AM5 } \\
\text { AM7 }\end{array}$ & $\begin{array}{c}563 \pm 78 \\
758 \pm 72 \% \\
797 \pm 92 \%\end{array}$ & $\begin{array}{l}502 \pm 107 \\
676 \pm 131 * \\
777 \pm 169 \%\end{array}$ & $\begin{array}{l}474 \pm 70 \downarrow \\
645 \pm 113 \neq \downarrow \\
665 \pm 113 \downarrow\end{array}$ & $\begin{array}{l}42 \downarrow \pm 92 \downarrow \\
651 \pm 154 \\
671 \pm 125 \downarrow\end{array}$ \\
\hline $\begin{array}{l}\text { Effective renal blood flow. } \\
\left.\text { (ml.min }{ }^{-1} .1 .73 \mathrm{~m}^{2}\right)\end{array}$ & $\begin{array}{l}\text { FP } \\
\text { AM5 } \\
\text { AM7 }\end{array}$ & $\begin{array}{c}878 \pm 127 \\
1160 \pm 120 \\
1217 \pm 162\end{array}$ & $\begin{array}{c}796 \pm 190 \\
1035 \pm 230^{*} \\
1167 \pm 256^{*}\end{array}$ & $\begin{array}{c}753 \pm 110 \downarrow \\
1013 \pm 192 * \\
1028 \pm 170^{*} \downarrow\end{array}$ & $\begin{array}{l}691 \pm 157 \downarrow \\
1026 \pm 251 \% \\
1033 \pm 190 \%\end{array}$ \\
\hline $\begin{array}{l}\text { Renal vascular resistance } \\
\left(\mathrm{x} 10^{3}\right)\left(\text { dyne. }^{-5} \mathrm{~cm}^{-5} \cdot 1.73 \mathrm{~m}^{-2}\right) \\
\end{array}$ & $\begin{array}{l}\text { FP } \\
\text { AM5 } \\
\text { AM7 }\end{array}$ & $\begin{array}{l}7.1 \pm 1.3 \\
5.0 \pm 0.7^{*} \\
4.8 \pm 0.6^{*}\end{array}$ & $\begin{array}{l}8.7 \pm 2.3 \\
6.1 \pm 1.2 \\
5.4 \pm 1.3\end{array}$ & $\begin{array}{l}8.9 \pm 1.8 \uparrow \\
6.4 \pm 1.2 * \uparrow \\
6.1 \pm 1.1 \% \uparrow\end{array}$ & $\begin{array}{r}12.5 \pm 3.6 \uparrow \\
7.7 \pm 2.4 * \uparrow \\
7.2 \pm 1.5 * \uparrow\end{array}$ \\
\hline $\begin{array}{l}\text { Filtration fraction } \\
\left.\text { (GFR.ERPF }{ }^{-1}\right) \\
\quad \vdots\end{array}$ & $\begin{array}{l}\text { FP } \\
\text { AM5 } \\
\text { AM7 }\end{array}$ & $\begin{array}{l}0.22 \pm 0.02 \\
0.19 \pm 0.02 \\
0.20 \pm 0.03\end{array}$ & $\begin{array}{l}0.23 \pm 0.03 \\
0.21 \pm 0.03 \\
0.20 \pm 0.02\end{array}$ & $\begin{array}{l}0.24 \pm 0.03 \\
0.21 \pm 0.04 \\
0.22 \pm 0.03\end{array}$ & $\begin{array}{l}0.27 \pm 0.04 \uparrow \\
0.21 \pm 0.04 \\
0.22 \pm 0.04\end{array}$ \\
\hline $\begin{array}{l}\text { Sodium excretion } \\
\left.\text { (nmol. } 24 \mathrm{~h}^{-1}\right)\end{array}$ & $\begin{array}{l}\mathrm{FP} \\
\mathrm{AM} 5 \\
\mathrm{AM} 7\end{array}$ & $\begin{array}{l}115 \pm 25 \\
134 \pm 49 \\
157 \pm 77\end{array}$ & $\begin{array}{r}94 \pm 32 \\
104 \pm 40 \\
95 \pm 34\end{array}$ & $\begin{array}{r}89 \pm 33 \\
108 \pm 57 \\
117 \pm 49\end{array}$ & $\begin{array}{r}99 \pm 22 \\
116 \pm 42 \\
99 \pm 23\end{array}$ \\
\hline
\end{tabular}

The endocrine data are listed in Table IV. The baseline values for the volume-regulatory hormones, catecholamines and sex steroids were comparable in the 4 groups except for a higher norepinephrine in the HYPERT subgroup as compared to the control group. All groups responded to pregnancy with a similar rise in renin-angiotensin-aldosterone system activity and sex steroids. Only in HYPERT and NONTHROMB subjects, these changes were accompanied by a rise in $\alpha$-atrial natriuretic peptide. In these latter 2 groups the norepinephrine level in the 7 th week of gestation was lower than that in the follicular phase and lower than that in 7 weeks pregnant controls. Changes in epinephrine and dopamine were inconsistent. 
Table IV: Endocrine variables as determined in the follicular phase (FP) of the menstrual period (MP) and at 5 and 7 weeks amenorrhea (AM5 and AM7). An arrow indicates higher ( $\uparrow$ ) or lower ( $\downarrow$ ) than the one in the control group in the corresponding phase $(p<0.05)$. The symbol $:$ indicates the value in a particular subgroup to be different from that in the follicular phase $(p<0.05)$.

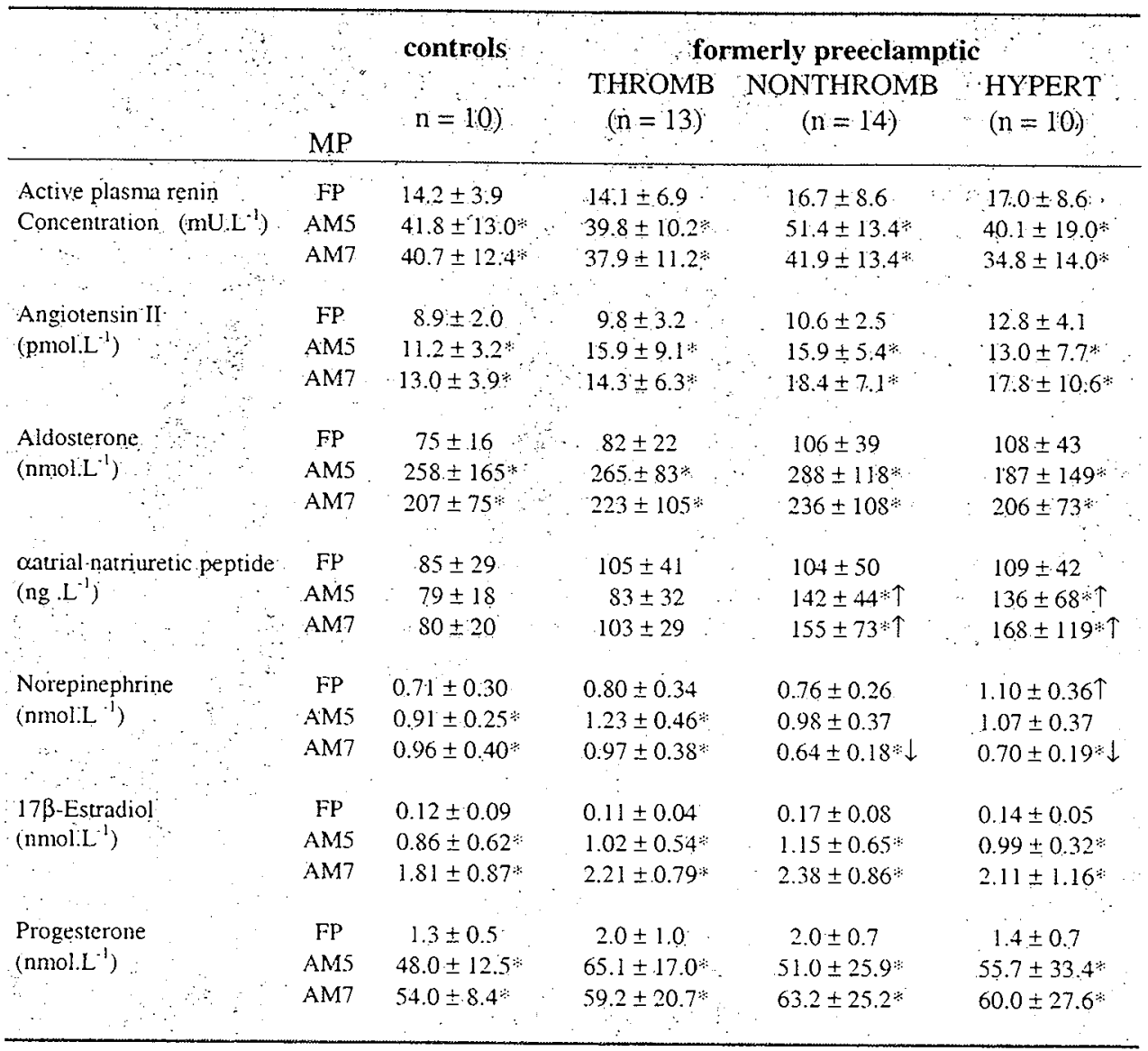

The change in $\alpha$-atrial natriuretic peptide in early pregnancy correlated with various changes in hemodynamic and renal adaptation. We noticed that the larger the fall in $\alpha$-atrial natriuretic in early-pregnancy, the greater were the concomitant rises in effective renal plasma flow $(r=-0.32, p<0.05)$, and heart rate $(r=-0.32 ; p<0.05)$ but also the higher were plasma volume $(r=-0.35 ; p<0.05)$, venous compliance $(r=-0.33 ; p<0.05)$ and renal hemodynamics in the $7^{\text {th }}$ week of pregnancy (effective renal plasma flow: $r=-0.42, p<0.01$; effective renal blood flow: $\mathrm{r}=-0.36, \mathrm{p}<0.05$; and glomerular filtration rate: $\mathrm{r}=-0.31, \mathrm{p}<$ $0.05)$. 
In addition, at 7 weeks pregnancy, the circulating level of $\alpha$-atrial natriuretic peptide inversely correlated with the 7 weeks' plasma volume $(r=-0.49, p<0.001)$ (Figure la), renal hemodynamics (effective renal plasma flow: $r=-0.49$ (Figure $1 b$ ), $p<0.001$; effective renal blood flow: $r=-0.40, p<0.01$; glomerular filtration rate: $r=-0.40, p<0.01$ ) and total peripheral vascular resistance $(r=-0.29, p<0.05)$. On the other hand, at this gestational age, the $\alpha$-atrial natriuretic peptide correlated positively with left atrial diameter $(r=0.51, p$ $<0.0001)$, stroke volume $(r=0.52, \mathrm{p}<0.0001)$ (Figure $1 \mathrm{c}$ ), cardiac output $(\mathrm{r}=0.30, \mathrm{r}<$ $0.05)$ and left ventricular work $(r=0.32, p<0.05)$.

Figure 1a: Linear regression analysis of plasma volume (ml.kg ${ }^{-1}$ lean body mass) as a function of $\alpha$ atrial natriuretic peptide (nmol. $\left.]^{-1}\right)$ at 7 weeks of gestation. $(y=-0.11 x+74, \mathrm{r}=0-0.49$, $\mathrm{p}<0.001)$.

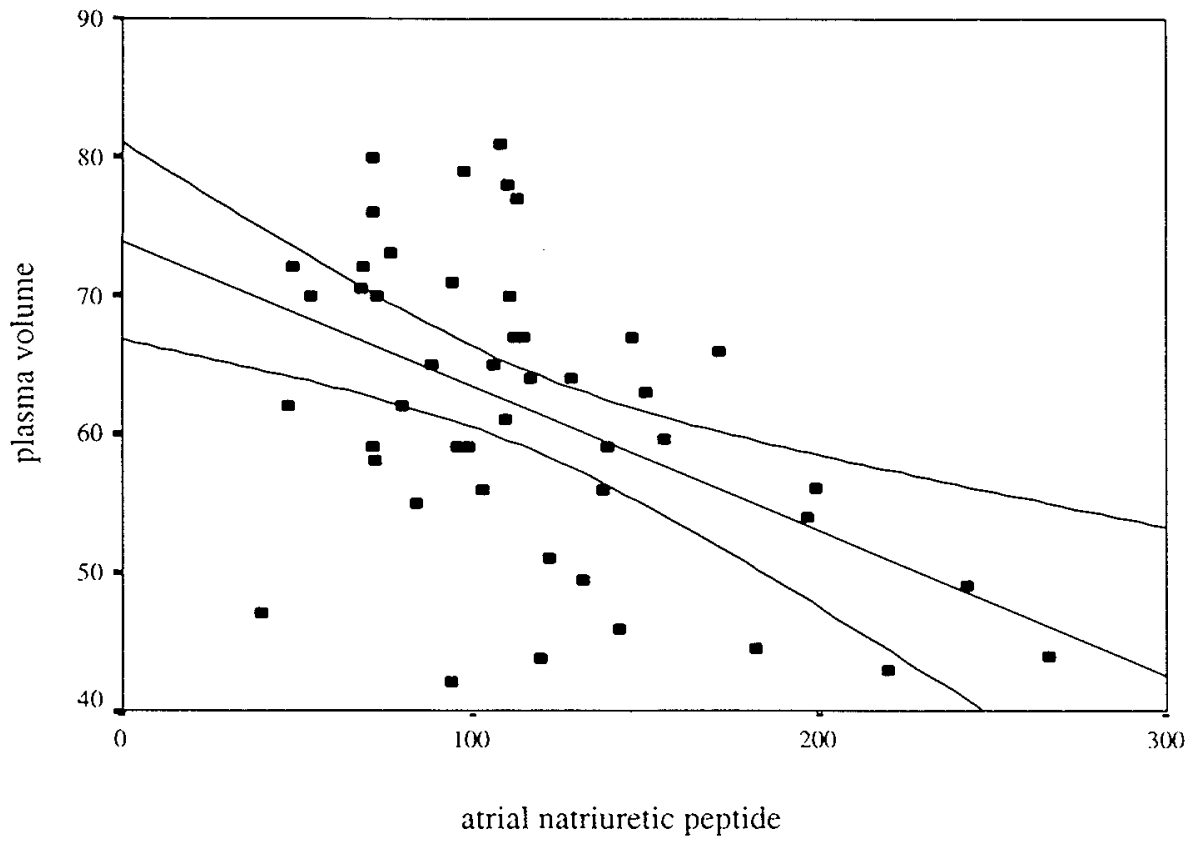


Figure 1b: Linear regression analysis of effective renal plasma flow $\left(\mathrm{ml}_{\mathrm{min}} \mathrm{m}^{-1} .1 .73^{-2}\right)$ as a function of $\alpha$-atrial natriuretic peptide (nmol. ${ }^{-1}$ ) at 7 weeks of gestation. $(y=-1.5 x+903, \mathrm{r}=-0.49, \mathrm{p}<$ 0.001 ).

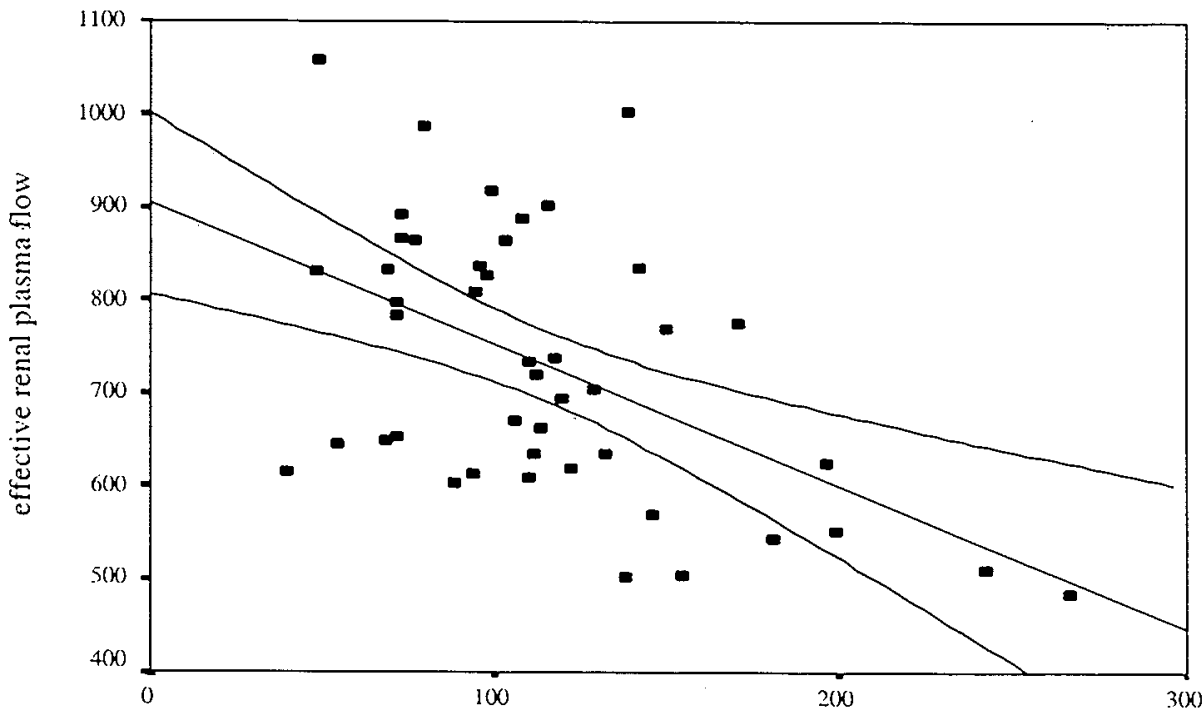

atrial natriuretic peptide

Figure 1c: Linear regression analysis of stroke volume $(\mathrm{ml})$ as a function of $\alpha$-atrial natriuretic peptide $\left(\right.$ nmol. $\left.1^{-1}\right)$ at 7 weeks of gestation. $(y=0.11 x+70, r=0.52, p<0.0001)$.

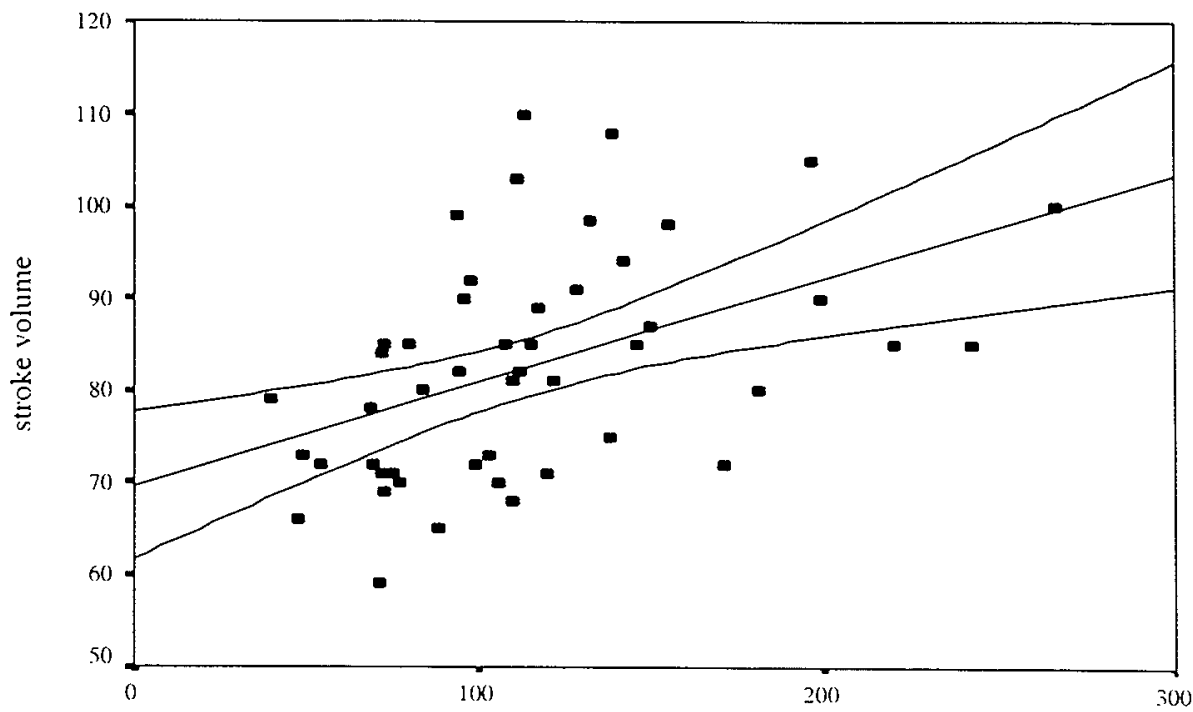

atrial natriuretic peptide 


\section{Discussion}

It is generally accepted that the clinical expression of preeclampsia arises from endothelial dysfunction, a condition which can be provoked by excessive exposure to biochemical (i.e. thrombophilia, diabetes mellitus, hypercholesterolemia) and/or mechanical stressors (i.e. hypertension, renovascular disease) ${ }^{14}$. Therefore it is plausible that preeclampsia is a disease state superimposed upon a pre-existing disorder, with "endothelial decompensation" representing the common endpoint of different pathophysiologic pathways. With this concept as a starting point, we subdivided our group of formerly preeclamptic subjects into a HYPERT - and normotensive subgroup, further subdivided into a group of normotensive formerly preeclamptic women either with or without thrombophilia (THROMB and NONTHROMB, respectively). Since preeclampsia often is preceded by early-pregnancy hemodynamic and renal maladaptation as compared to uncomplicated pregnancies, these findings raised the question whether this adaptation, as seen in healthy women, would be preserved in the above mentioned formerly preeclamptic subgroups. To elucidate this pathogenetic problem, we performed 3 consecutive hemodynamic and renal measurements, once in the pre-pregnant state and twice in early pregnancy, in women at risk for preeclampsia on the basis of their medical history.

The inter-group differences in demographic variables were small and inconsistent except for a higher body mass index in the NONTHROMB subgroup. Most women in the THROMB subgroup had thrombophilia in conjunction with the antiphospholipid syndrome, protein-Sdeficiency or hyperhomocysteinemia, an observation in line with previous reports ${ }^{1,2}$. An important finding in the present study was the higher cardiac output and renovascular resistance, and lower plasma volume in the non-pregnant state, in HYPERT and NONTHROMB subgroups as compared to controls. Nevertheless, at first sight these differences did not seem to have affected the early-pregnancy adaptation which also have been reported by others 7. 15. 16: Both controls and THROMB participants as well as HYPERT and NONTHROMB subjects responded to pregnancy by a rise in cardiac output, renal hemodynamics, RAAS activity and plasma volume expansion, together with a fall in mean arterial blood pressure and total peripheral vascular resistance. However, the response to pregnancy in the latter two groups differed in one important aspect from that in controls and THROMB: The early-pregnancy rise in circulating level of $\alpha$-atrial natriuretic peptide was only observed in HYPERT and NONTHROMB, a phenomenon, at 7 weeks pregnancy accompanied by an inverse correlation between the achieved plasma volume and the 
circulating level of $\alpha$-atrial natriuretic peptide. These data support the concept that in these subgroups elevated $\alpha$-atrial natriuretic peptide levels could have interfered with the initial plasma volume expansion. The absence of an increase in $\alpha$-atrial natriuretic peptide in early normal pregnancy has been observed previously ${ }^{15}$. In NONTHROMB the rise in $\alpha$-atrial natriuretic peptide was paralleled not only by a rise in left atrial diameter, but also by a lack of improvement in venous compliance. These phenomena suggest that $\alpha$-atrial natriuretic peptide increases in response to a relative venous overfill. In this reasoning, early-pregnancy plasma volume expansion may be inhibited by a lack of concomitant increase in venous storage capacity as a consequence of either the absent rise in venous compliance or of an adverse response of the autonomic control of the cardiovascular system. As a consequence, the rise in plasma volume is inadequately accommodated in the venous system causing the venous pressure to increase and with it the $\alpha$-atrial natriuretic peptide release.

It is known that in the early stages of essential hypertension plasma volume is reduced ${ }^{17}$. Plasma volume was indeed reduced in the subjects in the HYPERT subgroup, possibly as an early compensation to keep arterial blood pressure in the normal range in spite of the presence of blood-pressure raising stimuli. It is unlikely that the lower plasma volume was secondary to the awareness of having hypertension as in only 2 of the 10 women in the HYPERT subgroup the diagnosis "hypertension" was made prior to the study ${ }^{18}$. Most data on bascline hemodynamic and renal variables, plasma volume and hormones in the NONTHROMB subgroup were intermediate between HYPERT and controls. In addition, the NONTHROMB subjects resembled the HYPERT subjects with respect to the abnormal rise in circulating $\alpha$-atrial natriuretic peptide. The resemblance in laboratory findings with the HYPERT subgroup led us to classify these normotensive women as "latent" hypertensives 8 . On the basis of the results of the present study we postulate the following sequence of events in normal and complicated pregnancy. The early-pregnancy endocrine environment triggers by some still unknown mechanism, a generalized fall in systemic vascular tone. This is accompanied by a higher compliance of the arteries, veins and possibly also the myocardium, together with vasodilation in the microcirculation. As a consequence, the relative filling state of the vascular bed decreases giving rise to a fall in both cardiac preload and afterload. The cardiovascular regulatory systems are activated in the arteries (baroreceptors), the kidneys (renin-angiotensin-aldosterone system) and the central veins and right atrium (stretch receptors). Furthermore, concomitantly with the fall in vascular tone, 
resetting and alteration of these blood pressure regulating systems occurs. These latter effects include firstly an altered baroreceptor response to blood pressure variation, secondly a reduction in angiotensin-sensitivity and renal sensitivity to $\alpha$-atrial natriuretic peptide, and thirdly resetting of the osmoreceptor without concomitant change in its sensitivity $6,19,20,21$. The rise in baroreceptor activity, triggered by the afterload reduction, will raise heart rate, cardiac contractility and mobilization of venous blood towards the arterial vascular compartment. Meanwhile, increased renin-angiotensin-aldosterone system activity and nonosmotic vasopressin release accelerates volume retention and restoration of the cardiac preload. A concomitant pregnancy-related decrease in atrial responsiveness to stretch suppresses the release of $\alpha$-atrial natriuretic peptide during the gradual restoration of the central venous filling state in conjunction with the ongoing plasma volume expansion ${ }^{22}$. In HYPERT and NONTHROMB subjects the effects on these systems seems to be insufficient and paradoxical, as evidenced by the increase in $\alpha$-atrial natriuretic peptide, a decrease in nor-epinephrine and a lower plasma volume at 7 weeks as compared to controls and THROMB. The $\alpha$-atrial natriuretic peptide level not only provides an indirect estimate for vascular filling state, it also correlates positively with changes in right atrial pressure $22,23,24$. A baroreceptor-mediated rise in sympathetic tone can be expected to raise cardiac preload and with it right atrial pressure. The latter effect can be counterbalanced by an increased cardiac contractility and heart rate to prevent atrial overflow and increased release of $\alpha$-atrial natriuretic peptide. Since an isovolumetric load induces a lower pressure rise at increased compliance, rise in arterial compliance can be expected to elevate baroreceptor activity when stroke volume remains unaltered. In contrast, reduced arterial compliance can be expected to lower baroreceptor activity. Therefore, a reduction in vascular resistance, compensated by elevation in stroke volume without elevation of arterial compliance, can be expected to lower baroreceptor activity when arterial filling is restored. In that case, to compensate for a reduction in afterload, the required higher cardiac output can only be maintained at the expense of an elevated stroke volume and atrial diameter, leading to the paradoxical enhanced release of $\alpha$-atrial natriuretic peptide and a reduced release in norepinephrine as observed in NONTHROMB and HYPERT women. Even though pregnancy is associated with an attenuated renal response to $\alpha$-atrial natriuretic peptide ${ }^{19}$, its rise can be expected to alter volume regulation, which is supported by the correlation's between atrial natriuretic peptide and renal, cardiac, volume and vascular adaptation. The rise in venous compliance, 
as observed in HYPERT subjects, may be the result of the anti-hypertensive treatment given after the non-pregnant measurement session.

In summary, the pattern of hemodynamic and volume response to pregnancy is similar in formerly preeclamptic subjects and controls. However, HYPERT and NONTHROMB subjects differed from controls and THROMB by a paradoxical early-pregnancy rise in $\alpha$ atrial natriuretic peptide, together with a lower plasma volume at 7 weeks.

\section{Acknowledgments}

We like to thank APG Hoeks from the department of Biophysics for his careful review of this paper and HJA Schouten from the department of Methodology and Statistics for his valuable contributions to the statistical analysis. 


\section{References}

1. van Pampus MG, Dekker GA, Wolf H, Huijgens PC, Koopman MM, von Blomberg BM, Buller HR. High prevalence of hemostatic abnormalities in women with a history of severe preeclampsia. Am J Obstet Gynecol 1999; 180(5):1146-50.

2. Kupferminc MJ, Eldor A, Steinman N, Many A, Bar-Am A, Jaffa A, Fạit G, Lessing JB. Increased frequency of genetic thrombophilia in women with complications of pregnancy. $\mathrm{N}$ Eng J Med 1999; 340:9-13.

3. Zhoe Y, Damsky CH Chiu K, Roberts JM and Fisher SJ. Preeclampsia is associated with abnormal expression of adhesion molecules by invasive cytotrophoblasts. J Clin Invest 1993; 91: $950-960$.

4. Duvekot JJ, Cheriex EC, Pieters FAA, Menheere PPCA, Peeters LLH. Maternal volume homeostasis in early pregnancy in relation to fetal growth restriction. Obstet Gynecol 1995; 85: 361-367.

5. Schrier RW, Briner VA. Peripheral arterial vasodilatation hypothesis of sodium and water retention in pregnancy: implications for pathogenesis of preeclampsia-eclampsia. Obstet Gynecol 1991;77:632-9.

6. Schrier RW, Dür JJ, Pregnancy: an overfill or underfill state. Am J Kidney Dis 1987; 9:284-9.

7. Duvekot JJ, Cheriex EC, Pieters FAA, Peeters LLH. Early-pregnancy changes in hemodynamics and volume homeostasis are consecutive adjustments triggered by a primary fall in systemic vascular tone. Am J Obstet Gynecol 1993;169:1382-1392.

8. Spaanderman MEA, Ekhart THA, van Eyck J, Cheriex EC, de Leeuw PW, Peeters LLH. Asymptomatic ex-preeclamptic women have latent hemodynamic abnormalities. Am J Obstet Gynecol 2000: 182;101-107.

9. Sibai BM. Prevention of preeclampsia: a big disappointment. Am J Obstet Gynecol 1998; 179:1275-78.

10. National High Blood Pressure Education Program Working Group Report on High Blood Pressure in Pregnancy. Am J Obstet Gynecol 1990; 163:1691-1712.

11. Kooman JP, Wijnen JAG, Draaijer P, Van Bortel LMAB, Glad ziwa U, Peltenburg HG, Struyker-Boudier HAJ, Van Hooff JP, Leunissen KML. Compliance and reactivity of the peripheral venous system in chronic intermittent hemodialysis. Kidney Int 1992; 41:1041-1048.

12. Spaanderman MEA, Willekes C, Hoeks APG, Ekhart THA, Peeters LLH. The effect of pregnancy on the compliance of large arteries and veins in normal parous controls and formerly preeclamptics. Am J Obstet Gynecol 2000; 183:1278-86.

13. van Kreel BK, van Beek E, Spaanderman MEA, Peeters LLH. The validity of plasma volume measurements with dextran-70 instead of ${ }^{125}$ I-Albumen as indicator. Clin Chim Acta $1998 ; 275(1): 71-80$.

14. Roberts JM. Endothelial dysfunction in preeclampsia. Semin Reprod Endocrinol 1998;16:5-15.

15. Chapman AB, Abraham WT, Zamudio S, Coffin C, Merouani A, Young D, Johnson A, Osoria F, Goldberg C, Moore LG, Dahms T, Schrier RW. Temporal relationships between hormonal and hemodynamic changes in early human pregnancy. Kidney Int 1998: 54: 2056-2063.

16. Easterling TR, Bencdetti TJ, Schmucker BC, Millard SP. Maternal hemodynamics in normal and preeclamptic pregnancies: A longitudinal study. Obstet Gynecol 1990;76:1061-1069.

17. Lebel M, Grose JH, Blais R. Increased hematocrit with normal red blood cell mass in early borderline essential hypertension. Clin Exp Hypertens 1989; 11:1505-1514. 
18. Rostrup M, Mundall HH, Westheim A, Eide I. Awareness of high blood pressure increases arterial plasma catecholamines, platelet noradrenaline and adrenergic responses to mental stress. J Hypertension 1991;9:159-166.

19. Omer S, Vaillancourt P, Peri KG, Varma DR, Mulay S. Downregulation of renal atrial natriuretic factor receptors and receptor mRNAs during rat pregnancy. Am J Physiol 1997: 272: F87-93.

20. Ekholm EM, Piha SJ, Erkkola RA, Antila KJ. Autonomic cardiovascular reflexes in pregnancy. A longitudinal study. Clin Auton Res 1994; 4:161-5.

21. Gant NF, Daley GL, Chand S, Whalley PJ, MacDonald PC. A study of angiotensin II pressor response throughout primigravid pregnancy. J Clin Invest 1973; 52:2682-9.

22. Zhang $Y$, Novak $\mathbf{K}$, Kaufman S. Atrial natriuretic factor release during pregnancy in rats. $\mathbf{J}$ Physiol (Lond) 1995; 488: 509-514.

23. Leunissen KML, Menheere PPCA, Cheriex EC, van den Berg BW, Noordzij TC, van Hooff JP. Plasma alpha-human atrial natriuretic peptide and dry weight in chronic hemodialysis. Nephr Dial Transpl 1989; 4:382-386.

24. Hirata $Y$, Ishii $M$, Matsuoka $H$, Sugimoto $T$, lizuka $M$, Uchida $Y$, Serizawa $T$, Sato $H$, Kohmoto O, Mochizuki T, Sugimoto T, Miyata A, Kangawa K, Matsuo H. Plasma concentrations of $\alpha$-human atrial natriuretic polypeptide and cyclic GMP in patients with heart disease. Am Heart J 1987; 113:1463-1469. 


\section{Chapter 7}

\section{PRE-PREGNANT PREDICTION OF RECURRENT PREECLAMPSIA AND/OR FETAL GROWTH RESTRICTION IN FORMERLY PREECLAMPTIC WOMEN}

Spaanderman MEA, Aardenburg $R$, Ekhart THA, van Eyndhoven HWF, van der Heijden OWH, van Eyck J, de Leeuw PW, Peeters LLH.

Departments of Obstetrics and Gynecology and Internal Medicine, Academic Hospital Maastricht and Sophia Hospital Zwolle, The Netherlands.

Submitted 


\section{Abstract}

Background In the last decade evidence is accumulating that preeclampsia is superimposed upon a preexisting hemodynamic, hemostatic, autoimmune or metabolic disorder. In this study we tested the hypothesis that in formerly preeclamptic subjects certain abnormalities in hemodynamic and hemostatic function as measured under non-pregnant conditions predict the development of hypertensive disorders and/or fetal growth restriction in the subsequent pregnancy.

Methods In 250 non-diabetic formerly preeclamptic women and 15 normal parous controls, we measured the following variables at least 5 months postpartum, at day $5( \pm 2)$ of the menstrual cycle: Mean arterial pressure, heart rate, cardiac output, central cardiovascular dimensions, venous compliance, plasma volume, glomerular filtration rate, effective renal plasma flow, 17ß-estradiol and progesterone, the hormones of the renin-angiotensin-aldosterone (RAAS) axis and $\alpha$-atrial natriuretic peptide. In the subsequent pregnancy we determined, birth weight and birth weight centile, recurrence rate of prematurity, of fetal growth restriction and of incidence of pregnancy-induced hypertension, preeclampsia and HELLP-syndrome. Inclusion for final analysis required a subsequent singleton pregnancy, established within one year following the pre-pregnant evaluation and ongoing beyond 16 weeks gestation. As a consequence, 57 formerly preeclamptic women and 12 controls could be included for final analysis. All formerly preeclamptic participants received aspirin throughout pregnancy. Furthermore, those with thrombophilia, hyperhomocysteinemia and preexistent hypertension were treated with low molecular-weight heparin, with pyridoxine and folic acid supplementation and with antihypertensives, respectively.

Results Among 250 formerly preeclamptic women, $202(81 \%)$ were normotensive and 48 (19\%) hypertensive. Furthermore, $151 / 250(60 \%)$ formerly preeclamptic women had a thrombophilic disorder, whereas 71/250 (28\%) had neither thrombophilia nor hypertension. In controls neither hypertension nor thrombophilia was observed. Fifty-seven (23\%) formerly preeclamptic participants and $12(80 \%)$ controls succeeded in establishing an ongoing 
pregnancy within one year. From this subset of formerly preeclamptic women, $12(21 \%)$ were hypertensive (HYPERT), 23 (20\%) normotensive thrombophilic (THROMB) and 22 (39\%) normotensive nonthrombophilic (NONTHROMB). The latter subgroup was more obese than controls. The HYPERT and NONTHROMB subgroups differed from controls, by a higher non-pregnant cardiac output, lower renal hemodynamic function, a lower plasma volume and a lower venous compliance. The THROMB subgroup did not differ from controls for all measured variables. With respect to pregnancy outcome, the women in all formerly preeclamptic subgroups gave birth to an infant with a lower birth-weight centile relative to controls. The incidence of pregnancy-induced hypertension was the highest in the NONTHROMB subgroup $(73 \%)$ and the lowest in the THROMB participants (44\%). Preeclampsia with or without the HELLP-syndrome recurred in $13 \%, 23 \%$ and $33 \%$ of the participants in the THROMB, the NONTHROMB and the HYPERT subgroup, respectively. Predisposing factors differed between these three risk groups. In THROMB, a low pre-pregnant plasma volume predisposed for pregnancy-induced hypertension, preeclampsia and HELLP syndrome. In NONTHROMB women, an elevated cardiac output and cardiac index prior to pregnancy were associated with a higher incidence of pregnancy-induced hypertension. Finally, in HYPERT participants, we noticed that a higher pre-pregnant blood pressure was associated with a higher recurrence rate of preeclampsia.

Conclusion Pre-pregnant hemodynamic, renal, metabolic and clotting variables in formerly preeclamptic women can predict hypertensive complications and fetal growth restriction in the subsequent pregnancy. 


\section{Chapter 7}

\section{Introduction}

High blood pressure complicates almost 10 percent of all pregnancies ${ }^{1}$. Together with obstetric hemorrhage, embolism and obstetric infection, it is the most common cause of maternal mortality ${ }^{2}$. It is also an important cause of perinatal mortality and morbidity, because it predisposes for fetal growth restriction and iatrogenic preterm birth.

In recent years, evidence is accumulating that particularly women with a preexisting vascular, metabolic or clotting disorder are prone to pregnancy-related hypertensive syndromes $3,4,5,6,7$. The latter suggests that in these cases the preexistent disorder predisposes for "endothelial decompensation" in pregnancy, the common endpoint of different pathophysiologic pathways in pregnancy-related hypertensive syndromes $\$$. However, in most studies, subgroups of patients at risk were identified only after their complicated pregnancy. It is not clear whether the risk conditions identified, do indeed predispose for recurrent vascular complications in a next pregnancy, and if so, whether the recurrence rate differs between different disorders. Such information would be essential to develop a predictive test for formerly preeclamptic women seeking counseling with respect to a next pregnancy. In addition, it would contribute to our understanding of the pathogenesis of the vascular complications of pregnancy.

Taking a preexisting risk condition as a starting point ${ }^{6}$, the following questions emerge: Firstly, what is the recurrence rate of hypertensive complications in a subsequent pregnancy for certain identifiable risk conditions? Secondly, does the presence of more than one disorder influence this recurrence rate? And thirdly, does the severity of the vascular complications in the preceding pregnancy predict the development of recurrent disease in a subsequent pregnancy ?

The objective of the present study was to test the hypothesis that in formerly preeclamptic women, hemodynamic - hemostatic, metabolic and volume variables determined in the follicular phase of the menstrual cycle can be used as predictors for recurrent hypertensive disorders and/or fetal growth restriction in a subsequent pregnancy. To this end, we determined in formerly preeclamptic women and normal parous controls clotting function, central and renal hemodynamics, venous compliance, plasma volume and a number of neurohumoral factors in the follicular phase of one of the menstrual periods that preceded the subsequent pregnancy. Subsequently, we recorded the recurrence rate of hypertensive complications and/or fetal growth restriction in the next pregnancy. 


\section{Methods}

\section{Selection of patients.}

250 formerly preeclamptic, non-diabetic women and 15 normal parous controls participated in this study. Data acquisition was initiated at least 5 months postpartum. Formerly preeclamptic women were recruited from our outpatient clinic at the postpartum follow-up. Controls were recruited by advertisement. Preeclampsia and (pregnancy-induced) hypertension were defined according to the criteria of the National High Blood Pressure Education Program Working Group Report on High Blood Pressure in Pregnancy '. Therefore, hypertension was defined as a mean systolic - and/or a mean diastolic arterial blood pressure higher than $140 \mathrm{mmHg}$ or higher than $90 \mathrm{mmHg}$, respectively, using all of the Dinamap recordings accumulated at the day of the experiment. We defined fetal growth restriction on the basis of the birth of a baby with a neonatal birth weight below the $10^{\text {th }}$ centile. All experiments were preceded by one week of standardized sodium intake of $100 \mathrm{mmol}$ per day, a figure that corresponds with the mean sodium intake in our population. Quantification of the 24-hour urinary sodium output on the day before the experiment was performed to estimate compliance with the diet. None of the participants used vitamin supplements or any other medication in the two weeks prior to measurement. Women on antihypertensive drugs discontinued this medication at least one week prior to the study session. After an overnight fast, participants were tested for thrombophilia, hemodynamic and renal function. Thrombophilia was defined as a condition characterized by the presence of at least one clotting disorder known to be associated with an increased risk of venous thrombo-embolism. Inclusion for final analysis required the establishment of an ongoing (>16 weeks gestational age) singleton pregnancy within one year after the pre-pregnant measurements. As a consequence, 57 formerly preeclamptic women and 12 controls could be included for final analysis. After the measurement sessions, formerly preeclamptic women were managed as illustrated in Figure 1. All subjects were Caucasian. Those who smoked refrained from smoking during pregnancy. All participants gave written informed consent. The hospital's medical-ethical committee approved the study.

\section{Experimental procedure}

\section{Methods}

The methodology of the measurements and calculations with respect to the thrombophilic screening and hemodynamic and renal function have been detailed elsewhere ${ }^{6}$. 
Thrombophilic screening: Anticardiolipin antibodies were determined spectrophotometrically by enzyne-linked immunoassay. Lupus anticoagulant was determined by mixing 1:1 patient and pooled normal plasma after finding a prolonged partial thromboplastin time. Subsequently, a thromboplastin dilution test was performed by measuring prothrombin time with progressively diluted thromboplastin. Lupus anticoagulant was considered to be present when all assays were positive. We defined the antiphospholipid syndrome as the condition where the titer of the circulating anti-cardiolipin antibodies was higher than 10 GPL for IgG antiphospholipid antibodies and 6 MPL for IgM antiphospholipid antibodies.

Coagulation tests were performed after a venous puncture. After elimination of platelets, samples were stored at $-80^{\circ} \mathrm{C}$ prior to assay. Protein $\mathrm{C}$ activity was determined with Coamate protein C (Chromogenix, Mölndal, Sweden). Total protein $\mathrm{S}$ antigen and free protein $\mathrm{S}$ were measured by an enzyme- linked immunosorbent assay (ELISA) (DAKO, Glostrup, Denmark). Activated protein $C$ resistance was quantified by a chromogenic APCresistance assay. Antithrombin activity was assayed with chromogenic substrate S-2765 (Chromogenix, Mölndal, Sweden).

A methionine-loading test was used to diagnose hyperhomocysteinemia. Homocysteine was measured by high-performance liquid chromatography with fluorescence detection. During the test participants used a standard low-methionine breakfast and lunch. Individuals were considered to have hyperhomocysteinemia when fasting and/or post-load plasma homocysteine levels were more than 2 standard deviations higher than the mean of the laboratory control group.

Measurement of blood pressure and renal hemodynamics: In the mid-follicular phase (day 5 \pm 2 ) of the menstrual period these measurements were performed under standardized environmental conditions in a temperature-controlled room $\left(25-26^{\circ} \mathrm{C}\right)$ with as little as possible external disturbances. The measurement session started at 08:00 AM, with the insertion of a 20 -gauge catheter into a vein of the right forearm, to enable determination of renal function as detailed below. A second catheter was inserted into a vein of the contralateral forearm so as to collect blood samples. Participants did not drink caffeine-or alcoholcontaining beverages and refrained from smoking and eating for at least 10 hours before the experiment. Throughout the measurement session, subjects were in supine position on a comfortable bed. Arterial blood pressure and heart rate were recorded intermittently by a semi-automatic oscillometric device (Dinamap Vital Signs Monitor 1846, Critikon, Tampa, 
FL, USA), only interrupted during blood sampling and during the echocardiographic measurements (see below). Effective renal plasma flow and glomerular filtration rate were measured by continuous infusion of PAH (PAH: para-aminohippurate sodium; MSD, West Point, PA, USA) and inulin (Inutest, Laevosan Gesellschaft, Linz, Austria), respectively. Both variables were corrected for body surface area and expressed in $\mathrm{ml.min} \mathrm{min}^{-1} .1 .73 \mathrm{~m}^{-2}$. Effective renal blood flow was calculated by dividing renal plasma flow by (1-hematocrit). Renal vascular resistance (RVR, dyne.s. $\mathrm{cm}^{-5} .1 .73 \mathrm{~m}^{-2}$ ) was obtained by dividing the mean arterial blood pressure by the effective renal blood flow. From these data the filtration fraction was calculated as defined as the ratio of glomerular filtration rate and effective renal plasma flow.

At least two hours after the initiation of the PAH/inulin infusion, blood samples were collected for the later determination of circulating levels of inulin, $\mathrm{PAH}$ and creatinine. Creatinine was measured by standard chemical procedures. In addition, blood was collected for assay of active plasma renin concentration, angiotensin $\mathrm{I}$, aldosterone, $\alpha$ atrial natriuretic peptide, $17 \beta$ estradiol, progesterone and catecholamines. Active plasma renin concentration was determined by an immunoradiometric assay technique (Nichols Institute Diagnostics, Wychen, The Netherlands). Angiotensin II was assayed by radioimmunoassay (RIA) following Phenyl column extraction (Amersham Int, Amersham, UK). A solid-phase protein binding RIA (Diagnostic Products Corporation, LA, USA) assessed aldosterone. $\alpha$-Atrial natriuretic peptide was analyzed by radioimmunoassay (Nichols Institute Diagnostics, Wychen, The Netherlands). Serum 17- $\beta$-estradiol and progestcrone were determined with a commercially available solid phase radioimmunoassay kit (DPC, Los Angeles, Cal, USA). Samples were collected on ice and immediately centrifuged at $4{ }^{\circ} \mathrm{C}$ for 10 min at I500 $g$ immediately after sampling. All samples were stored deep-frozen $\left(-80^{\circ} \mathrm{C}\right)$ prior to assay.

Urinary sodium and creatinine concentration were measured by standard chemical procedures in a urine sample collected over the 24 hours preceding the measurement session. Creatinine clearance, expressed in $\mathrm{ml} . \mathrm{min}^{-1}$, was calculated according to the formula:

\section{Creatinine Clearance $=10^{3} \times$ urinary creatinine $($ mmol//) $\times$ urinan volume $(1 / 1440 \mathrm{~min})$ serum creatinine (mmol/l)}

Venous compliance, representing venous visco-elastic properties, was defined as the plethysmographically determined slope of the relationship of intravenous volume- and 
pressure changes (Periflow, JSI, Beerse, Belgium) ${ }^{9,16}$. The measurement procedure has been detailed previously ${ }^{16}$. This variable has a coefficient of variation of $11.4 \%$.

Measurement of plasma volume. Plasma volume was measured next, using the Iodine ${ }^{125}$ Albumin $\left({ }^{125} \mathrm{I}-\mathrm{HSA}\right)$ indicator dilution method and expressed in $\mathrm{ml}$ per kilogram $(\mathrm{kg})$ lean body mass $(\mathrm{LBM})^{6}$.

Echocardiography to assess cardiac function was performed in semi-left lateral position, after completion of the PV measurement and after 5 minutes rest, using a cross-sectional, phased array echocardiographic Doppler system (Hewlett-Packard Sonos 2000 and 2500) 6.

Cardiac output (L.min ${ }^{-1}$ ) was calculated by multiplying stroke volume $(\mathrm{ml})$ and heart rate (bpm). In this formula, heart rate was obtained by taking the reciprocal of the mean of five consecutive R-R intervals on the ECG. Stroke volume was calculated by multiplying the aortic velocity integral and the aortic area. Aortic flow was measured across the aortic valves

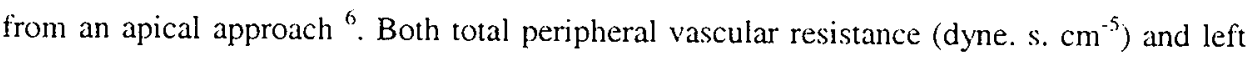
ventricular work $\left(\mathrm{mmHg}\right.$.L.min ${ }^{-1}$ ) were obtained by taking the quotient and product, respectively, of mean arterial pressure and cardiac output. The value used for mean arterial pressure $(\mathrm{mmHg}$ ) was obtained during the cardiac output measurement using the recordings of the Dinamap apparatus and was calculated as the mean of three consecutive recordings.

Statistical analysis: Data are presented as means with standard deviations unless stated otherwise. Intra-group differences were tested with Wilcoxon Signed-Ranks Matched-Pairs test, differences between groups with the Mann-Whitney-U Test, both tests with Bonferroni correction. Correlations, when calculated, between concomitantly measured potentially related variables, were tested by Spearman's Rank Correlation Analysis. A p-value less than 0.05 relative to the control group, was considered statistically significant.

\section{Results}

Of the 250 eligible formerly preeclamptic participants and 15 controls, 57 formerly preeclamptics and 12 controls were available for final analysis. This implies that $57 / 250$ or $23 \%$ of the formerly preeclamptic subjects and $12 / 15$ or $80 \%$ of the parous controls conceived and had an ongoing singleton pregnancy, within 12 months after the measurement session $(p<0.005)$. Among the formerly preeclamptics, 12 subjects had hypertension and were assigned to the HYPERT subgroup. From these 12 hypertensive subjects, four were found to have a thrombophilic disorder as well, three in conjunction with 
hyperhomocysteinemia (25\%) and one in conjunction with a combination of protein $\mathrm{S}$ deficiency and the antiphospholipid syndrome. Of the remaining 45 normotensive formerly preeclamptic subjects, 23 had either one $(n=21)$ or more $(n=2)$ thrombophilic disorder(s). They were assigned to the THROMB subgroup. The remaining 22 formerly preeclamptics had neither hypertension nor thrombophilia. They were assigned to the NONTHROMB subgroup. The demographic characteristics of all participants are listed in Table I. The 3 subgroups of formerly preeclamptics and the controls were comparable with respect to age, height, parity and urinary sodium output. The subjects in the NONTHROMB subgroup had a higher body mass index relative to controls. Obviously, mean arterial blood pressure was higher in the HYPERT subgroup than in the controls.

Figure 1: Management, subdivision and treatment of formerly preeclamptic participants.

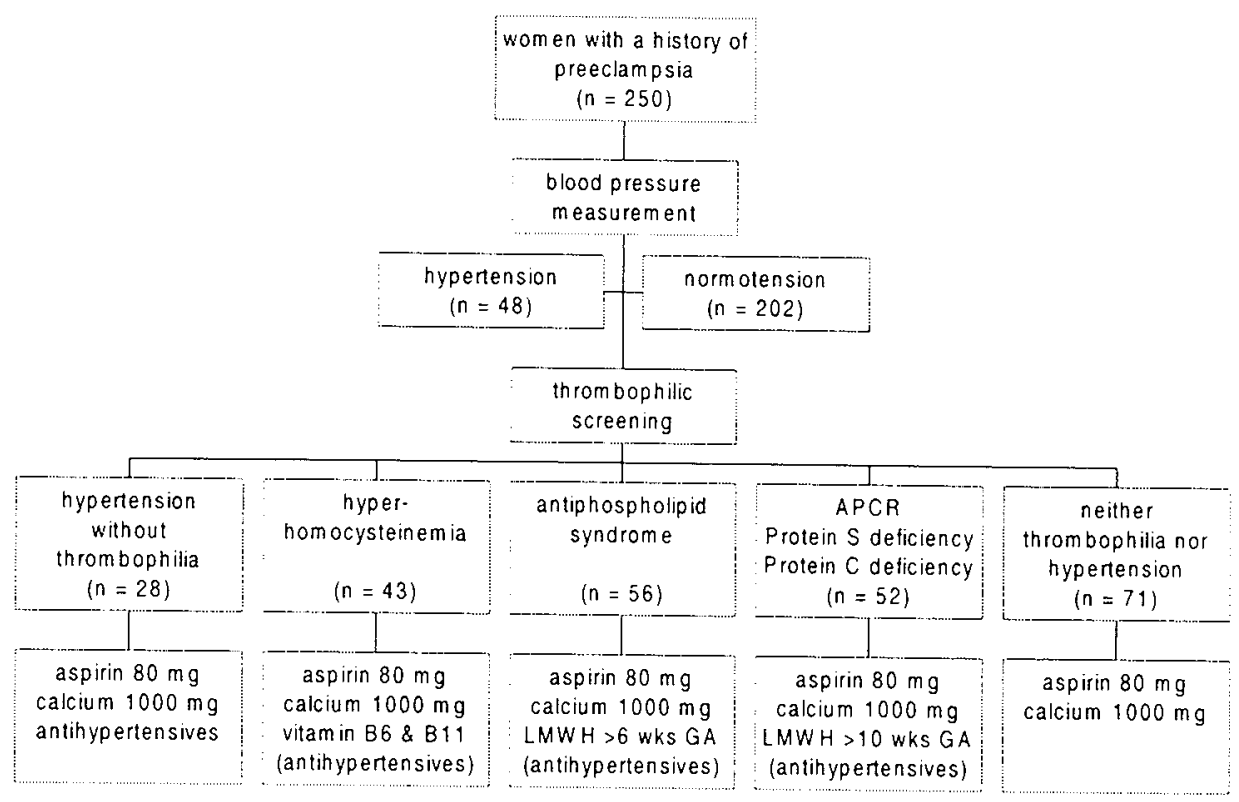

$\mathrm{APCR}=$ activated protein $\mathrm{C}$ resistance. Vitamin $\mathrm{B} 620 \mathrm{mg}$ per day, vitamin $\mathrm{B} 115 \mathrm{mg}$ per day. $\mathrm{LMWH}=$ low molecular-weight heparin ( 5800 anti Xa units per day). GA = gestational age (wecks). 
Table I: Demographic data from the 3 subgroups of formerly preeclamptics and the group of normal parous controls. If a value is followed by an anrow, this particular variable is higher $(\uparrow)$ or lower $(\downarrow)$ than the one in the control group $(\mathrm{p}<0.05)$.

\begin{tabular}{|c|c|c|c|c|}
\hline : & $\begin{array}{r}\text { controls } \\
\therefore \quad(n=12)\end{array}$ & $\begin{array}{l}\text { THROMB } \\
(\mathrm{n}=23)\end{array}$ & $\begin{array}{l}\text { ormerly preeclam } \\
\text { NONTHROMB } \\
\quad(n=22)\end{array}$ & $\begin{array}{l}\text { HYPERT } \\
(\mathrm{n}=12)\end{array}$ \\
\hline Age (years) & $31 \pm 3$ & $29 \pm 3$ & $29 \pm 3$ & $32 \pm 4$ \\
\hline Height $(\mathrm{cm})$ & $168 \pm 4$ & $170 \pm 7$ & $170 \pm 6$ & $166 \pm 6$ \\
\hline Body mass index $\left(\mathrm{kg} \cdot \mathrm{m}^{-2}\right)$ & $22 \pm 2$ & $24 \pm 5$ & $26 \pm 6 \uparrow$ & $26 \pm 7$ \\
\hline Parity (median with range) & $1(1-2)$ & $1(1-2)$ & $1-(1-2)$ & $1(1-4)$ \\
\hline Sodium excretion (mmol.24h $\left.\mathrm{h}^{-1}\right)$ & $108 \pm 31$ & $93 \pm 33$ & $91 \pm 26$ & $91 \pm 15$ \\
\hline
\end{tabular}

Among the 57 formerly preeclamptic participants, 47\% (27/57) had at least one thrombophilic disorder. In the subjects allocated to the THROMB subgroup, the antiphospholipid syndrome $(9 / 23,39 \%)$ and hyperhomocysteinemia $(7 / 23,30 \%)$ were most common, followed by protein S deficiency $(5 / 23,22 \%)$, APC resistance $(3 / 23,13 \%)$ and protein C deficiency $(1 / 23,4 \%)$. Seven formerly preeclamptic women, which were diagnosed as having the anti-phospholipid syndrome, were $\operatorname{IgG}$ serotypes. We did not identify women with antithrombin deficiency.

Table II lists the cardiovascular data and plasma volume. None of the variables listed differed between the THROMB subgroup and the control group. In both HYPERT and NONTHROMB subjects, cardiac output and left ventricular work were higher, and plasma volume and venous compliance lower than in controls. When normalized for body surface area, cardiac output was elevated only in the HYPERT subgroup.

Renal hemodynamic variables, volume regulating hormones and gonadal steroids are listed in table III. Differences between the THROMB subgroup and controls were small and inconsistent. In contrast, the NONTHROMB and HYPERT subgroup differed from controls by a lower effective renal plasma and blood flow, a lower glomerular filtration rate and a higher renal vascular resistance and filtration fraction (the latter only in HYPERT). Values for 17 - $\beta$-estradiol, progesterone, $\alpha$-atrial natriuretic peptide and the hormones of the reninangiotensin-aldosterone system did not differ appreciably between subgroups and controls. 
Table II: Hemodynamic and vascular data. The symbol * indicates the value in a particular subgroup to be different from that in the controls $(\mathrm{p}<0.05)$.

\begin{tabular}{|c|c|c|c|c|}
\hline $\begin{array}{llll} & & & \\
\ddots & & & \\
\ddots & \ddots & \\
\end{array}$ & $\begin{array}{l}\text { controls } \\
(n=12)\end{array}$ & $\begin{array}{r}\text { fo } \\
(n=23)^{\prime}\end{array}$ & $\begin{array}{l}\text { rly preeclam } \\
\text { NTHROMB } \\
(n=22)\end{array}$ & $\begin{array}{l}\text { lptic } \\
\text { HYPERT } \\
(n=12)\end{array}$ \\
\hline Mean arterial pressure $(\mathrm{mmHg})$ & $83 \pm 7$ & $85 \pm 7$ & $87 \pm 7$ & $110 \pm 8 \%$ \\
\hline Heart rate (bpm) & $64 \pm 9$ & $63 \pm 9$ & $65 \pm 9$ & $68 \pm 14$ \\
\hline Stroke volume (ml. beat ${ }^{-1}$ ) & $71 \pm 6$ & $78 \pm 12$ & $79 \pm 12$ & $77 \pm 10$ \\
\hline Cardiac output $\left(\mathrm{L} \cdot \mathrm{min}^{-1}\right)$ & $4.8 \pm 0.4$ & $5.2 \pm 0.5$ & $5.5 \pm 0.8$ & $5.7 \pm 0.6^{*}$ \\
\hline Cardiac index $\left(\mathrm{L} \cdot \mathrm{min}^{-1}, \mathrm{~m}^{-2}\right)$ & $2.8 \pm 0.3$ & $3.0 \pm 0.3$ & $29 \pm 0.5$ & $3.3 \pm 0.6$ \\
\hline TPVR $\left(10^{3}\right.$ dyne.s.cm $\left.{ }^{-5}\right)$ & $1.4 \pm 0.2$ & $13 \pm 0.2$ & $13 \pm 0.2$ & $1.5 \pm 0.2$ \\
\hline Left ventricular work $\left(.10^{3} \mathrm{nmHg}\right.$.L.min $\left.{ }^{-1}\right)$ & $30+4$ & $36 \pm 4$ & $39 \pm 9 *$ & $50 \pm 6 *$ \\
\hline Venous compliance (ml. $100 \mathrm{ml}^{-1} \cdot \mathrm{mmHg}^{-1}$ ) & $6.0 \pm 1.2$ & $6.0 \pm 1.2$ & $4.6 \pm 1.5 *$ & $4.9 \pm 1.0 \%$ \\
\hline 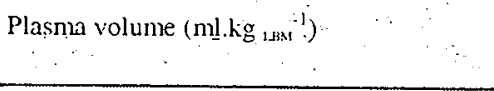 & $.54 \pm 5$ & $51 \pm 5$ & $46 \pm 3 *$ & $48 \pm 6$ \\
\hline
\end{tabular}

TPVR = total peripheral vascular resistance.

Maternal and fetal data with respect to the preceding and subsequent pregnancies are listed in tables IV and $\mathrm{V}$, respectively. In controls, gestational age at delivery did not differ appreciably the two pregnancies. Both birth weight $(287 \pm 195)$ and birth weight centile (12 \pm 15 ) had increased relatively to the preceding pregnancy. Each of the outcome variables in the three subgroups had improved markedly in the subsequent-relative to the preceding pregnancy. Nevertheless, as compared to controls, irrespective subgroup, formerly preeclamptic subjects persisted in having a higher incidence of pregnancy-induced hypertension and fetal growth restriction as indicated by a lower birth weight centile. Pregnancy-induced hypertension and fetal growth restriction in the subsequent pregnancy were observed more often in the NONTHROMB subgroup as compared to controls. As compared to the previous pregnancy, NONTHROMB delivered $8( \pm 4)$ weeks later, had a 1845 ( \pm 927$)$ grams heavier baby with also a $30( \pm 29) \%$ higher birth weight centile. If preeclampsia occurred in the NONTHROMB subgroup, it developed by a median of 7 [6-8] weeks later as compared to the index pregnancy. With respect to maternal pregnancy outcome measures, in NONTHROMB, we found the recurrence rate of pregnancy-induced hypertension to increase as a function of pre-pregnant cardiac output $(r=0.62, p=0.003)$, cardiac index $(r=0.49, p=0.02)$, left ventricular work $(r=0.67, p=0.009)$ and heart rate $(r$ $=0.56, p=0.03$ ) (Table VI a). A receiver operating characteristic (ROC) curve to explore 
the predictive potential of the pre-pregnant cardiac output measurements indicated that NONTHROMB participants with a cardiac output over $4.8 \mathrm{~L} \cdot \mathrm{min}^{-1}$ had a high chance to develop pregnancy-induced hypertension in the subsequent pregnancy, the sensitivity being $93 \%$ and the specificity $67 \%$. The associated positive and negative predictive values were $88 \%$ and $80 \%$, respectively (Figure 2). A pre-pregnant cardiac output above $5.6{\mathrm{~L} . \mathrm{min}^{-1}}^{-1}$ in a NONTHROMB woman is associated with an increased recurrence risk of preeclampsia, the sensitivity and specificity being $60 \%$ and $75 \%$, respectively (Figure 2). THROMB subjects developed more often pregnancy-induced hypertension and fetal growth restriction in the subsequent pregnancy than controls. As compared to the preceding complicated pregnancy, we noted an $8( \pm 4)$ weeks prolongation of pregnancy, which contributed to an increase in neonatal weight by $1815( \pm 771)$ gram corresponding with a $15( \pm 22) \%$ increase in birth weight centile. If in the THROMB subgroup the subsequent pregnancy was complicated by recurrent preeclampsia, the complication developed approximately 2 [-4-8] weeks later than in the preceding index pregnancy. In THROMB subjects, pre-pregnant plasma volume correlated inversely with the recurrence rate of pregnancy-induced hypertension $(r=-0.52, p$ $=0.01)$, preeclampsia $(r=-0.50, p=0.01)$ and HELLP syndrome $(r=-0.50, p=0.01)$. Also pre-pregnant venous compliance correlated inversely with the subsequent development of precclampsia $(r=-0.59, p=0.02)$ and HELLP syndrome $(r=-0.59, p=0.02)$ (Table VI $b)$. On the basis of a calculated ROC curve, it could be determined that in THROMB participants, a plasma volume below $49 \mathrm{ml} \mathrm{kg} \mathrm{I.BM}^{-1}$ was highly predictive with respect to the recurrence of preeclampsia in a subsequent pregnancy, the sensitivity and specificity being $100 \%$ and $75 \%$, respectively. The associated positive and negative predictive values were $38 \%$ and $100 \%$, respectively (Figure 3 ). Two-third of the THROMB population (15/23) had a plasma volume of at least $49 \mathrm{ml} \mathrm{kg} \mathrm{L.ß3M}^{-1}$. None of these women developed recurrent preeclampsia. Conversely, a plasma volume below $49 \mathrm{ml}_{\mathrm{kg} \mathrm{I.BM}^{-1}}$, identified THROMB women destined to develop PIH with a sensitivity and specificity of $89 \%$ and $86 \%$, and positive and negative predictive values of $80 \%$ and $92 \%$, respectively (Figure 3). The development of fetal growth restriction in THROMB women correlated inversely with prepregnant venous compliance $(r=-0.52, p=0.04)$. Furthermore, the gestational age at delivery $(r=0.54, p=0.04)$, and the achieved birth weight $(r=0.59, p=0.02)$ and birth weight centile ( $r=0.57, \mathrm{p}=0.02)$ in the subsequent pregnancy increased as a function of prepregnant venous compliance (Table VI b). 
Table IU: Renal hemodynamics, volume regulating hormones and gonadal steroids. The symbol * indicates the value in a particular subgroup to be different from that in the controls $(p<0.05)$.

\begin{tabular}{|c|c|c|c|c|}
\hline $\begin{array}{lll} & \\
\ddots & \ddots & \ddots \\
\vdots & \ddots & \ddots \\
\end{array}$ & $\begin{array}{c}\text { control: } \\
(\mathrm{n}=12)\end{array}$ & $\begin{array}{r}\text { forn } \\
\text { THROMB: } \\
(n=23)\end{array}$ & $\begin{array}{l}\text { nerly preec } \\
\text { NONTHRON } \\
(n=22)\end{array}$ & $\begin{array}{l}\text { Imptic } \\
\text { B HYPERT } \\
(\mathrm{n}=12)\end{array}$ \\
\hline$\therefore \quad \therefore$ & & $\therefore$ & $\therefore$ & \\
\hline Glomerular filtration rate $\left(\mathrm{ml} \cdot \min ^{-1} .1 .73 \mathrm{~m}^{-2}\right)$ & $123 \pm 9$ & $118 \pm 17$ & $111 \pm 11 \%$ & $109 \pm 25$ \\
\hline Effective renal plasma flow (ml min $\left.{ }^{-1} \cdot 1.73 \mathrm{~m}^{-2}\right)$ & $551 \pm 86$ & $522 \pm 86$ & $462 \pm 76 \%$ & $400 \pm 95$ \\
\hline Effective renal blood flow (ml.min $\left.{ }^{-1} .1 .73 \mathrm{~m}^{-2}\right)$ & $866 \pm 133$ & $828 \pm 159$ & $734 \pm 114 \%$ & $65 i \pm 158 \%$ \\
\hline Renal vascular resistance $\left(10^{3}\right.$ dyne.s.cm $\left.{ }^{-5}, 1.73 \mathrm{~m}^{-2}\right)$ & $7.4 \pm 1.7^{i}$ & $8.0 \pm 1.9$ & $9.3+1.7 *$ & $13.4 \pm 3.7 \%$ \\
\hline Filtration fraction & $0.23 \pm 0.03$ & $0.23 \pm 0.03$ & $0.24 \pm 0.03$ & $0.28 \pm 0.05 *$ \\
\hline Creatinine Clearance $\left(\mathrm{ml} \cdot \mathrm{min}^{-1}\right.$ ) & $104 \pm 19$ & $107 \pm 26$ & $112 \pm 26$ & $98 \pm 30$ \\
\hline Active plasma renin concentration $\left(m U . L^{-1}\right)$ & $14.0 \pm 3.9$ & $15.8 \pm 9.5$ & $14.4 \pm 7.2$ & $16.3 \pm 7.8$ \\
\hline Angiotensin II (pmol. $\left.\mathrm{L}^{-1}\right)$ & $9.4 \pm 1.9$ & $9.9 \pm 3.4$ & $10.2 \pm 2.6$ & $12.0 \pm 4.5$ \\
\hline Aldosterone (nmol. $L^{-1}$ ) & $92 \pm 40$ & $88 \pm 41$ & $87 \pm 34$ & $113 \pm 47$ \\
\hline$\alpha$ Atrial natriuretic peptide $\left(\mathrm{ng} . \mathrm{L}^{-1}\right)$ & $100 \pm 50$ & $94 \pm 41$ & $106 \pm 49$ & $103 \pm 47$ \\
\hline $17 \beta \underset{⿴}{\text { Estradiol (nmol.L.1 })}$ & $0.13 \pm 0.09$ & $\begin{array}{l}0.14 \pm \\
0.08\end{array}$ & $0.13 \pm 0.05$ & $0.14 \pm 0.05$ \\
\hline Progesterone (nmol.L-1) & $1.3 \pm 0.6$ & $2.4 \pm 1.7$ & $2.3 \pm 1.5$ & $1.6 \pm 0.9$ \\
\hline
\end{tabular}


Table IV: Maternal pregnancy outcome. An arrow indicates the value in a particular subgroup to be different from that in the controls, the symbol * indicates the value to be different from the previous pregnancy within the same subgroup $(\mathrm{p}<0.05)$. Data are presented as means and SD unless ending by [] , indicating median with range.

\begin{tabular}{|c|c|c|c|}
\hline$\therefore$ & $\begin{array}{l}\because \text { GROUP } \\
\because \\
\end{array}$ & $\begin{array}{l}\text { Previous pregnancy } \\
\text { n }(\%)\end{array}$ & $\begin{array}{l}\text { Current pregnancy } \\
\mathrm{n}(\%)\end{array}$ \\
\hline $\begin{array}{c}\text { Pregnancy induced } \\
\text { hyperension \# } \\
\therefore \\
\therefore\end{array}$ & $\begin{array}{l}\text { CONTROLS } \\
\text { THROMB } \\
\text { NONTHROMB } \\
\text { HYPERT }\end{array}$ & $\begin{array}{c}0(0 \%) \\
23(100 \%) \uparrow \\
22(100 \%) \uparrow \\
12(100 \%) \uparrow\end{array}$ & $\begin{array}{c}0(0 \%) \\
10(44 \%) \uparrow \\
16(73 \%) \uparrow \\
\delta(67 \%) \uparrow\end{array}$ \\
\hline Preeclampsia & $\begin{array}{ll} & \text { CONTROLS } \\
& \text { THROMB } \\
& \text { NONTHROMB } \\
& \text { HYPERT }\end{array}$ & $\begin{array}{c}0(0 \%) \\
23(100 \%) \uparrow \\
22(100 \%) \uparrow \\
12(100 \%) \uparrow\end{array}$ & $\begin{array}{l}0(0 \%) \\
3(13 \%) \\
5(23 \%) \\
4(33 \%) \uparrow\end{array}$ \\
\hline HELLP syndrome & $\begin{array}{l}\text { CONTROLS } \\
\text { THROMB } \\
\text { NONTHROMB } \\
\text { HYPERT }\end{array}$ & $\begin{array}{c}0(0 \%) \\
12(52 \%) \uparrow \\
\quad 7(32 \%) \uparrow \\
\therefore \quad 5(42 \%) \uparrow\end{array}$ & $\begin{array}{l}0(0 \%) \\
3(13 \%) \% \\
3(14 \%) \% \\
2(17 \%)\end{array}$ \\
\hline $\begin{array}{l}\text { Gestational age } \\
\text { PE/HELLP (weeks) }\end{array}$ & $\begin{array}{l}\text { CONTROLS } \\
\text { THROMB } \\
\text { NONTHROMB } \\
\text { HYPERT }\end{array}$ & $\because \begin{array}{r}29 \pm 4 \\
28 \pm 4 \\
27 \pm 5 \\
\vdots\end{array}$ & $\begin{array}{l}36[21-39] * \\
36[29-37]: \\
34[32-37] \downarrow\end{array}$ \\
\hline
\end{tabular}

\# In HYPERT, pregnancy-induced hypertension is defined as that condition in which diastolic blood pressure rose more than $15 \mathrm{mmHg}$ (followed by higher dose of the instituted antihypertensive medication). HELLP syndrome $=$ hemolysis, elevated liver enzymes, low platelets. $\mathrm{PE}=$ preeclampsia. 
Table V: Fetal pregnancy outcome. An arrow indicates the value in a particular subgroup to be different from that in the controls, the symbol * indicates the value to be different from the previous pregnancy within the same subgroup $(\mathrm{p}<0.05)$. Data are presented as means and SD unless ending by [ ], indicating median with range.

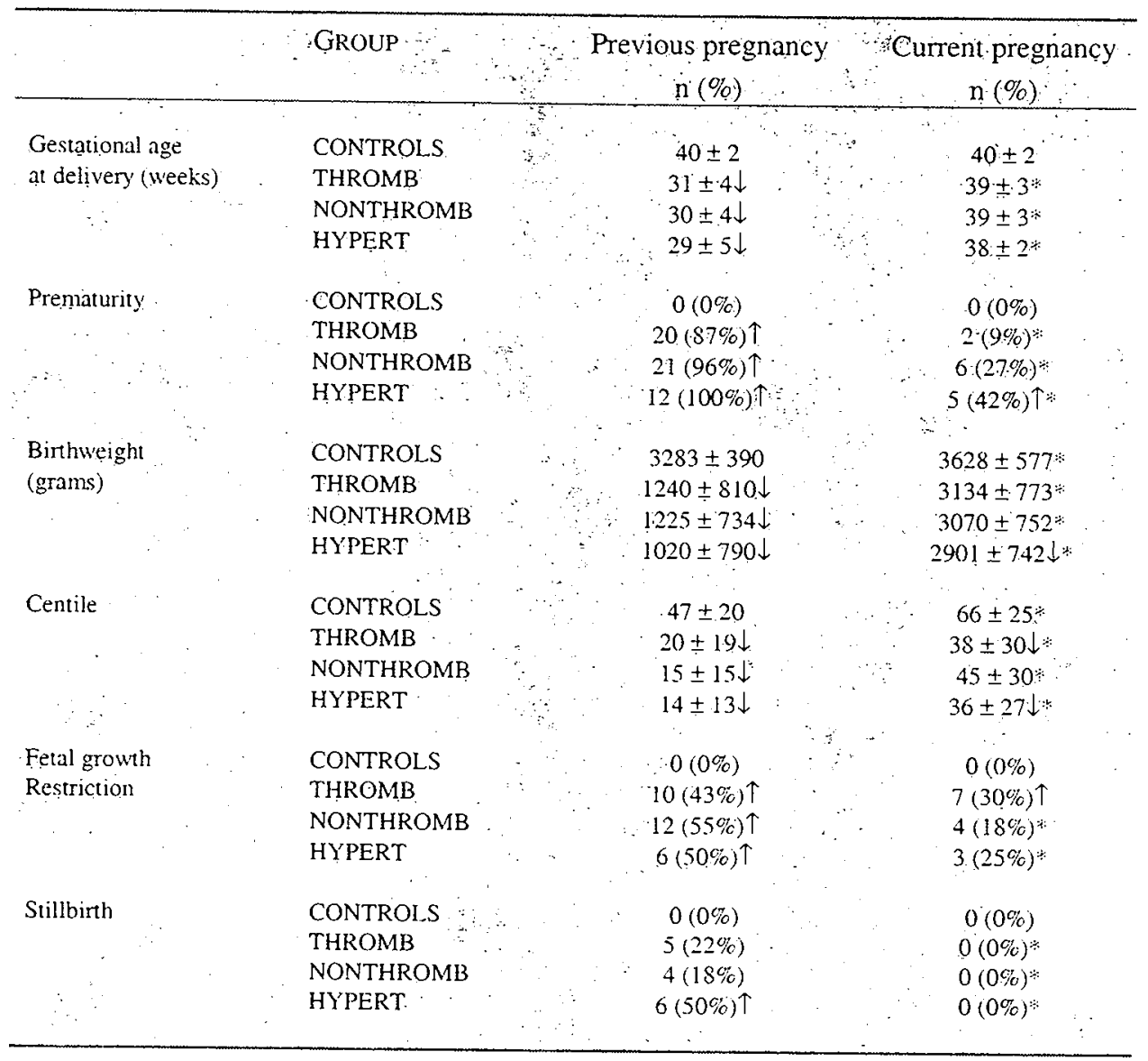


Table VI a: Correlations between a high pre-pregnant cardiac output, cardiac index, left ventricular work and heart rate and subsequent maternal and fetal outcome among normotensive nonthrombophilic (NONTHROMB) women.

\begin{tabular}{|c|c|c|c|c|}
\hline & $\begin{array}{c}\text { cardiac out put } \\
: \\
T\end{array}$ & cardiac index $\uparrow$ & $\begin{array}{l}\text { Left ventricular } \\
\text { work } \uparrow\end{array}$ & heart rate $\uparrow$ \\
\hline Pregnancy induced hypenension & $\uparrow \uparrow ?$ & $\uparrow$ & pl & $\uparrow$ \\
\hline Preeclampsia & $\because$ & $\because$ & 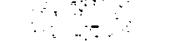 & $\cdots$ \\
\hline HELLP syndrome & - & - & $\because$ & - \\
\hline Gestational age at delivery & $\therefore$ & - & - & - \\
\hline Fetal growth restriction & - & - & - & - \\
\hline Birth weight & $\downarrow$ & $\because$ & - & - \\
\hline Birth weight centile & - & $\therefore \therefore$ & - & - \\
\hline
\end{tabular}

$\uparrow$ or $\downarrow$ indicates $\mathrm{p}<0.05, \uparrow \uparrow$ or $\downarrow \downarrow$ indicates $\mathrm{p} \leq 0.01, \uparrow \uparrow \uparrow$ or $\downarrow \downarrow \downarrow$ indicates $\mathrm{p} \leq 0.001$.

Table VI b: Correlations between a low pre-pregnant plasma volume ${ }_{1.1 \mathrm{~B} \text { a }}$ and venous compliance and subsequent maternal and fetal outcome among normotensive thrombophilic (THROMB) women.

\begin{tabular}{|c|c|c|}
\hline$\cdot$ & plasma volume $\downarrow$ & venous conpliance $\downarrow$ \\
\hline Pregnancy induced hypertension & $\uparrow \uparrow$ & - \\
\hline Preeclampsia & $\uparrow \uparrow$ & $\uparrow$ \\
\hline HELLP'syndrome & $\cdots \uparrow \uparrow$ & $\therefore \because \uparrow$ \\
\hline Gestational age at delivery & - & $\therefore \quad \downarrow$ \\
\hline Fetal growth restriction & - & $\because \uparrow$ \\
\hline Birth weight & - & $\because \because \cdots \downarrow$ \\
\hline Birth weight centile & - & $\therefore \downarrow$ \\
\hline
\end{tabular}

$\uparrow$ or $\downarrow$ indicates $\mathrm{p}<0.05, \uparrow \uparrow$ or $\downarrow \downarrow$ indicates $\mathrm{p} \leq 0.01, \uparrow \uparrow \uparrow$ or $\downarrow \downarrow \downarrow$ indicates $\mathrm{p} \leq 0.001$.

Table VI c: Correlations between a high pre-pregnant plasma volume rors., left ventricular work, systolic, diastolic and mean arterial blood pressure and subsequent maternal and fetal outcome among hypertensive (HYPERT) women.

\begin{tabular}{lcccccc}
\hline & $\begin{array}{c}\text { plasma } \\
\text { volume } \uparrow\end{array}$ & $\begin{array}{c}\text { left ventricular } \\
\text { work } \uparrow\end{array}$ & $\begin{array}{c}\text { systolic } \\
\text { pressure } \uparrow\end{array}$ & $\begin{array}{c}\text { diastolic } \\
\text { pressure } \uparrow\end{array}$ & $\begin{array}{c}\text { mean } \\
\text { pressure } \uparrow\end{array}$ \\
\hline Pregnancy-aggravated hypertension & - & - & - & - & - \\
Preeclampsia & - & - & $\ddots$ & $\uparrow$ & $\uparrow \uparrow$ \\
HELLP syndrome & - & - & - & $\uparrow$ & $\uparrow$ \\
Gestational age at delivery & - & $\downarrow$ & - & $\downarrow$ & $\downarrow$ \\
Fetal growth restriction & - & - & $-\uparrow$ & - & $\uparrow$ \\
Birth weight & $\uparrow$ & - & - & $\downarrow$ & $\downarrow \downarrow$ \\
Birth weight contile & $\uparrow \uparrow$ & - & - & $\downarrow$ & $\downarrow$ \\
\hline
\end{tabular}

$\uparrow$ or $\downarrow$ indicates $p<0.05$, $\uparrow \uparrow$ or $\downarrow \downarrow$ indicates $p \leq 0.01, \uparrow \uparrow \uparrow$ or $\downarrow \downarrow \downarrow$ indicates $p \leq 0.001$. 
Figure 2. Receiver operating characteristic curve for both pregnancy induced hypertension $(\mathrm{PIH})$ (dotted line, open circles) and preeclampsia (PE)(dashed line, solid circles) as a function of cardiac output $(\mathrm{CO})$ among nomotensive nonthrombophilic formerly preeclamptic women. An asterisk: indicates the test optinum.

*PIH: $\mathrm{CO} \geq 4.8 \mathrm{~L} \cdot \mathrm{min}^{-1}: \quad$ sensitivity $=93 \%$

specificity $=67 \%$

positive predictive value $=88 \%$

negative predictive value $=80 \%$

$\because$ PE: $\mathrm{CO} \geq 5.6 \mathrm{~L}^{\mathrm{m}} \mathrm{min}^{-1}: \quad$ sensitivity $=60 \%$

specificity $=75 \%$

positive predictive value $=43 \%$

negative predictive value $=86 \%$

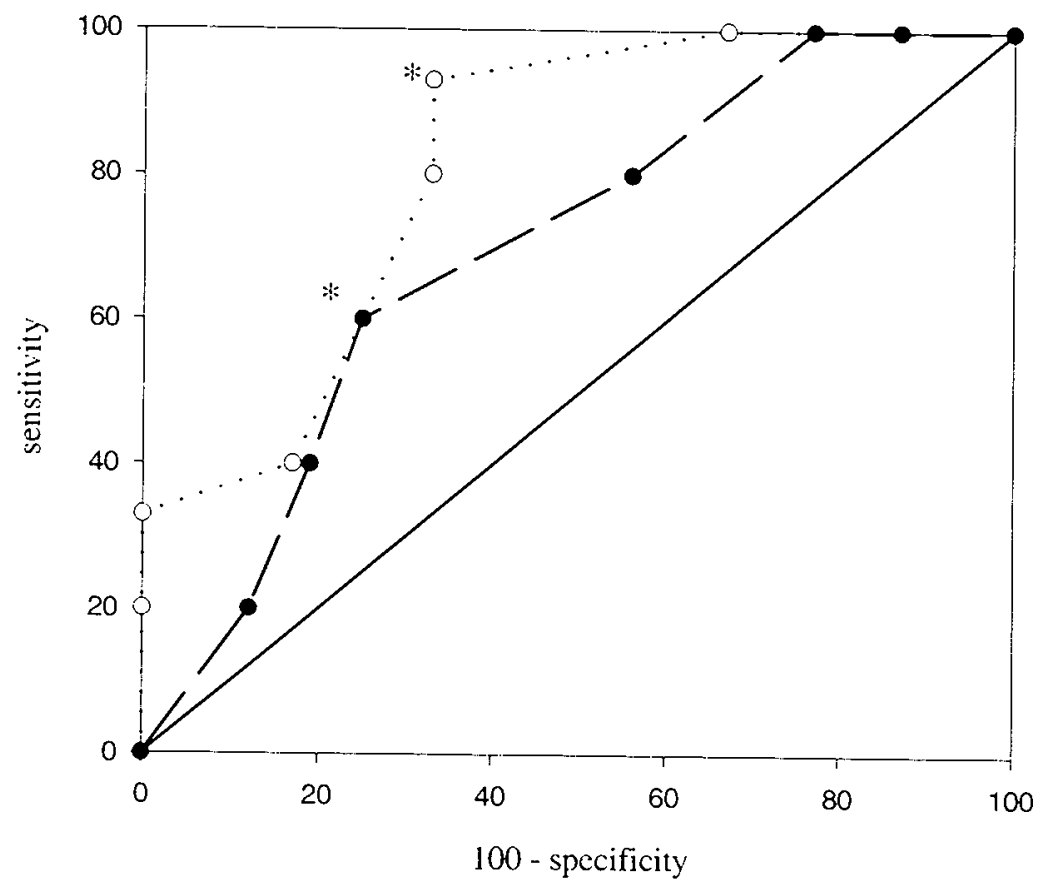


Figure 3. Receiver operating characteristic curve for both pregnancy-induced hypertension $(\mathrm{PIH})$ (dotted line, open circles) and preeclampsia (PE)(dashed line, solid circles) as a function of plasma volume among normotensive thrombophilic formerly preeclamptic women. An asterisk* indicates the test optimum.

$\therefore \mathrm{PIH}: \mathrm{PV} \leq 49 \mathrm{ml} \cdot \mathrm{kg}_{\text {IBM }^{-1}}{ }^{-1} \quad$ sensitivity $=89 \%$

specificity $=86 \%$

positive predictive value $=80 \%$

negative predictive value $=92 \%$

$* \mathrm{PE}: \mathrm{PV} \leq 48 \mathrm{ml} . \mathrm{kg}_{\mathrm{LBM}}{ }^{-1}: \quad$ sensitivity $=100 \%$

specificity $=75 \%$

positive predictive value $=38 \%$

negative predictive value $=100 \%$

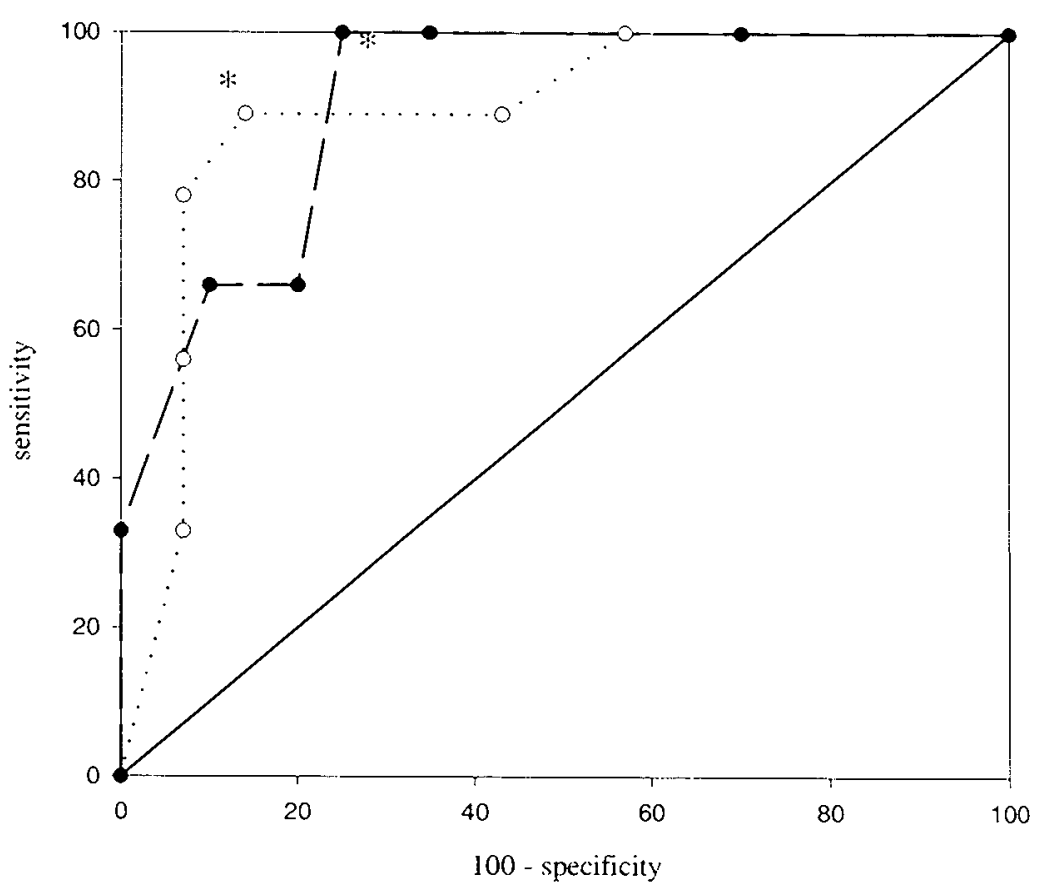


Figure 4. Receiver operating characteristic curve for both pregnancy-aggravated hypertension $(\mathrm{PAH})$ (dotted line, open circles) and preeclampsia (PE)(dashed line, solid circles) as a function of mean arterial blood pressure (MAP) among hypertensive formerly preeclamptic women. An asterisk: indicates the test optinum.

*PAH: MAP $\geq 112 \mathrm{mmHg}: \quad$ sensitivity $=63 \%$ specificity $=100 \%$

positive predictive value $=100 \%$ negative predictive value $=57 \%$

*PE: MAP $\geq 112 \mathrm{mmHg}: \quad$ sensitivity $=100 \%$ specificity $=88 \%$ positive predictive value $=80 \%$ negative predictive value $=100 \%$

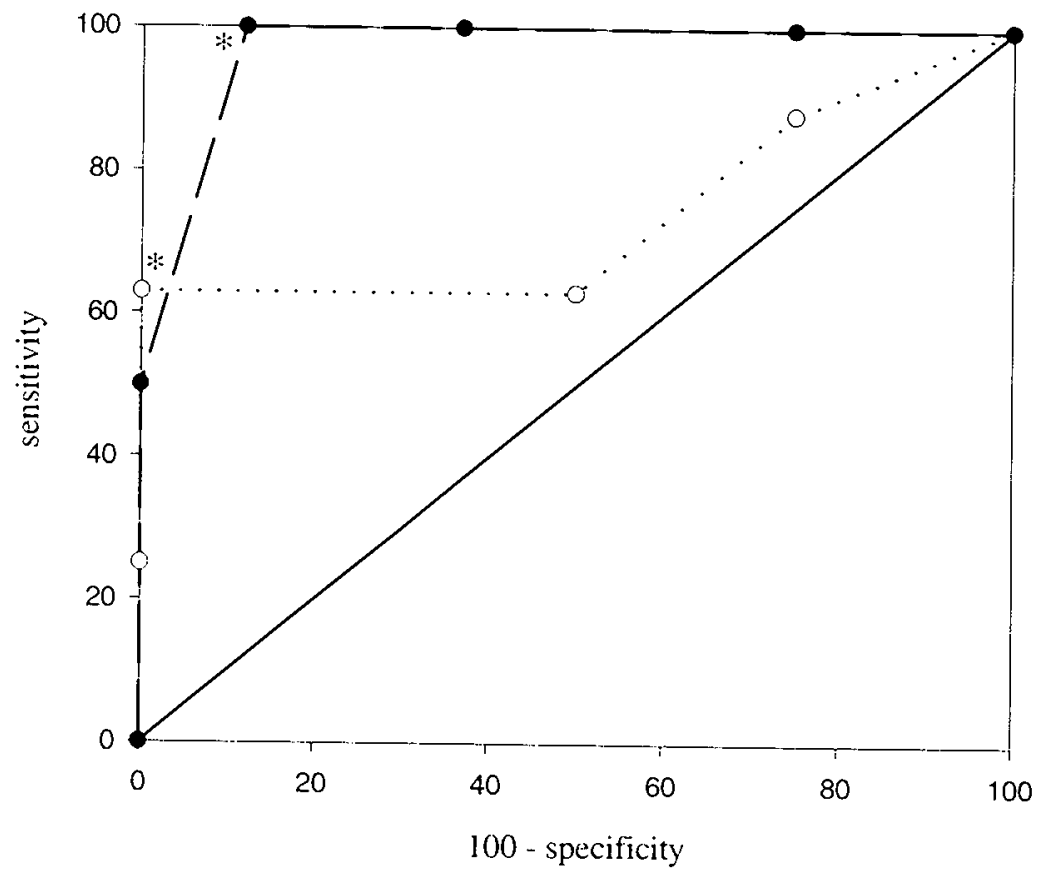


Finally, the worse the outcome in the preceding pregnancy, the less favorable was the outcome in the subsequent pregnancy: The chances for low birth weight centile in the subsequent pregnancy were higher with: I. a history of earlier onset preeclampsia ( $r=-0.60$, $p=0.005)$ and delivery $(r=-0.69, p=0.001), 2$ a history of a lower birth weight $(r=-0.68$, $\mathrm{p}=0.001)$ and centile $(\mathrm{r}=-0.59, \mathrm{p}=0.008)$ and 3 . the previous preeclamptic pregnancy being complicated by a HELLP syndrome $(r=-0.51, p=0.02)$. Interestingly, a history of stillbirth was associated with a high birth weight centile in the subsequent pregnancy $(\mathrm{r}=$ $0.72, \mathrm{p}=0.0001)$.

As compared to the preceding pregnancy, HYPERT subjects delivered approximately $9( \pm 6)$ weeks later in the subsequent pregnancy, giving rise to a 1957 ( \pm 1139 ) grams higher neonatal weight but also a 24 ( \pm 32$) \%$ higher birth-weight centile. Nevertheless, gestational age, birth weight and birth-weight centile in the subsequent pregnancy in this subgroup were still significantly lower than in the controls. In $8 / 12$ of the hypertensive participants, antihypertensive medication needed to be augmented in the course of the subsequent pregnancy. Recurrent preeclampsia developed by a median of 7 [5-13] weeks later than in the preceding pregnancy. A higher pre-pregnant systolic, diastolic and mean arterial blood pressure were associated with a higher incidence of superimposed preeclampsia $(r=0.59, p$ $=0.04 ; \mathrm{r}=0.62, \mathrm{p}=0.03 ; \mathrm{r}=0.78, \mathrm{p}=0.003$, respectively) and HELLP-syndrome (for diastolic and mean arterial bloodpressure, $r=0.65, p=0.02$ and $r=0.65, p=0.02$, respectively)(Table VI c). Determining the ROC curve for pregnancy-aggravated hypertension and preeclampsia as a function of mean arterial blood pressure, the optimum predictive blood pressure would be above $112 \mathrm{mmHg}$, a figure associated with a sensitivity of $63 \%$ and $100 \%$ and a specificity of $100 \%$ and $88 \%$, respectively (positive and negative predictive value of $100 \%$ and $57 \%$ for pregnancy-aggravated hypertension and $80 \%$ and $100 \%$ for preeclampsia, respectively) (Figure 4). Furthermore, lower pre-pregnant diastolic and mean arterial blood pressure were followed by a more advanced gestational age at delivery and with it a higher birth weight and corresponding birth-weight centile (for diastolic blood pressure $r=0.61, p=0.04 ; r=0.63, p=0.03 ; r=0.63, p=0.03$, for mean arterial blood pressure $r=0.611, p=0.04 ; r=0.70, p=0.01 ; r=0.61, p=0.04$, respectively) (Table VI c). Finally, pre-pregnant total plasma volume correlated with birth weight $(r=0.66, p=0.03)$ and birth-weight centile $(r=0.79, p=0.004)($ Table VI $c)$. 


\section{Discussion}

Although the underlying pathogenetic mechanisms of preeclampsia are still unclear, there is general agreement about a central role for dysfunctional endothelium in triggering the typical clinical symptoms $\$$. Endothelial function can be jeopardized by numerous factors, either biochemically, such as in thrombophilia or diabetes mellitus, or mechanically, such as in hypertension. Normal pregnancy is associated with a physiological rise in the strain exerted upon the endothelium. Therefore, it is not surprising that accompanying risk factors enhance the development of vascular complications during pregnancy. In this prospective study, preexistent maternal features with extra endothelial strain as common denominator, were found to predispose for recurrent hypertensive disorders and fetal growth restriction in highrisk pregnancies.

With respect to the demographic characteristics, except for a higher body mass index in the NONTHROMB, the three formerly preeclamptic subgroups did not differ appreciably from the control group. A higher body mass index in formerly preeclamptic women has also been reported by others and is a well-known risk factor for both cardiovascular and metabolic complications ${ }^{14}$. The increased incidence of thrombophilic disorders among the formerly preeclamptic individuals relative to normal parous controls is in line with previous findings in Israeli and Dutch populations $3,4,5$.

Despite their differences in mean arterial blood pressure, both HYPERT and NONTHROMB subjects were characterized by an elevated cardiac output, reduced venous compliance, low plasma volume, reduced renal perfusion and glomerular filtration, and increased renal vascular resistance. On the basis of these observations we previously proposed to consider NONTHROMB women as being latent hypertensive ${ }^{6}$. This view is further supported by our observation that in the majority of NONTHROMB subjects ( $73 \%$ ) pregnancy is complicated by the development of hypertension. The consistently low pre-pregnant plasma volume in (latent) hypertensive women and the contribution of a low plasma volume to the risk of recurrent precclampsia in normotensive thrombophilic formerly preeclamptic women in this study emphasize the importance of this variable. Our data indicate that reduced plasma volume is a sensitive marker to identify women at risk for recurrent hypertensive disorders in pregnancy.

Most previous studies on recurrence of hypertensive disorders in pregnancy are based on obstetrical history as a starting point rather than underlying disorders. Furthermore, most of these studies were performed retrospectively, in untreated women and in a different 
geographically localized population. Nevertheless, among normotensive formerly preeclamptic women, the reported recurrence rate of preeclampsia in a subsequent pregnancy ranged from 32 to $55 \%$ 10, 11, 15. Normotensive women with a history of HELLP-syndrome had recurrent preeclampsia and HELLP-syndrome in 19 to $23 \%$ and 3 to $27 \%$, respectively 12. 13. In hypertensive formerly preeclamptic women, preeclampsia recurred in $46-97 \%$ of the cases, which contrasts with the only $5 \%$ recurrence rate of HELLP-syndrome in the subsequent pregnancy $11,13,15$. In addition, with respect to gestational age, subsequent HELLP-pregnancies lasted on the average 2 weeks longer than the preceding pregnancy 12 . In our study, preeclampsia recurred in $18 \%$ of the normotensive- and in $33 \%$ of the hypertensive formerly preeclamptic participants. Taking the underlying disorder into consideration, we found recurrent preeclampsia to occur in about $1 / 8$ of the THROMB women, $1 / 4$ of the NONTHROMB and 1/3 of the HYPERT population. However, clinically it is important to consider this recurrence rate in the context of a milder course of the recurrent disease as indicated by its later onset and the substantially higher birth weight and corresponding birth-weight centile.

Most hypertensive women in our study were unaware of their elevated blood pressure. As a consequence, they were evaluated without any antihypertensive medication. Those who used antihypertensive drugs discontinued their medication for at least one week prior to measurement. After evaluation, antihypentensive medication was (re)instituted, with the aim of reducing diastolic blood pressure to below $90 \mathrm{mmHg}$. During the subsequent pregnancy, superimposed hypertension, preeclampsia and HELLP syndrome recurred in $67 \%, 33 \%$ and $17 \%$ of the HYPERT subgroup, respectively. Although in all patients the preexistent hypertension was adequately controlled with antihypertensive drugs, their 'pre-treatment' systolic and mean arterial blood pressure before pregnancy was still predictive for recurrent hypertensive complications in the next pregnancy. This suggests that in these preeclamptic recidivists, even though blood pressure can be normalized, vascular adaptive capacity to pregnancy is impaired, possibly as a result of structural changes in the vessel wall ${ }^{16.17}$.

In contrast to NONTHROMB and HYPERT women, pre-pregnant hemodynamic, renal and vascular function in THROMB were not different from those in controls. All these women received a prophylactic regimen as detailed in Figure 1. In spite of this, pregnancy-induced hypertension, preeclampsia and HELLP syndrome recurred in $44 \%, 13 \%$ and $13 \%$ of the cases. Interestingly, the recurrence rate was closely linked to a low plasma volume, the most characteristic feature of a (latent) hypertensive hemodynamic phenotype ${ }^{6}$. More explicitly, if 
plasma volume exceeded $49 \mathrm{ml} / \mathrm{kg} \mathrm{lbm}$, which was the case in $65 \%$ of the THROMB population, preeclampsia and HELLP syndrome did not recur. Likewise, a reduced venous compliance was associated with recurrent preeclampsia, HELLP-syndrome and fetal growth restriction. Both plasma volume and venous compliance seem to provide an index of cardiovascular adaptive capacity. Low values for these parameters may therefore indicate a diminished capacity to meet the increased blood flow demands of pregnancy, which, in some cases, can be expected to lead to hemodynamic maladaptation and with it, the development of hypertensive complications and fetal growth restriction.

In normotensive women with a history of preeclampsia and HELLP-syndrome, the reported incidence of preterm birth, fetal growth restriction and perinatal mortality in a subsequent pregnancy were $21 \%, 12 \%$ and $4 \%$, respectively ${ }^{13}$. These figures are at least four times higher in hypertensive formerly preeclamptic patients ${ }^{13}$. In our study, also the course of the preceding complicated pregnancy contributed to the recurrence rate of fetal growth restriction in the subsequent pregnancy. In THROMB participants, a previous late-onset of hypertensive disease and a relatively high previous birth weight and birth-weight centile were associated with a lower recurrence rate of fetal growth restriction. In contrast, a history of stillbirth seemed to 'protect' against fetal growth restriction. The latter finding supports the view that an acute intrauterine accident, such as placental thrombosis or infarction resulting in fetal mortality, is not associated with a poor prognosis with respect to the outcome of a subsequent pregnancy.

The present study was not designed to prove the efficacy of low molecular-weight heparin and/or vitamin supplementation in reducing the recurrence risk of hypertensive complications in pregnancy in formerly preeclamptic women with a thrombophilic phenotype. Nevertheless, in thrombophilic formerly preeclamptic women, recurrent preeclampsia, HELLP syndrome and growth restriction seems to be related to the latent hypertensive profile rather than the underlying thrombophilia. Therefore, our data indicate that a prospective randomized study designed to evaluate the efficacy of this prophylactic regimen, might benefit from the consideration that concomitantly reduced vascular reserves be able to interfere with the study results. The results of the present study suggest that insight into the hemodynamic and clotting functions adds an extra dimension to the counseling of women with a history of severe vascular complications in a preceding pregnancy. 
In conclusion, pre-pregnant hemodynamic and hemostatic variables in formerly preeclamptic women predict recurrent hypertensive complications and fetal growth restriction in a subsequent pregnancy. 


\section{References}

1. Report of the National High Blood Pressure Education Program Working Group on High Blood Pressure in Pregnancy. An1 J Obstet Gynecol 2000; 183:S1-S22.

2. Schuitemaker NEW, van Roosmalen J, Dekker GA, van Dongen PWJ, van Geijn HP, Bennebroek Gravenhorst J. Confidential Inquiry into maternal deaths in The Netherlands 1983 . 1992. Eur J Obstet Gynecol Reprod Biol 1998; 79:57-62.

3. Dekker GA, de Vries JIP, Doelitzsch PM, Huijgens PC, von Blomberg BME, Jacobs C, van Geijn HP. Underlying disorders associated with severe early-onset preeclampsia. Am J Obstet Gynecol 1995;173:1042-8.

4. van Pampus MG, Dekker GA, Wolf H, Huijgens PC, Koopman MM, von Blomberg BM, Buller HR. High prevalence of hemostatic abnormalities in women with a history of severe preeclampsia. Am J Obstet Gynecol 1999; 180(5):1146-50.

5. Kupferminc MJ, Eldor A, Steinman N, Many A, Bar-Am A, Jaffa A, Fait G, Lessing JB. Increased frequency of genetic thrombophilia in women with complications of pregnancy. $N$ Eng J Med 1999; 340:9-13.

6. Spaanderman MEA, Ekhart THA, van Eyck J, Cheriex EC, de Leeuw PW, Peeters LLH. Asymptomatic ex-preeclamptic women have latent hemodynamic abnormalities. Am $\mathrm{J}$ Obstet Gynecol 2000; 182:101-7.

7. van Beek E, Ekhart THA, Schiffers PMH, van Eyck J, Peeters LLH, de Leeuw PW. Persistent abnormalities in volume homeostasis and renal hemodynamics in patients with a history of preeclampsia. Am J Obstet Gynecol 1998;179:690-6.

8. Roberts JM. Endothelial dysfunction in preeclampsia. Semin Reprod Endocrinol 1998;16:5-15.

9. Kooman JP, Wijnen JAG, Draaijer P, Van Bortel LMAB, Glad Ziwa U, Peltenburg HG, Struyker-Boudier HAJ, Van Hooff JP, Leunissen KML. Compliance and reactivity of the peripheral venous system in chronic intermittent hemodialy'sis. Kidney Int 1992; 41:1041-1048.

10. Sibai BM, el-Nazer A, Gonzalez-Ruiz A. Severe preeclampsia-eclampsia in young primigravid women: subsequent pregnancy outcome and remote prognosis. An J Obstet Gynecol 1986; 155:1011-6.

11. Sibai BM, Mercer B, Sarinoglu C. Severe preeclampsia in the second trimester: recurrence risk and long-term prognosis. Am J Obstet Gynecol 1991; 165:1408-12.

12. Sullivan CA, Magnann EF, Perry KG Jr, Roberts WE, Blake PG, Martin JN Jr. The recurrence risk of the syndrome of hemolysis, elevated liver enzymes, and low platelets (HELLP) in subsequent gestations. Am J Obstet Gynecol 1994; 171:940-3.

13. Sibai BM, Ramadan MK, Chari RS, Friedman SA. Pregnancies complicated by HELLP syndrome (hemolysis, elevated liver enzymes, and low platelets): subsequent pregnancy outcome and long-term prognosis. Am J Obstet Gynecol 1995; 172:125-9.

14. Eskenazi B, Fenster L, Sidney S. A multivariate analysis of risk factors for preeclampsia. JAMA $1991 ; 266: 237-241$.

15. Zhang J, Troendle J, Levine R. Risk of hypertensive disorders in the second pregnancy. Obstet Gynecol 2000; 95: S77. 
16. Spaanderman MEA, Willekes C, Hoeks APG, Ekhart THA, Peeters LLH. The effect of pregnancy on the compliance of large arteries and veins in normal parous controls and formerly preeclamptics. Am J Obstet Gynecol 2000; 183: 1278-86.

17. Simons PC, Algra A, Bots ML, Grobbee DE, van der Graaf Y. Common carotid intima-media thickness and arterial stiffness: indicators of cardiovascular risk in high-risk patients. The SMART Study (Second Manifestations of ARTerial disease). Circulation 1999; 100:951-7. 
Chapter 8

\section{GENERAL DISCUSSION}




\section{Chapter 8}

\section{General discussion}

Most of current obstetric care involving the management of vascular complications of pregnancy consists of symptomatic treatment only. This is primarily related to the limited insight in cause and pathogenesis of these problems. The present doctorate thesis is composed of six studies each focusing on different aspects of vascular adaptations and limitations in pregnancy. In this context the following clinical entities are considered vascular complications of pregnancy: placental insufficiency giving rise to fetal growth restriction, pregnancy-induced hypertension, preeclampsia, eclampsia, HELLP-syndrome (hemolysis, elevated liver enzymes, low platelets) and placental abruption.

The objectives of the 4 studies presented in chapters 2, 3, 4 and 7 were to describe the composition, characteristics and responses to a next pregnancy of the heterogeneous subset of women with a history of some severe vascular complication in pregnancy. The following aspects formed separate topics of study in this target population: demography, prevalence and type of thrombophilic and vascular disorders, fluctuations in hemodynamics, renal function and volume homeostasis with the menstrual cycle and recurrence rate of vascular complications in the next pregnancy. The two studies presented in chapters 5 and 6 were designed to explore some aspects of the initial hemodynamic adaptation (chapter 5) or maladaptation (chapter 6) to pregnancy.

The demonstration of the heterogeneity in preexistent disorders among women at risk for vascular complications in pregnancy not only provides us with a plausible explanation for the disappointing outcome of large trials in unselected risk groups designed to evaluate some promising prophylactic strategies, but it also encourages the development of tailor-made prevention for homogeneous subgroups?

\section{ASYMPTOMATIC FORMERLY PREECLAMPTIC WOMEN HAVE LATENT HEMODYNAMIC ABNORMALITIES}

Women with essential hypertension, renovascular disease, diabetes mellitus and some thrombophilic disorders are prone to develop preeclampsia in pregnancy 2. 3. 4. 5. Interestingly, in all these conditions the preexistent disorder is known to be associated with extra strain exerted upon the endothelium. It is still unsettled how the various subgroups of formerly preeclamptic women differ from each other and from normal parous controls with 
respect to pathogenesis of the vascular complications in pregnancy. Therefore, we studied the hemodynamic -, renal - and clotting functions in formerly preeclamptic women and compared the results with those obtained in normal parous controls.

Among formerly preeclamptic women almost $25 \%$ had hypertension and almost $50 \%$ had some thrombophilic disorder. About one-third of these women had neither hypertension nor thrombophilia. In the latter subgroup, neither renal function and circulating levels of volume regulatory hormones, nor cardiac index differed from the values observed in controls. However, probably as a consequence of the higher body mass index in most of these women, their absolute cardiac output and with it, left ventricular work was higher. Although obesity, chronic hypertension and preeclampsia are related conditions, chronic hypertension and overweight contribute independently to the development of preeclampsia 6. 7 . Total plasma volume increases as a function of body mass ${ }^{6}$. Therefore, indexing for body mass is necessary to enable comparisons of plasma volume. We observed in both obese and nonobese asymptomatic formerly preeclamptic women and hypertensives a lower plasma volume per $\mathrm{kg}$ lean body mass as compared to controls. It is known that in the early stages of essential hypertension plasma volume is reduced $\&$. Therefore, asymptomatic formerly preeclamptic women may be considered to be latent - or pre-hypertensive. This is supported by the observation that formerly preeclamptic women have an increased likelihood to develop hypertension later in life ${ }^{10}$.

In the present study, about $46 \%$ of the formerly preeclamptic participants had thrombophilia, which agrees with the figure reported by others in a comparable population ${ }^{4}$. Thrombophilia not only predisposes for preeclampsia, but also for miscarriage, placental infarcts, placental abruption and stillbirth ${ }^{11}$. In thrombophilic formerly preeclamptic women, antiphospholipid syndrome, protein $\mathrm{S}$ deficiency, hyperhomocysteinemia and activated protein $\mathrm{C}$ resistance are most common. We diagnosed hyperhomocysteinemia in $36 \%$ of the hypertensive formerly preeclamptic participants.

Based on the above inferences, formerly preeclamptic women can be subdivided into a hypertensive (HYPERT) -, a normotensive thrombophilic (THROMB)- and a normotensive non-thrombophilic subgroup. The latter subgroup resembles the hypertensive subgroup closely with respect to hemodynamic function. Therefore, we propose to categorize these women as latent hypertensives (LATHYPERT). These observations support the notion that the endothelium plays a central role in the development of preeclampsia and that this disease 
is mostly superimposed upon a pre-existing disorder either with a thrombophilic- or (latent) hypertensive phenotype.

\section{CHANGES IN HEMODYNAMICS AND VOLUME HOMEOSTASIS WITH THE MENSTRUAL CYCLE IN WOMEN WITH A HISTORY OF PREECLAMPSLA}

The magnitude of the cyclic changes in central and renal hemodynamics with the menstrual cycle in healthy females was for most variables less than $5 \%$ and thus often difficult to discern with the methodology employed. Consistent changes in the luteal phase relative to the follicular phase, were a fall in renal vascular resistance, and a rise in heart rate, effective renal plasma- and blood flow and plasma volume. These changes were paralleled by activation of the renin-angiotensin-aldosterone axis, a decrease in the plasma level of $\alpha$ atrial natriuretic peptide and an increase in the plasma level of norepinephrine. Similar findings have been reported by others ${ }^{12 .}{ }^{13}$. These changes are consistent with a state of mild vasorelaxation in the luteal phase of the menstrual cycle, resembling that of early pregnancy. Preeclampsia is often preceded by hemodynamic and renal maladaptation. These findings raised the question whether the normal pattern and magnitude of the hemodynamic and neuroendocrine fluctuations differ in the above mentioned formerly preeclamptic subgroups as compared to normal parous controls. If so, this would offer interesting possibilities to identify women at risk for vascular complications in pregnancy. To answer this question, we studied in the follicular and luteal phases of the menstrual cycle, the renal and cardiovascular functions in formerly preeclamptic women and compared the results with the ones delineated above for normal parous controls. Neither pattern nor magnitude of the cyclic changes with the menstrual cycle differed appreciably between controls and the three subgroups of formerly preeclamptic women, except for an elevated and non-cycling plasma level of norepinephrine in HYPERT only. It follows that this physiologic phenomenon is not usable to screen women at risk for vascular complications in pregnancy. In this study we found in both phases of the menstrual cycle, a lower plasma volume in the HYPERT and LATHYPERT subgroups, as compared to controls and the THROMB subgroup. A lower plasma volume may be a consequence of an increased vascular tone. However, the venous compartment and with it, plasma volume, may also be reduced as a result of interference with early vascular development e.g. due to a genetic defect or some intra-uterine insult ${ }^{14}$. About $2 / 3$ of the plasma volume is located within the venous compartment and can be 
mobilized in response to a fall in arterial tone ${ }^{15}$. The luteal decrease in afterload most likely activates both the renin-angiotensin-aldosterone-system and the sympathetic nervous system $15,16,17$. The latter enhances venous return by increasing venous tone. It also raises cardiac contractility and heart rate. Together, these effects enable the preservation of the arterial blood pressure at the expense of a diminished venous capacitance. Meanwhile, the higher activity of the renin-angiotensin-aldosterone axis and the lower circulating levels of $\alpha$-atrial natriuretic peptide accelerate volume retention so as to restore venous filling state. In concert with the restoration of the venous filling state, sympathetic activity in the cardiovascular system returns to the level of the pre-stimulus condition. It is conceivable that inadequate volume retention leads to chronically rather than transiently increased sympathetic tone. Consequences of the latter are not only a higher heart rate, myocardial contractility and mean arterial blood pressure, but also a sustained rise in cardiac pre-load, and eventually structural changes of heart and vessels ${ }^{15,17}$.

The release of $\alpha$-atrial natriuretic peptide by the atrial wall increases as a function of both vascular filling state and right atrial pressure ${ }^{18,19}$. Therefore, we postulate that a subnormal size of the venous compartment with inadequate capacity to raise venous return in response to higher arterial flow demands triggers an increase in sympathetic tone and with it, a higher atrial pressure and higher plasma levels of $\alpha$-atrial natriuretic peptide. The observation of higher basal norepinephrine levels in HYPERT relative to controls may indicate that in these individuals the higher demand for venous return in the luteal phase is primarily achieved by a rise in sympathetic tone rather than by volume retention.

\section{THE EFFECT OF PREGNANCY ON THE COMPLIANCE OF LARGE ARTERIES AND VEINS IN FORMERLY PREECLAMPTIC WOMEN AND NORMAI PAROUS CONTROLS}

The early-pregnancy drop in vascular resistance is accompanied by an increase in vascular compliance. The present study was designed to determine the contribution of the latter adaptive change in large vessels, to the institution of a high-flow/low resistance circulation in the first weeks of pregnancy. In addition, we wanted to find out whether possible pregnancy-dependent changes in the compliance of large vessels differ between formerly preeclamptic women and controls. To this end, we studied longitudinally in these populations total peripheral vascular resistance and the compliance of a capacity artery 
(predominantly elastic wall properties: carotid artery) a conductive artery (predominantly muscular wall properties: femoral artery) and of forearm veins. We chose two functionally different arteries as vasorelaxation was expected to affect the compliance of a muscular artery more than that of an elastic artery. Measurements were performed in the follicularand luteal phases of the menstrual cycle and subsequently at 5 and 7 weeks of gestation.

In all groups, total peripheral vascular resistance decreased by 20 to $25 \%$ in early pregnancy, with an abrupt decline already by 5 weeks gestational age, which is consistent with previous studies 20,21 . However, only in controls, this phenomenon was paralleled by a gradual increase in the carotid and femoral artery distension coefficient, and forearm venous compliance. In the THROMB subgroup the rise in femoral artery distension coefficient was not accompanied by an increase in venous compliance. Interestingly, both LATHYPERT and HYPERT women failed to respond to pregnancy with a rise in vascular compliance as observed in controls. Previous reports showed a rise in aortic compliance in the first trimester of human pregnancy, which was maintained until term 22,23 . In the present study, this adaptive change was already noticeable in the early part of the first trimester of pregnancy. The observation that this phenomenon develops very early in pregnancy is supported by similar observations in the conscious pregnant rat ${ }^{24}$. The different response to pregnancy of the femoral and carotid arterial compliance suggests that arterial compliance increases as a result of relaxation of the muscular layer of the vessel wall. Theoretically, the impact of a given rise in vascular compliance on vascular impedance increases progressively towards the microcirculation. This may explain why the early-pregnancy fall in total peripheral vascular resistance seemed to occur earlier and to be larger than the rise in femoral artery compliance. It should be emphasized that factors, such as concomitant changes in vascular filling state and sympathetic tone, may modulate the pregnancydependent rise in vascular compliance. It is likely that both the decrement in total peripheral vascular resistance and the increment in vascular compliance are effects resulting from the same, still obscure mechanism, possibly triggered by the endocrine environment of pregnancy. In-vitro studies support the involvement of a lower myogenic vascular tone and reactivity 25 . However, the exact pathway is still to be unraveled. Interestingly, LATHYPERT and HYPERT subjects did not respond to pregnancy with a rise in arterial compliance. This abnormality could be the result of a faint pregnancy-related stimulus or a blunted responsiveness of the vascular bed. Since the changes in circulating steroid levels were comparable in controls and all formerly preeclamptic subgroups, reduced relaxational 
responsiveness of vascular smooth muscle seems to be the most plausible explanation for the lack of increase in arterial compliance. In summary, the data in this study support the concept that in normal pregnancy the fall in total peripheral vascular resistance is paralleled by improved macrovascular compliance. The latter adaptive change is not seen in latent hypertensive and hypertensive formerly preeclamptic women.

\section{CARDIAC OUTPUT INCREASES INDEPENDENTLY OF BASAL METABOLIC RATE IN EARLY HUMAN PREGNANCY}

Early pregnancy is characterized by the institution of a high-flow / low-resistance circulation. It is unclear, whether or not the latter develops in response to a rise in metabolic rate $20,21,26,27,28,29$. To clarify this issue, we determined longitudinally the relationship between blood pressure, cardiac output and basal metabolic rate in healthy women, once before pregnancy and subsequently at $6,8,10$ and 12 weeks of gestational age.

Reported results on the change in resting energy expenditure with pregnancy are conflicting, mostly due to differences in study design, methodology employed and standardization procedure 29,30 . With respect to standardization, particularly the body mass index is important. In early pregnancy, for instance, only slim women seem to respond to pregnancy with a fall in resting energy expenditure ${ }^{30,31}$. During the first 12 weeks of pregnancy we found neither an appreciable change in resting energy expenditure nor in respiratory quotient, while cardiac output had already increased by the $6^{\text {th }}$ week of gestation. Also the cardiac output per unit resting energy expenditure, both in absolute terms and when expressed per kilogram fat free mass, increased with advancing amenorrhea. All these phenomena support the development of a hyperdynamic circulation in the first weeks of pregnancy. To balance the Starling forces in the capillary bed, the institution of a hyperdynamic circulation requires the concomitant opening of protective arteriovenous shunts. This will lead to a fall in the extraction of oxygen by the systemic circulation, an effect indeed observed by various other investigators, in both human and animal pregnancy 32. 33. 34.35 . Opening of these arteriovenous fistulae is considered to be limited to the nonplacental tissues, as the intervillous space is deprived of perfusion by maternal blood until the end of the first trimester ${ }^{36}$.

These findings indicate that the early pregnancy systemic vasorelaxation develops independently of changes in basal metabolism. How this is brought about remains to be 
established. Prolonged changes in steroid environment giving rise to an altered balance between vasoconstrictor and vasodilator stimuli, are thought to be responsible for the initial vasorelaxation 37,39 . Support for this concept comes from observations during the menstrual cycle and from rat studies. During the luteal phase of the menstrual cycle, the pattern of change in hemodynamics and renal function, although much smaller, resembles that observed in early pregnancy ${ }^{1 \hat{3}}$. Meanwhile, in the pseudopregnant rat, the initial adaptations in hemodynamic and volume homeostasis are similar to those observed in normal rat pregnancy $38,40,41$. There are also reports indicating that the administration of $17 \beta$-estradiol and progesterone to ovariectomized rats, to a level similar as observed in pregnancy, increases the vascular sensitivity to vasodilator stimuli as seen in normal rat pregnancy 37,42 . The latter studies indicate that, at least in the rat, the trophoblast is not involved in the mechanism that results in the institution of the high-flow low-resistance circulation of pregnancy.

In summary, early pregnancy is characterized by the development of a hyperdynamic circulation. This adaptive change seems to be the result of a primary relaxation of the arterial bed, thereby inducing the compensatory opening of protective arteriovenous shunts.

\section{MALADAPTATION TO PREGNANCY: A ROLE FOR ATRIAL NATRIURETIC PEPTIDE?}

In contrast to uncomplicated pregnancies, preeclampsia is often preceded by early-pregnancy hemodynamic and renal maladaptation 4,4, These findings raise the question whether this adaptation, is preserved in the above mentioned formerly preeclamptic subgroups. To elucidate this pathogenetic problem, we performed 3 consecutive hemodynamic and renal measurements, once before and twice during the early-pregnancy period.

All participants showed comparable patterns in hemodynamic, renal and endocrine changes from five-weeks pregnancy onwards. That is to say, mean arterial blood pressure and total peripheral vascular resistance decreased, while heart rate, stroke volume, cardiac output, cardiac index, plasma volume and renal hemodynamics together with circulating levels of active plasma renin, angiotensin and aldosterone, increased. Similar findings have been reported by others ${ }^{20,21,26}$. One important difference between controls and THROMB on the one hand, and the HYPERT and LATHYPERT on the other hand, was the early-pregnancy rise in circulating levels of $\alpha$-atrial natriuretic peptide. Moreover, circulating levels of $\alpha$ - 
atrial natriuretic peptide at 7 weeks were inversely correlated with the concomitant plasma volume. This data supports the concept that in these subgroups elevated $\alpha$-atrial natriuretic peptide levels could have interfered with the initial plasma volume expansion. The absence of a rise in $\alpha$-atrial natriuretic peptide in early normal pregnancy has been observed before 21. In LATHYPERT, the rise in $\alpha$-atrial natriuretic peptide was paralleled not only by an increase in left atrial diameter, but also by a lack of improvement in venous compliance. These findings indicate that $\alpha$-atrial natriuretic peptide may have increased in response to relative venous overfill. In this reasoning, early-pregnancy plasma volume expansion may be inhibited by a lack of concomitant increase in venous storage capacity. That is to say, the venous compartment fails to increase its compliance, needed to accommodate a larger blood volume. As a consequence, venous pressure increases, which, in turn, stimulates the release of $\alpha$-atrial natriuretic peptide. The latter effect may have led to a reduced plasma volume expansion. A similar explanation may underlie the fact that in the early stages of essential hypertension, plasma volume is reduced ". In the HYPERT subgroup, a reduction in plasma volume was indeed found, and which may be seen as an early compensation to keep blood pressure in the normal range in spite of the presence of blood-pressure raising stimuli.

On the basis of the results of this study we postulate the following sequence of events in normal and complicated pregnancy. The early-pregnancy endocrine environment triggers by some still unknown mechanism, a generalized fall in systemic vascular tone. This must be accompanied by a higher compliance of the arteries and veins, together with vasodilatation in the microcirculation. As a consequence, the relative filling state of the vascular bed decreases giving rise to a fall in both cardiac preload and afterload. The cardiovascular regulatory systems are activated in the arteries (baroreceptors), the kidneys (reninangiotensin-aldosterone system), central veins and right atrium (stretch receptors) (figure 1).

Figure 1. Illustration of the atrial stretch receptor. An increase in volume leads to more stretch and with it enhanced release of $\alpha$-atrial natriuretic peptide.

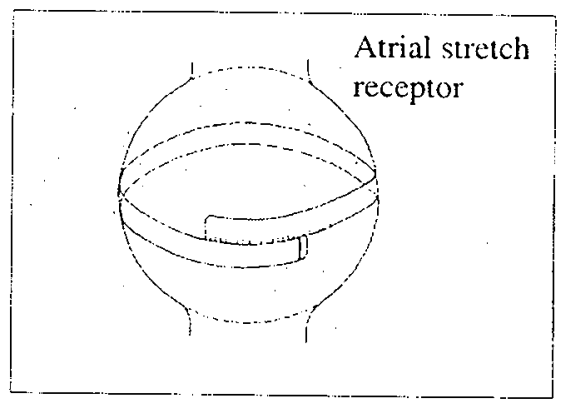


Concomitantly with the fall in vascular tone, resetting and alteration of these blood pressure regulating systems occurs. These latter effects include firstly an altered baroreceptor response to blood pressure variation, secondly a reduction in angiotensin-sensitivity and renal sensitivity to $\alpha$-atrial natriuretic peptide, and thirdly resetting of the osmoreceptor without a concomitant change in its sensitivity ${ }^{45,46,47,48,49}$. The rise in baroreceptor activity, triggered by the afterload reduction, will raise heart rate, cardiac contractility and mobilization of venous blood towards the arterial vascular compartment. Meanwhile, increased renin-angiotensin-aldosterone system activity and non-osmotic vasopressin release accelerate volume retention and restoration of the cardiac preload. A concomitant pregnancy-related decrease in atrial responsiveness to stretch, suppresses the release of $\alpha$ atrial natriuretic peptide during the gradual restoration of the central venous filling state in conjunction with the ongoing plasma volume expansion ${ }^{50}$. In HYPERT and LATHYPERT subjects the effects on these systems seem to be insufficient and paradoxical, as evidenced by the increase in $\alpha$-atrial natriuretic peptide, a decrease in norepinephrine and a lower plasma volume at 7 weeks as compared to controls and THROMB. The $\alpha$-atrial natriuretic peptide level not only provides an indirect estimate for vascular filling state, it also correlates positively with changes in right atrial pressure ${ }^{18.19 .50}$. A baroreceptor-mediated rise in sympathetic tone can be expected to raise cardiac preload and with it right atrial pressure. The latter effect can be counterbalanced by an increased cardiac contractility and heart rate to prevent atrial overflow and increased release of $\alpha$-atrial natriuretic peptide. Since an isovolumetric load induces a smaller pressure rise at increased compliance, rise in arterial compliance can be expected to elevate baroreceptor activity, when stroke volume remains unaltered (figure 2a and $2 b$ ). In contrast, reduced arterial compliance can be expected to lower baroreceptor activity. Therefore, a fall in total peripheral vascular resistance triggers a compensatory rise in stroke volume. If the latter is not accompanied by a rise in arterial compliance, baroreceptor activity is not adequately raised while the vascular filling state is restored. In this case, the response to the reduction in afterload consists also of a rise in cardiac output, only achieved by a higher stroke volume and atrial diameter, giving rise to the paradoxical release of $\alpha$-atrial natriuretic peptide, while circulating levels of norepinephrine are reduced, a response observed in LATHYPERT and HYPERT women (figure 3). Even though pregnancy is associated with an attenuated renal response to $\alpha$-atrial natriuretic peptide, its rise can be expected to affect volume regulation, which is supported 
by the correlations between $\alpha$-atrial natriuretic peptide and renal, cardiac, volume and vascular adaptation ${ }^{46}$.

Figure 2a. The baroreceptor as it is positioned within the endothelial layer (view from endothelial lumen).

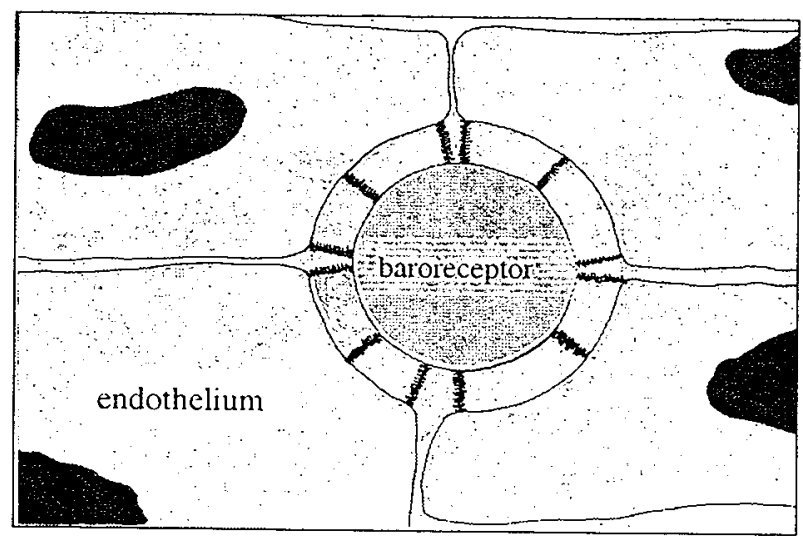

Figure $\mathbf{2 b}$. The baroreceptor as it is positioned in the vascular wall (transverse view). The higher the baroreceptor activity, the more heart rate is tempered. At low transmural pressure $P$, the signal that is transduced corresponds with distance $d_{1}$. At raised pressure $P^{\prime}$, the signal transduction increases as a function of increasing $d^{\prime}{ }_{1}$. However, when the vessel becomes more compliant, a certain pressure $P^{\prime}$ will lead to a smaller protraction and therefore a lower nerve excitation. As a consequence, an increase in vascular compliance can be expected to decrease baroreceptor activity and to increase heart rate, even when blood pressure remains unaltered.

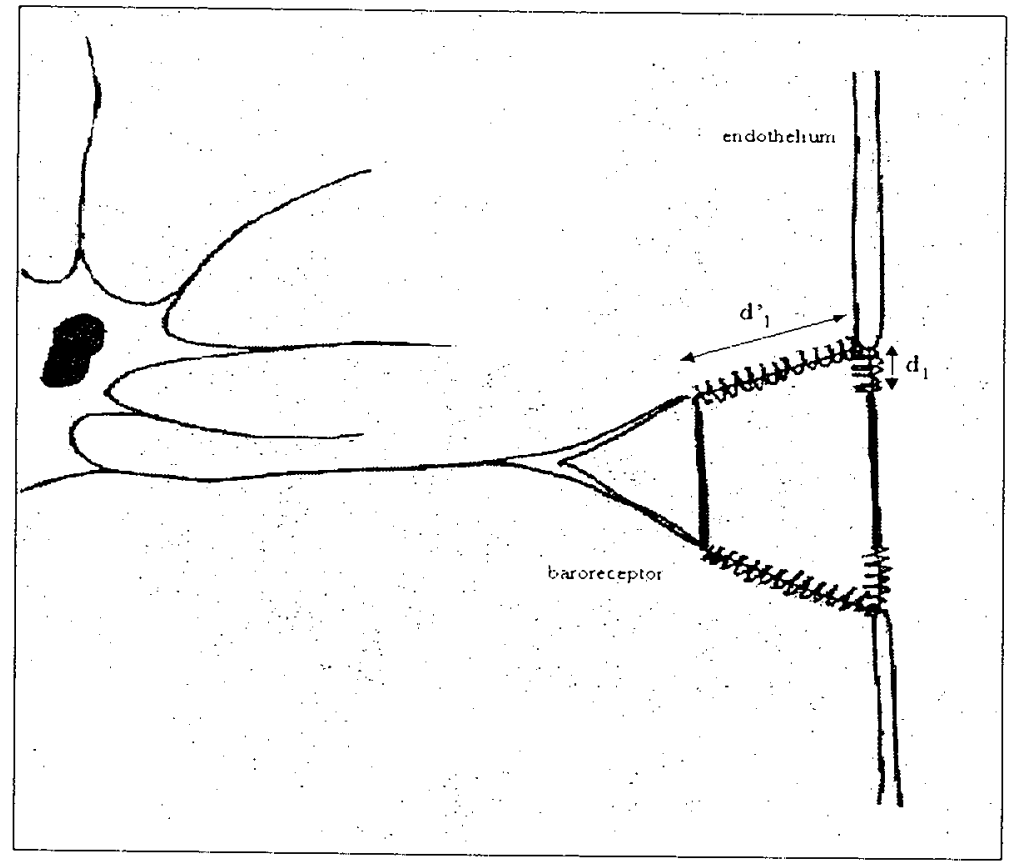


Therefore, in general, the pattern of hemodynamic and volume response to pregnancy is similar in formerly preeclamptic subjects and controls. However, HYPERT and LATHYPERT subjects differ from controls and THROMB by a paradoxical early-pregnancy rise in $\alpha$-atrial natriuretic peptide, together with a lower plasma volume at 7 weeks. These results suggest that normal early-pregnancy volume expansion requires a sufficiently large vascular reserve capacity prior to pregnancy.

Figure 3. Volume regulatory response system. The red compartment represents the arterial system, the blue compartment the venous system. In healthy females, blood pressure falls in response to the pregnancy-related arterial relaxation, which is characterized by a decrease in vascular resistance, increment of vascular compliance and opening of arterio-venous shunts (AV shunt). As a consequence, the renin-angiotensin-aldosterone system (RAAS) will be activated. With respect to volume retention, the latter response will accelerate fluid retention by the kidney. Furthermore, both the decrease in arterial blood pressure and the increase in arterial compliance are followed by a compensatory, baroreceptor-mediated rise in cardiac output. This early baroreceptor-mediated response results in an increase in heart rate and cardiac contractility and with it venous constriction and a reduction in end-diastolic atrial filling volume. As a consequence, atrial distension will be reduced, leading to diminished release of $\alpha$-atrial natriuretic peptide (ANP). Together with the activated RAAS, the latter response invigorates renal sodium- and fluid retention. In addition, the early pregnancy non-osmotic anti diuretic hormone release results in an even more pronounced volume retention. The ongoing restoration of vascular filling state is paralleled by increments in both arterial and venous compliance. The latter two effects will contribute to enhanced responsiveness of the baroreceptors and with it reduction in atrial stretch. These effects give rise to enhanced RAAS activity and reduced release of ANP, thereby reinforcing a sustained volumeretaining situation until vascular filling state is restored.

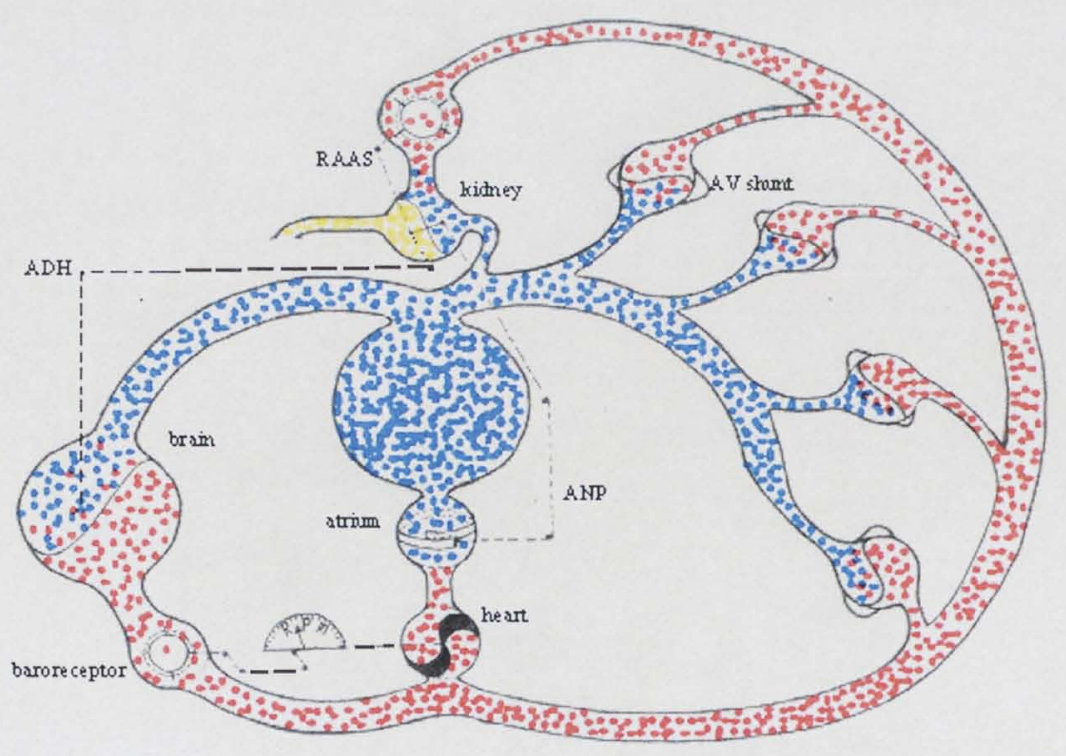




\section{PRE-PREGNANT PREDICTION OF RECURRENT PREECLAMPSIA AND/OR FETAL GROWTH RESTRICTION IN FORMERLY PREECLAMPTIC WOMEN}

A women who experienced a severe vascular complication during her pregnancy, is usually traumatized and puzzled about many aspects of her preceding pregnancy. The following questions are commonly posed, when she consults her physician: "Why did I develop this disease in spite of my good health?', 'Is it sure that I will recover completely?' and 'What would be my recurrence risk in a next pregnancy?' These questions are difficult to answer, as reliable information on this topic is scarce. We intended to address this clinical problem by trying to answer the following questions in a large group of formerly preeclamptic patients: What is the recurrence rate of hypertensive disorders and fetal growth restriction in a subsequent pregnancy in these women? If these complications recur, are they equally severe as experienced in the preceding pregnancy? Furthermore, is it possible to predict this recurrence on the basis of the severity of the vascular complication in the preceding pregnancy and/or on the basis of abnormal hemodynamic - hemostatic, metabolic and volume parameters in the pre-pregnant state?

After extensive pre-pregnancy testing, we were able to identify a number of fairly homogeneous subgroups in our study population of formerly preeclamptic women. In their subsequent pregnancy, we offered them a prophylactic regime. In doing so, the patients were informed about the limited experimental evidence for the efficacy of some of these strategies. All formerly preeclamptic participants received aspirin throughout pregnancy. Furthermore, those with thrombophilia, hyperhomocysteinemia and preexistent hypertension were treated with low molecular weight heparin, with pyridoxine and folic acid supplementation and with antihypertensives, respectively.

The results of this prospective study supported the usefulness of pre-pregnant maternal testing for a number of constitutional factors. Particularly, plasma volume and venous compliance were found to be clinically useful predictors of the recurrence rate of hypertensive complications and fetal growth restriction in the next pregnancy. However, in spite of our attempts to minimize the recurrence rate, by instituting even preventive measures that are still under investigation in large clinical trials, we were unable to abolish the recurrence of these complications. The latter is partly attributable to the occurrence of multiple (latent) disorders in some individuals. For instance, about $1 / 3$ of the THROMB formerly preeclamptic women also had a latent hypertensive phenotype as evidenced by a 
reduced plasma volume. Recurrent vascular complications in the next pregnancy were confined to this particular subgroup. This brings up the heterogeneity of the whole group of patients and emphasizes the need for subdivision into homogeneous subgroups. It also indicates the problems that we face when we want to compare our results with data reported by others. Among normotensive formerly preeclamptic women, the reported recurrence rates of preeclampsia ranged from 32 to $55 \%$ 7, 51, 52. Normotensive women with a history of HELLP-syndrome had recurrent preeclampsia and HELLP-syndrome in 19 to $23 \%$ and 3 to $27 \%$, respectively $5.3,54$. Apparently, preeclampsia recurs more often than HELLP. If a formerly preeclamptic woman (with or without HELLP-syndrome) turns out to have hypertension, her reported chance to develop recurrent preeclampsia ranges from 46 to $97 \%$. Similarly, the recurrence rate of prematurity is higher in hypertensive formerly preeclamptics, whereas that of HELLP-syndrome is low as indicated by the reported recurrence rate of only $5 \% 51,52,54$. With respect to gestational age, subsequent HELLPpregnancies lasted approximately 2 weeks longer than the previous complicated pregnancy 5.3. In our study, we also found a higher recurrence rate of preeclampsia in hypertensive(33\%) as compared to normotensive formerly preeclamptic women (18\%). Considering the underlying disorder, preeclampsia recurred in about 1/8 of the THROMB population, 1/4 of the LATHYPERT women and $1 / 3$ of the HYPERT participants. However, in counseling it is important to view these recurrence rates in the context of the milder course of the recurrent disease as indicated by its approximately 8 weeks later onset and the substantial higher birth weight and birth weight centile.

Another interesting result of this study was the association between the 'untreated' prepregnant blood pressure and the recurrence of vascular complications in the subsequent pregnancy among HYPERT participants. Apparently, optimal blood pressure control with antihypertensive drugs prior to pregnancy does not eliminate the recurrence of these complications in the next pregnancy. The latter indicates that in these preeclamptic recidivists, the untreated blood pressure provides indirect information about the impaired cardiovascular reserve capacity when faced with the extra demands of pregnancy. In this respect, the reduced cardiovascular reserve capacity may be related to structural changes in the arterial bed, such as diminished cardiovascular compliance 55 .

Besides hemodynamic findings, also the course of the previous pregnancy had predictive value with respect to fetal growth in the subsequent pregnancy. In THROMB participants, a previous late onset of hypertensive disease and a high previous birth weight and centile were 
associated with a lower incidence of fetal growth restriction. In contrast, a history of stillbirth seemed to 'protect' against fetal growth restriction. The latter finding supports the hypothesis that fetal distress and mortality result from an acute intrauterine accident, such as placental thrombosis or infarction.

\section{Conclusions}

Functionally, formerly preeclamptic women can be subdivided into four pathophysiological entities; 1. A hypertensive phenotype (la: latent, 1b: established), 2. A thrombophilic phenotype (2a: inherited, 2b: acquired) 3. A metabolic disordered phenotype. 4. An (auto)immunological phenotype.

Pre-pregnant evaluation of the hemodynamic -, clotting - and metabolic function was found to be both feasible and suitable to subdivide the heterogeneous group of formerly preeclamptics into more homogenous subgroups. Information on pattern and amplitude of the cyclic changes in hemodynamic and renal function with the menstrual cycle did not contribute appreciably to this categorization. In contrast, the response to early pregnancy was found to facilitate the identification of the (latent) hypertensive subgroup, as women with this phenotype respond to pregnancy with a subnormal rise in plasma volume and an aberrant rise in $\alpha$-atrial natriuretic peptide. The importance of the identification of the latter subgroup is emphasized by the fact that these women were found to have the poorest prognosis with respect to recurrent vascular complications during pregnancy and recurrent fetal growth restriction

The institution of preventive measures with anti-inflammatory, anti-coagulant and/or vitamin supplementary medication failed to reduce the recurrence rate of hypertensive complications in pregnancy and fetal growth restriction in formerly preeclamptic women to the level seen in normal parous controls. Nevertheless, our data enabled us to estimate this elevated recurrence rate of hypertensive disorders and fetal growth restriction in a subsequent pregnancy for the various subgroups. This information is clinically relevant not only for the obstetrician providing care to those women in the subsequent pregnancy, but also for these women, who want to know whether the risks of a subsequent pregnancy are acceptable for her. Another important finding of this study is the limited efficacy of current preventive strategies to reduce the recurrence rate of these complications, especially for women classified as having a (supplementary) hypertensive phenotype. 


\section{References}

1. Sibai BM. Prevention of preeclampsia: a big disappointment. Am J Obstet Gynecol 1998; 179 : $1275-1278$

2. Report of the National High Blood Pressure Education Program Working Group on High Blood Pressure in Pregnancy. Am J Obstet Gynecol 2000; 183:S1-S22.

3. ACOG Technical bulletin. Hypertension in Pregnancy. Number 219, 1996. Int J Gynaecol Obstet 1996; 53:175-183.

4. van Pampus MG, Dekker GA, Wolf $H$, Huijgens PC, Koopman MM, von Blomberg BM, Buller HR. High prevalence of hemostatic abnormalities in women with a history of severe preeclampsia. Am J Obstet Gynecol 1999; 180(5):1146-50.

5. Kupferminc MJ, Eldor A, Steinman N, Many A, Bar-Am A, Jaffa A, Fait G, Lessing JB. Increased frequency of genetic thrombophilia in women with complications of pregnancy. $N$ Eng J Med 1999; 340:9-13.

6. Mujais SK, Tarazi RC, Dustan HP, Fouad FM, Bravo EL. Hypertension in obese patients: hemodynamic and volume studies. Hypertension 1982;4:84-92.

7. Eskenazi B, Fenster L, Sidney S. A multivariate analysis of risk factors for precclampsia. JAMA 1991;266:237-241.

8. Lebel M, Grose $\mathrm{JH}$, Blais R. Increased hematocrit with normal red blood cell mass in early borderline essential hypertension. Clin Exp Hypertens 1989;11:1505-1514.

9. Roberts JM. Endothelial dysfunction in preeclampsia. Semin Reprod Endocrinol 1998;16:5-15.

10. Sibai BM, el Nazer A, Gonzalez Ruiz A. Severe preeclampsia-eclampsia in young primigravid women: subsequent pregnancy outcome and remote prognosis. Am J Obstet Gynecol 1986;155:1011-6.

11. Preston FE, Rosendaal FR, Walker ID, Briet E, Berntorp E, Conrad J, Fontcuberta J, Makris M, Mariani G, Noteboom W, Pabinger I, Legnani C, Scharrer I, Schulman S, van der Meer FJ. Increased fetal loss in women with heritable thrombophilia. Lancet 1996;342:913-6.

12. Beek v. E, Houben AJHM, van Es PN, Willekes C, Konten ECCM, de Leeuw PW, Peeters LLH. Cyclic changes in hemodynamics and renal function in the menstrual cycle. Clin Science 1996; 91: 163-168.

13. Chapman AB, Zamudio S, Woodmansee W, Merouani A, Osorio F, Johnson A, Moore LG, Dahms T, Coffin C, Abraham WT, Schrier RW. Systemic and renal hemodynamic changes in the luteal phase of the menstrual cycle mimic early pregnancy. Am J Physiol 1997; 273: F777F782.

14. Barker DJP. Fetal origins of coronary heart disease. BMJ 1995;311:171-174.

15. Guyton AC. Cardiac output, venous return and their regulation. In :Guyton AC, ed. Textbook of medical physiology. Philadelphia: Saunders, 1986:272-286.

16. Henrich WL, Berl T, McDonald KM, Anderson RJ, Schrier RW. Angiotensin II, renal nerves, and prostaglandins in renal hemodynamics during hemorrhage. Am J Physiol 1978; 235:F46F51.

17. Schobel HP, Fischer T, Heuszer K, Geiger H, Schmieder RE. Preeclampsia-A state of sympathetic overactivity. N Eng J Med 1996;335:1480-5. 
18. Leunissen KML, Menheere PPCA, Cheriex EC, van den Berg BW, Noordzij TC, van Hooff JP. Plasma alpha-human atrial natriuretic peptide and dry weight in chronic hemodialysis. Nephr Dial Transpl 1989; 4:382-386.

19. Hirata $Y$, Ishii $M$, Matsuoka $H$, Sugimoto $T$, Iizuka $M$, Uchida $Y$, Serizawa $T$, Sato $H$, Kohmoto O, Mochizuki T, Sugimoto T, Miyata A, Kangawa K, Matsuo H. Plasma concentrations of $\alpha$-human atrial natriuretic polypeptide and cyclic GMP in patients with heart disease. Am Heart J 1987; 113:1463-1469.

20. Duvekot JJ, Cheriex EC, Pieters FAA, Peeters LLH. Early-pregnancy changes in haemodynamics and volume homeostasis are consecutive adjustments triggered by a primary fall in systemic vascular tone. Am J Obstet Gynecol 1993; 169: 1382-1392.

21. Chapman AB, Abraham WT, Zamudio S, Coffin C, Merouani A, Young D, Johnson A, Osoria F, Goldberg C, Moore LG, Dahms T, Schrier RW. Temporal relationships between hormonal and hemodynamic changes in early human pregnancy. Kidney Int 1998: 54: 2056-2063.

22. Hart MV, Morton MJ, Hosenpud JD, Metcalfe J. Aortic function during normal human pregnancy. Am J Obstet Gynecol 1986; 154:887-891.

23. Poppas A, Schroff SG, Korcarz CE, Hibbard JU, Berger DS, Lindheimer MD, Lang RM. Serial assessment of the cardiovascular system in normal pregnancy. Role of arterial compliance and pulsatile arterial load. Circulation 1997; 95 (10): 2407-15.

24. Slangen BFM, van Ingen Schenau DS, van Gorp AW, De Mey JGR, Peeters LLH. Aortic distensibility and compliance in conscious pregnant rats. Am J Physiol 1997; 272:H1260-1265.

25. Meyer MC, Osol G, McLaughlin M. Flow decreases myogenic reactivity of mesenteric arteries from pregnant rats. J Soc Gynecol Invest 1997; 293-297.

26. Easterling TR, Benedetti TJ, Schmucker BC, Millard SP. Maternal hemodynamics in normal and preeclamptic pregnancies: A longitudinal study. Obstet Gynecol 1990;76:1061-1069.

27. Capeless EL, Clapp JF. Cardiovascular changes in early phase of pregnancy. Am J Obstet Gynecol 1989; 161:1449-53.

28. Robson SC, Hunter S, Boys RJ, Dunlop W. Serial study of factors influencing changes in cardiac output during human pregnancy. Am J Physiol 1989; 256:H1060-5.

29. Clapp JF, Seaward BL, Sleamaker RH, Hiser J. Matemal physiologic adaptations to early human pregnancy. An J Obstet Gynecol 1988; 159:1456-60.

30. Prentice AM, Goldberg GR, Davies HL, Murgatroyd PR, Scott W. Energy-sparing adaptations in human pregnancy assessed by whole-body calorimetry. Br J Nutr 1989; 62:5-22.

31. Bronstein MN, Mak RP, King JC. Unexpected relationship between fat mass and basal metabolic rate in pregnant women. Br J Nutr 1996; 75:659-68.

32. Bader RA, Bader ME, Rose DJ, Braunwald E. Hemodynamics at rest and during exercise in normal pregnancy as studied by' cardiac cathetcrization. J Clin Invest 1955; 34:1524-36.

33. Burwell CS, Strayhom WD, Flickinger D, Corlette MB. Circulation during pregnancy. Arch Intern Med 1938; 62:979-1003.

34. Gilson GJ, Mosher MD, Conrad KP. Systemic hemodynamics and oxygen transport during pregnancy in chronically instrumented, conscious rats. Am J Physiol 1992; 263:H1911-8. 
35. Metcalfe J, Ueland K. Maternal cardiovascular adjustments to pregnancy. Prog Cardiovasc Dis $1974 ; 16: 364-374$.

36. Jaffe R, Jauniaux $E$, Hustin $J$. Maternal circulation in the first-trimester human placenta: myth or reality? Am J Obstet Gynecol 1997; 176:695-705.

37. Grewal M, Cuevas J, Chaudhuri G, Nathan L. Effects of calcitonin gene-related peptide on vascular resistance in rats: role of sex steroids. Am J Physiol 1999; 276:H2063-8.

38. Atherton JC, Bu'lock D, Pirie SC.The effect of pseudopregnancy on glomerular filtration rate and salt and water reabsorption in the rat. J Physiol (Lond) 1982; 324:11-20.

39. Magness RR, Phemetton TM, Zheng J. Systemic and uterine blood flow distribution during prolonged infusion of 17beta-estradiol. Am J Physiol 1998; 275:H731-43.

40. Baylis C. Glomerular ultrafiltration in the pseudopregnant rat. Am J Physiol 1982; 243:F300-5.

41. Slangen BFM, Out ICM, Verkeste CM, Smits JFM, Peeters LLH. Hemodynamic changes in pseudopregnancy in chronically instrumented, conscious rats. Am J Physiol 1997; 272:H695700 .

42. Conrad KP, Mosher MD, Brinck-Johnsen T, Colpoys MC. Effects of 17 beta-estradiol and progesterone on pressor responses in conscious ovariectomized rats. Am J Physiol 1994; 266:R1267-72.

43. Duvekot JJ, Cheriex EC, Pieters FAA, Menheere PPCA, Peeters LLH. Maternal volume homeostasis in early pregnancy in relation to fetal growth restriction. Obstet Gynecol $1995 ; 85$ : $361-367$.

44. Duvekot JJ, Cheriex EC, Pieters FA, Peeters LLH. Severely impaired fetal growth is preceded by matemal hemodynamic maladaptation in very early pregnancy. Acta Obstet Gynecol Scand 1995; 74:693-697.

45. Ekholm EM, Piha SJ, Erkkola RA, Antila KJ. Autonomic cardiovascular reflexes in pregnancy. A longitudinal study. Clin Auton Res 1994; 4:161-5.

46. Omer S, Vaillancourt P, Peri KG, Varma DR, Mulay S. Downregulation of renal atrial natriuretic factor receptors and receptor mRNAs during rat pregnancy. Am J Physiol 1997: 272: F87-93.

47. Schrier RW, Dürr JJ, Pregnancy: an overfill or underfill state. Am J Kidney Dis 1987; 9:284-9.

48. Gant NF, Daley GL, Chand S, Whalley PJ, MacDonald PC. A study of angiotensin II pressor response throughout primigravid pregnancy. J Clin Invest 1973; 52:2682-9.

49. Schrier RW, Briner VA. Peripheral arterial vasodilatation hypothesis of sodium and water retention in pregnancy: implications for pathogenesis of preeclampsia-eclampsia. Obstet Gynecol 1991;77:632-9.

50. Zhang $\mathrm{Y}$, Novak $\mathrm{K}$, Kaufman S. Atrial natriuretic factor release during pregnancy in rats. J Physiol (Lond) 1995; 488: 509-5I4.

51. Sibai BM, Mercer B, Sarinoglu C. Severe preeclampsia in the second trimester: recurrence risk and long-term prognosis. Am J Obstet Gynecol 1991; 165:1408-12.

52. Zhang J, Troendle J, Levine R. Risk of hypertensive disorders in the second pregnancy. Obstet Gynecol 2000; 95: S77. 
53. Sullivan CA, Magnann EF, Perry KG Jr, Roberts WE, Blake PG, Martin JN Jr. The recurrence risk of the syndrome of hemolysis, elevated liver enzymes, and low platelets (HELLP) in subsequent gestations. Am J Obstet Gynecol 1994; 171:940-3.

54. Sibai BM, Ramadan MK, Chari RS, Friedman SA. Pregnancies complicated by HELLP syndrome (hemolysis, elevated liver enzymes, and low platelets): subsequent pregnancy outcome and long-term prognosis. Am J Obstet Gynecol 1995; 172:125-9.

55. Simons PC, Algra A, Bots ML, Grobbee DE, van der Graaf Y. Common carotid intima-media thickness and arterial stiffness: indicators of cardiovascular risk in high-risk patients. The SMART Study (Second Manifestations of ARTerial disease). Circulation 1999; 100:951-7. 


\section{Chapter 9}

FUTURE RESEARCH 


\section{CHAPTER 9}

\section{Future research}

Until now, it is still obscure why and how vascular resistance falls in early pregnancy. Likewise, it is not clear, why women with a (latent) hypertensive phenotype fail to increase the compliance of their cardiovascular system in response to pregnancy and whether this is related to structural or functional abnormalities. Current research suggests that the steroid environment of early pregnancy activate some still unknown mechanism, which results in systemic vasodilatation and with it, a fall in cardiac pre- and afterload. Ex-vivo and in-vitro (molecular) techniques may contribute to more insight in the underlying mechanisms at the subcellular level.

The studies lined up in this thesis indicate that a (latent) hypertensive phenotype represents the most common underlying disorder associated with maladaptation in pregnancy. Most likely the origin of such a phenotype is multifactorial, as is the case with essential hypertension. Currently, the information on the distribution of 'hypertensive' genetic polymorphisms in populations at risk is increasing rapidly and this may improve our understanding of the relationships between 'risk'-genes and the characteristics of the (latent) hypertensive phenotype. Hypertensive complications of pregnancy have been associated with cardiovascular morbidity at later age. Therefore, longitudinal studies of these women are headed, which will not only lead to a better understanding of the pathogenesis and management of cardiovascular disease, but may also contribute to the development of prophylactic strategies to delay or prevent the development of overt cardiovascular morbidity later in life.

Preeclampsia is a multifactorial disease. Therefore, in reviewing the efficacy of current preventive strategies in women at risk for vascular complications in pregnancy, one should be aware of the heterogeneity of underlying disorders, which frequently appear simultaneously among high-risk patients.

Both non-pregnant clotting and volume status are strong predictors for recurrent vascular disease in pregnancy among formerly preeclamptic women. A randomized controlled study evaluating these parameters among nulliparous women with a wish to become pregnant, and comparing two groups with or without a 'tailor-made' treatment regime, may provide more insight in the possibilities for preventive care. In concert with the obstetrical and/or family history, the development of simple, inexpensive and reliable tests and treatment regimes in women at risk for vascular complications in pregnancy may contribute to repel the incidence 
of preeclampsia among primiparous women. In our opinion, 'tailor-made' preventive medication should be designed according to the underlying phenotypical disorder, such as detailed in chapter 7 and expanded by 'anti-hypertensive' treatment among latent hypertensives. 
Chapter 10

\section{SUMMARY}




\section{ChAPTER 10}

\section{Summary}

The mechanism leading to maternal hypertensive complications in pregnancy and fetal growth restriction is still unsolved. Nevertheless, some important inferences can be deduced from epidemiological observations. For instance, the incidence of these complications is markedly increased in women with preexistent vascular, metabolic and clotting disorders. Interestingly, these disorders have in common that they all are associated with extra strain exerted upon the endothelial lining of the cardiovascular bed. The objective of the set of studies clustered in this thesis was to obtain detailed pre-and early-pregnant information on reno- and hemodynamic function, volume homeostasis and clotting function from women with a history of these complications to resolve, at least in part, the heterogeneity in the composition of the population of formerly preeclamptics. Furthermore we intended to explore the similarities and differences in hemodynamic changes with the menstrual cycle as well as the hemodynamic adaptation to pregnancy in formerly preeclamptics and healthy parous controls. Moreover we wanted to determine whether some elements of the prepregnant information on hemodynamic, renal and volume regulatory function might be useable to identify women at risk for recurrent disease in their next pregnancy.

The study in chapter $\mathbf{2}$ was designed to categorize formerly preeclamptic women into more or less homogeneous subgroups selected on the basis of underlying disorder. For this purpose we determined in the pre-pregnant state, the hemodynamic, renal and volume functions as well as clotting functions and compared the results with those obtained in healthy parous controls. Functionally, three subgroups of formerly preeclamptic women could be identified; women with a hypertensive phenotype, either manifest or latent and women with a thrombophilic phenotype. Only women with a hypertensive phenotype differed hemodynamically from healthy parous controls by a lower plasma volume and an elevated cardiac output.

Chapter 3 describes the changes in hemodynamic and renal function with the menstrual cycle. In spite of differences in baseline values, we noticed preserved fluctuations with the menstrual cycle in all formerly preeclamptic women, similar as seen in healthy parous controls. The pattern of change in hemodynamic and renal function in the luteal phase relative to the follicular phase of the menstrual cycle resembles that observed in early pregnancy. 
The study described in chapter 4 provides evidence for an early-pregnancy increase in the compliance of large arteries and veins in concert with the fall in total peripheral vascular resistance This rise in vascular compliance, though, was blunted only in the subgroup of (latent) hypertensive formerly preeclamptic women.

Chapter 5 describes a study, which was designed to determine whether or not the systemic vasorelaxation of early pregnancy develops in response to a rise in basal metabolism. The evidence generated supports the concept that the early-pregnancy vasorelaxation develops independent of changes in basal metabolic rate. It indicates that the opening of protective arteriovenous shunts is required to accommodate the early-pregnancy rise in cardiac output.

Chapter 6 explores the differences and similarities in central-and renal vascular adaptations to pregnancy in formerly preeclamptic women and controls. Most aspects of the adaptive responses to the fall in vascular resistance are similar in controls and formerly preeclamptics. However, the women allocated to the two hypertensive subgroups differed from those with a thrombophilic phenotype and normal parous controls by a paradoxical rise in the circulating levels of $\alpha$-atrial natriuretic peptide and a subnormal plasma volume expansion achieved by 7 weeks gestation.

Chapter 7 describes our evaluation of hemodynamic, renal and volume homeostatic parameters in the pre-pregnant state, as predictors of recurrent vascular complication and /or fetal growth restriction in a subsequent pregnancy. Clinically effective predictors in the various subgroups of formerly preeclamptics were among others obstetrical history, cardiac output, plasma volume and venous compliance.

In summary, among formerly preeclamptic women, four functional phenotypes can be

identified: $\quad$ 1. hypertensive (latent or established)

2. thrombophilic (inherited or acquired)

3. metabolic-disordered

4. (auto)immunological

All subgroups share the potency to damage the endothelium, either mechanically (group 1) or biochemical (group 2, 3 and 4). Only the hypertensive subgroup is characterized by limited systemic and renal hemodynamic reserves. Although the central-hemodynamic and renal response to the luteal fall in vascular resistance is also preserved in this subgroup, the much larger vasodilator effects of early-pregnancy elicit a paradoxical rise in $\alpha$-atrial natriuretic peptide, an effect accompanied by a subnormal plasma volume expansion. We postulate that the resulting hemodynamic maladaptation is caused by the inability to raise 
arterial compliance properly in concert with the early-pregnancy fall in vascular resistance. By pre-pregnant assessment of hemodynamic, hemostatic and metabolic parameters, most formerly preeclamptic patients can be categorized and counseled about their risk for recurrent hypertensive disorders and fetal growth restriction in a future pregnancy.

Preeclampsia appears to be a fairly homogeneous derailment of the cardiovascular function in the second half of pregnancy. However, the wide variety in predisposing risk conditions supports a heterogeneous pathogenesis. The latter should be taken into account, when one intends to develop preventive measures. That is to say, it may turn out to be necessary to develop a different 'tailor-made' prophylactic strategy for each identified risk condition. It is obvious that the latter will benefit markedly from a better insight in the initial stimulus and subsequent sequence of events that lead to the normal early-pregnancy fall in vascular tone and in the exact defect in this cascade in women destined to develop preeclampsia. Together with the obstetrical and family history, these insights may lead to the development of simple and inexpensive tests to screen women at risk for vascular complications in pregnancy. Such tests should be developed with the intention to screen not only risk groups, but rather all women who wish to conceive for the first time, since the largest incidence of preeclampsia is observed among primiparous women. 


\section{Samenvatting}

Het mechanisme, dat tijdens de zwangerschap leidt tot maternale hypertensieve complicaties en foetale groei vertraging, is nog steeds onopgelost. Desalniettemin kunnen sommige belangrijke conclusies worden getrokken uit epidemiologische observaties. Zo is bijvoorbeeld het vóorkomen van deze problemen verhoogd onder vrouwen met van tevoren bestaande stolling- en stofwisselingsstoormissen en hart- en vaatlijden. Deze stoornissen hebben gemeenschappelijk dat zij allen geassocieerd zijn met toegenomen belasting op de vaatwand. Dit proefschrift heeft tot doel gedetailleerde informatie te verkrijgen over de niet-

zwangere en de hierop volgende vroeg-zwangere nierfunctie, bloedsomloop, vochthuishouding en stollingsfunctie van vrouwen met een belaste voorgeschiedenis ten aanzien van deze complicaties, ten einde meer inzicht te krijgen in de heterogeniteit van deze populatie vrouwen. Bovendien wilden we de overeenkomsten en verschillen in veranderingen van de bloedsomloop tijdens de menstruele cyclus en de vroege zwangerschap bij voormalige preeclampsie patiënten en gezonde controles in kaart brengen. Daarenboven wilden we bepalen, of sommige elementen uit de niet-zwangere bloedsomloop, nierfunctie en vochtregulerende functie, bruikbaar waren risicopatiënten voor herhaalde ziekte in de volgende zwangerschap te identificeren.

De studie in hoofdstuk 2 was ontworpen om voormalige pre-eclampsie patiènten op basis van onderliggende problematiek in te delen in min of meer homogene groepen. Voor dit doel werd in een niet-zwangere situatie, de bloedsomloop, nier- en stollingsfunctie alsmede vochthuishouding bestudeerd en vergeleken met dezelfde gegevens van gezonde vrouwen met een probleemloze zwangerschap in de voorgeschiedenis. Er konden drie functionele subgroepen voormalige preeclampsie patiënten worden onderscheiden; vrouwen met een hypertensief bloedsomloopprofiel, aanwezig (1) danwel sluimerend (2) en vrouwen met een thrombofilisch profiel (neiging tot aderlijke stolselvorming) (3). Alleen de vrouwen met een hypertensief profiel verschilden voor wat betreft bloedsomloop van gezonde controles in een kleinere hoeveelheid plasma volume en een groter hartminuut volume.

Hoofdstuk 3 beschrijft de veranderingen in bloedsomloop en nierfunctie tijdens de menstruele cyclus. Zowel bij voormalige preeclampsie patiënten alsmede bij gezonde controles bleven, ondanks verschillen in de waarden van de eerste cyclushelft (folliculaire fase), de schommelingen in functie tijdens de menstruele cyclus bestaan. De veranderingen van bloedsomloop en nier functies tijdens de tweede cyclushelft (luteale fase) ten opzichte 
van de eerste cyclushelft van de menstruele cyclus gelijken op die van de vroege zwangerschap.

De studie beschreven in hoofdstuk 4 voert bewijzen aan voor een vroeg-zwangere toename in de rekbaarheid van grote arteriën en venen tezamen met de daling in totaal perifere weerstand. De toename in rekbaarheid van de vaten was echter aanzienlijk minder uitgesproken bij de (latent) hypertensieve voormalig pre-eclampsie patiënten.

Hoofdstuk 5 beschrijft een studie waarin onderzocht wordt of de systemische vaatverslapping van de vroege zwangerschap zich ontwikkelt in reactie op een stijging in basale stofwisseling. Het gegenereerde bewijs ondersteunt het concept dat de vroegzwangere vaatverslapping zich onafhankelijk van veranderingen in basale stofwisseling ontwikkelt. Voor de aanpassing aan de vroeg-zwangere stijging in hartminuut volume is de opening van beschermende arterioveneuze shunts noodzakelijk.

Hoofdstuk 6 onderzoekt de overeenkomsten en verschillen in bloedsomloop- en nierfunctieaanpassingen aan de zwangerschap in voormalig pre-eclampsie patiënten en controles. De meeste aspecten van deze aanpassende reacties op de daling in vaatweerstand zijn vergelijkbaar. Echter de twee hypertensieve subgroepen verschilden van vrouwen met een thrombofilisch profiel en gezonde controles in een paradoxale stijging in circulerend $\alpha$ atriaal natriuretisch peptide en een subnormale expansie van het plasma volume bij een amenorrhoeduur van 7 weken.

Hoofdstuk 7 beschrijft onze evaluatie van de niet-zwangere bloedsomloop, nierfunctie en vochthuishouding als voorspellers van herhaalde vaatproblemen en/of foetale groeivertraging in een daaropvolgende zwangerschap. Klinisch bruikbare voorspellers in de verscheidene subgroepen van voormalige pre-eclampsie patiënten waren onder andere obstetrische voorgeschiedenis, hartminuut volume, plasma volume en aderlijke rekbaarheid.

Samenvattend kunnen onder voormalig pre-eclampsie patiënten vier functionele profielen worden onderscheiden:

1. hypertensief (latent of manifest)

2. thrombofilisch (aangeboren of verworven)

3. metabool gestoord

4. (auto)immunologisch

Al deze groepen delen de eigenschap de vaatwand te kunnen schaden, ofwel op mechanische basis (groep 1) danwel op biochemische basis (groep 2, 3 en 4). Alleen de hypertensieve subgroep wordt gekarakteriseerd door een beperkte reservecapaciteit van de bloedsomloop en nierfunctie. Ofschoon de reactie van de bloedsomloop en nierfunctie op de luteale daling 
in vaatweerstand in deze groep is behouden, ontlokt de veel grotere vaatverslapping van de vroege zwangerschap een paradoxale stijging in $\alpha$-atriaal natriuretisch peptide, een effect geflankeerd door een subnormale toename in plasma volume. Wij postuleren dat de resulterende maladaptatie van de bloedsomloop veroorzaakt wordt door de onmogelijkheid de slagaderlijke rekbaarheid, in samenspraak met de vroeg-zwangere daling in vaatweerstand, te vergroten. Door niet-zwangere bepaling van het functioneren van bloedsomloop, stolling en stofwisseling, kunnen de meeste voormalig pre-eclampsie patiënten worden onderverdeeld in één van bovengenoemde subgroepen en daarmee worden voorgelicht ten aanzien van hun risico op herhaling van de hypertensieve stoornissen en foetale groei vertraging in een toekomstige zwangerschap.

Pre-eclampsie lijkt een vrij homogene ontsporing te zijn van het functioneren van het harten vaatstelsel in de tweede helft van de zwangerschap. Echter, de uitgebreide variatie in predisponerende risico factoren, ondersteunt een heterogene ontstaanswijze. Deze diversiteit moet in ogenschouw worden genomen als men preventieve strategieën wil ontwikkelen. Daarom lijkt het eerder noodzakelijk voor ieder risico profiel een 'op-maat-ontworpen' profylaxe te kiezen. Het moge duidelijk zijn dat een beter inzicht in de initiële stimulus leidend tot de fysiologische daling in vaatwandspanning vroeg in de zwangerschap en het specifieke tekort in de aanpassingsmogelijkheden van sommige vrouwen gedoemd preeclampsic te ontwikkelen, zal leiden tot betere ontwikkeling van profylactische mogelijkheden. Tezamen met de obstetrische en familiaire voorgeschiedenis zouden deze inzichten kunnen leiden tot de ontwikkeling van eenvoudige en goedkope testen om vrouwen te kunnen identificeren met een verhoogd risico op vasculaire complicaties tijdens de zwangerschap. Aangezien de grootste incidentie van pre-eclampsie met name onder eerstzwangeren wordt gezien, zouden dergelijke testen niet alleen beschikbaar moeten zijn voor risicopatiënten, maar ook voor vrouwen die voor de eerste keer zwanger willen worden. 


\section{Dankwoord}

Zonder ondersteuning kan vrijwel geen enkel onderzoek tot een goed einde worden gebracht. Dit gold zeker voor de studies beschreven in dit proefschrift. Hoewel de een meer inspanning heeft verricht dan de ander, waren allen betrokkenen van onschatbare waarde. Juist de samenwerking van het geheel heeft geleid tot succes; de afzonderlijke tijdsinvestering van de teamleden was daarbij van ondergeschikt belang. Voor de uitzonderlijke flexibiliteit en inzet van alle betrokken bij ons onderzoek wil ik dan ook volgaarne mijn dank uitspreken. Zonder iemand te kort te willen doen, wil ik toch enkele mensen extra bedanken:

Dr. L.L.H. Peeters, Louis, jij hebt mijn onophoudelijke bombardement aan theorieën, hypotheses en andere gezichtspunten overleefd. Sterker nog, je hebt dit altijd gestimuleerd. Vreselijk bedankt.

Prof. Dr. P.W. de Leeuw, Peter, hoe hoger de vlieger ging, hoe dieper jij het geheel verankerde. Jij hebt gezorgd voor een steviger structuur en basis. Veel dank hiervoor.

Prof. Dr. J. de Haan. Professor, samen met dr. Frans Smits heeft u waarschijnlijk al in ons eerste gesprek in de gaten gehad dat het verrichten van wetenschappelijk onderzoek mij genoegen schept. Mijn waardering en dank is dan ook groot voor de wijziging die u later in mijn opleidingschema heeft gemaakt, dit onderzoek te kunnen verrichten.

Dr. J. van Eyck, Jim, jouw' sympathieke aanwezigheid op de achtergrond en de niet aflatende stroom patiënten naar ons, heeft dit onderzoek mede tot een succes gemaakt. Naast jou, wil ik ook graag je kompanen dr. Brigitte Arabin en dr. Harm de Haan danken.

De relatieve onvoorspelbaarheid van de instroom van proefpersonen, maakten dat flexibiliteit een sleutelwoord was in dit promotieonderzoek. Omdat veel werk werd verricht door functieafdelingen met reguliere patiëntenstromen, was het lang niet altijd eenvoudig onze proefpersonen daarbij te plannen. Toch verliep de samenwerking vrijwel altijd vlekkeloos. Alle betrokken medewerkers van de functieafdeling cardiologie onder leiding van 'zuster' Andrea en Dr. Emiel Cheriex, ontzettend bedankt voor jullie inzet. Alle medewerkers van de afdeling nucleaire geneeskunde, in het bijzonder Sandra en Florence; zelfs op jullie vrije dagen en altijd tijdens de lunchpauze, kwamen jullie teng om bij onze patiënten plasma volume metingen te verrichten. Geweldig bedankt voor jullie uitzonderlijke betrokkenheid, interesse en inzet. De afdeling diëtetiek, met name Esther maar ook alle anderen; jullie adviezen en persoonlijke diëtaire aanpassingen zorgden iedere keer weer voor 
de juiste zoutinname bij onze proefpersonen in de weken voorafgaande aan de metingen. Ontzettend bedankt. Dr. Christine Willekes en prof. dr. ir. Arnold Hoeks; Christine, jouw arteriële compliantiemetingen waren van onschatbare waarde. Je inbreng, inzet maar bovenal menselijke betrokkenheid, waren voor de proefpersonen vaak het hoogtepunt van de zeven uur durende meetsessies. Je weet hoe ontzettend ik jouw aanwezigheid en betrokkenheid heb gewaardeerd. Arnold, graag wil ik je niet alleen bedanken voor het 'uitlenen' van jouw promovenda Christine, maar ook voor je zorgvuldige en kritische evaluatie van onze compliantiegegevens.

Naast direct patiëntgebonden bepalingen, werden ook veel bloedmonsters afgenomen. Allereerst Ellen, Mirjam en Yvanka en in het bijzonder Timo; zonder jullie aanwezigheid waren er nooit metingen verricht. Het prepareren van de infusievloeistoffen, het klaarzetten en afdraaien van alle monsters, het begeleiden van proefpersonen, enzovoort, konden alleen door jullie inzet doorgang vinden. Timo, ondanks onze valse start en in waarschijnlijk de moeilijkste periode van je leven, heb je me voortdurend met raad en daad bijgestaan. We kunnen met recht zeggen tropenjaren achter de rug te hebben. Ik ben dan ook blij dat je me ook als paranimf wilt flankeren. Alle medewerkers van het hematologisch lab, in het bijzonder Carina, Dave, Monique, Alain, dr. Lizzy van Pampus en dr. Karly Hamulyak, zeer bedankt voor jullie grootse inzet voor alle hematologische evaluaties van onze proefpersonen en patiënten. Jullie gegevens zijn een zeer belangrijke pijler gebleken van ons onderzoek. Graag wil ik van het klinisch-chemisch lab Lou en dr. Bernard van Kreel bedanken voor onder andere de gezamenlijke ontwikkeling van een nieuwe zwangerschapsveilige plasmavolume bepaling en de talloze dextranbepalingen die daarop volgden. Prof. dr. van Breda Vriesman, dr. Jan Damoiseaux, Henk en Ines Anne wil ik graag bedanken voor onze immunologische pilotstudie. Tevens wil ik graag het neurohumorale lab van Jet en Geertje onder leiding van dr. Paul Schiffers danken voor hun bepalingen van ontzettend veel monsters, bepalingen die vaak onder grote tijdsdruk werden vervolbracht. Tenslotte het interne hypertensie lab; Monique, Gusta, Claudia, Wilko en dr. Boy Houben, bedankt voor jullie betrokkenheid.

Gaandeweg de rit werd steeds duidelijker dat onder de psychische nood onder de ex-preeclamptische patiënten hoog was. Om de precieze omvang van het probleem in kaart te brengen, hebben we een pilot-studie gestart met hulp van geneeskunde studenten en de afdeling psychologie; graag wil ik binnen dit kader de studenten Maartje, Inge, Lisette en van de afdeling psychologie dr. Rutger Lulofs en Iris bedanken voor hun inzet en 
doorzettingsvermogen. Maar er werd meer onderzoek door studenten verricht; naast de medewerkers van functieafdeling van de longen wil ik met name Marieke en Maaike bedanken voor hun inspanning en onderzoek naar de metabole aspecten van de vroege zwangerschap. Alle onderliggende problemen bij onze pre-eclamptische patiëntenpopulatie veronderstelden een grotere incidentie recidieven bij onbehandelde volgende zwangerschappen alsmede toegenomen cardiovasculaire problematiek op latere leeftijd. Raph, jouw onderzoek naar bovengenoemde problemen loopt ten einde, levert fraaie resultaten en belooft een mooie publicatie te worden. Bedankt. Ten slotte Astrid; niet zonder de nodige frustraties heb jij je gebogen over de autonome regulatiemechanismen tijdens cyclus en vroege zwangerschap met behulp van spectraalanalyse, een studie mede begeleidt door dr. Ben Janssen. Beiden bedankt.

Het dankwoord wordt langzamerhand ernstig lang, maar nu bereik ik een belangrijk punt in het onderzoek wat me aan het hart ligt; het team. Het is, en dat moge duidelijk zijn uit bovenstaande bedankjes, een misvatting te denken dat succes in onderzoek bereikt kan worden op eigen kracht. In het algemeen is het een gezamenlijke prestatie, waarin ieder een rol speelt. Niet zozeer de grootte van de inspanning, maar veel meer een soms cruciale korte individuele prestatie, kan het verschil uitmaken tussen falen en succes. Binnen dit kader wil ik de volgende PERIM-personen noemen: Robert, Olivier, Hugo, Dorette, Inez, Marian, maar ook Audrey; bedankt en succes. Brigitte, Carla, Han en Ralph; zonder jullie was er dit onderzoek een vroege dood gestorven. Jullie vriendschap, steun en loyaliteit in de aanvangsfase waren cruciaal. Brigitte, ik ben verheugd dat jij eveneens mijn paranimf bent. De gynaecologen, assistenten, secretaresses en verpleegkundigen in zowel het AZM alsmede het Atrium Ziekenhuis Heerlen dank ik voor hun belangstelling. Opleider dr. Frans Roumen, maar ook de andere maatschapsleden wil ik graag danken voor niet alleen buitengewone werksfeer waarin ik nu mag werken, maar ook de mogelijkheden die mij geboden worden door te kunnen gaan met onderzoek.

Koos en Cathy, bedankt voor de steun en opvang van onze kleine rakkers Dieuwertje en Benthe. Zonder jullie hulp had ik nauwelijks de tijd gehad dit boekje af te schrijven. Mam en pap; af en toe ruik ik zijn sigarenrook nog. Ik denk dat hij trots is. En tenslotte Miranda; moosje, zonder jouw onuitputtelijke steun, wijsheid en aanwezigheid zou er helemaal niets zijn geweest. Jaren heb je mij gesteund en gereflecteerd in al mijn tegenslagen, worstelingen, bespiegelingen, theorieën, modellen en gedachten. Je weet hoe ontzettend gelukkig ik ben met jou en onze 'jongens'. 


\section{Curriculum vitae}

Marc Spaanderman werd op 16 maart 1966 in Waldbauer, Duitsland, geboren. Als kind was hij naast een dromer ook vaak ziek, gemiddeld 1 tot 2 dagen per week. Dit was reden voor zijn ouders hem een 'vrij-tempo' middelbare school te laten doorlopen. Aansluitend kon hij starten met de studie Geneeskunde aan de Rijksuniversiteit Utrecht. Tijdens deze periode was hij onder andere werkzaam als student-assistent anatomie en als steward bij de KLM. In de tweede helft van 1993 begon hij als arts-assistent gynaecologie in het Diaconessen Ziekenhuis te Utrecht (opleider dr. M.V.A.M. Kroeks). Na enkele maanden werd deze loopbaan vervolgd in het Elisabeth Ziekenhuis te Tilburg (opleider dr. J. de Graaff). In 1994 werd gestart met de opleiding tot gynaecoloog in het Academisch Ziekenhuis Maastricht (opleider prof. dr. J. de Haan en later prof. dr. J.L.H. Evers). De start tot de studies beschreven in dit proefschrift werd gemaakt in 1996. Hiervoor ontving hij in 1998 een 'Young Investigator Award for distinguished research' ter gelegenheid van het elfde wereld congres van de ISSHP in Kobe, Japan. Thans is hij werkzaam in het Atrium Ziekenhuis te Heerlen (opleider dr. F.J.M.E. Roumen). Vanaf oktober 2001 hoopt hij geregistreerd te zijn als gynaecoloog. Hij is nog steeds vaak in gedachten, ziek echter zelden. 
De publicatie van dit proefschrift werd mede mogelijk gemaakt door:

\section{Ferring BV}

Organon (Akzo Nobel)

Novo Nordisk

Pharmacia \& Upjohn

Serono

Wyeth-Lederle 